\title{
(2) OPEN ACCESS \\ Consensus practice guidelines on interventions for lumbar facet joint pain from a multispecialty, international working group
}

\author{
Steven P Cohen (D) , Arun Bhaskar, ${ }^{2}$ Anuj Bhatia, ${ }^{3}$ Asokumar Buvanendran, ${ }^{4}$ \\ Tim Deer, ${ }^{5}$ Shuchita Garg, ${ }^{6}$ W Michael Hooten (D) , ${ }^{7}$ Robert W Hurley, ${ }^{8}$ \\ David J Kennedy, ${ }^{9}$ Brian C McLean, ${ }^{10}$ Jee Youn Moon, ${ }^{11}$ Samer Narouze, ${ }^{12}$ \\ Sanjog Pangarkar, ${ }_{1}^{13}$ David Anthony Provenzano, ${ }^{14}$ Richard Rauck, $^{15}$ B Todd Sitzman, ${ }^{16}$ \\ Matthew Smuck, ${ }^{17}$ Jan van Zundert (D) , ${ }^{18,19}$ Kevin Vorenkamp, ${ }^{20}$ Mark S Wallace, ${ }^{21}$ \\ Zirong Zhao ${ }^{22}$
}

- Additional material is published online only. To view, please visit the journal online (http://dx.doi.org/10.1136/ rapm-2019-101243).

For numbered affiliations see end of article.

\section{Correspondence to}

Dr Steven P Cohen, Anesthesiology, Pain Medicine Division, Johns Hopkins School of Medicine, Baltimore, MD 21205, USA;

scohen40@jhmi.edu

Received 21 December 2019 Revised 7 February 2020 Accepted 11 February 2020 Published Online First 3 April 2020

Check for updates

(C) American Society of Regional Anesthesia \& Pain Medicine 2020. Re-use permitted under CC BY-NC. No commercial re-use. Published by BMJ.

To cite: Cohen $S P$

Bhaskar A, Bhatia A, et al.

Reg Anesth Pain Med

2020:45:424-467.

\begin{abstract}
Background The past two decades have witnessed a surge in the use of lumbar facet blocks and radiofrequency ablation (RFA) to treat low back pain $(\mathrm{LBP})$, yet nearly all aspects of the procedures remain controversial.
\end{abstract}

Methods After approval by the Board of Directors of the American Society of Regional Anesthesia and Pain Medicine, letters were sent to a dozen pain societies, as well as representatives from the US Departments of Veterans Affairs and Defense. A steering committee was convened to select preliminary questions, which were revised by the full committee. Questions were assigned to 4-5 person modules, who worked with the Subcommittee Lead and Committee Chair on preliminary versions, which were sent to the full committee. We used a modified Delphi method, whereby the questions were sent to the committee en bloc and comments were returned in a non-blinded fashion to the Chair, who incorporated the comments and sent out revised versions until consensus was reached.

Results 17 questions were selected for guideline development, with $100 \%$ consensus achieved by committee members on all topics. All societies except for one approved every recommendation, with one society dissenting on two questions (number of blocks and cut-off for a positive block before RFA), but approving the document. Specific questions that were addressed included the value of history and physical examination in selecting patients for blocks, the value of imaging in patient selection, whether conservative treatment should be used before injections, whether imaging is necessary for block performance, the diagnostic and prognostic value of medial branch blocks (MBB) and intra-articular (IA) injections, the effects of sedation and injectate volume on validity, whether facet blocks have therapeutic value, what the ideal cut-off value is for a prognostic block, how many blocks should be performed before RFA, how electrodes should be oriented, the evidence for larger lesions, whether stimulation should be used before RFA, ways to mitigate complications, if different standards should be applied to clinical practice and clinical trials and the evidence for repeating RFA (see table 12 for summary).
Conclusions Lumbar medial branch RFA may provide benefit to well-selected individuals, with MBB being more predictive than IA injections. More stringent selection criteria are likely to improve denervation outcomes, but at the expense of more false-negatives. Clinical trials should be tailored based on objectives, and selection criteria for some may be more stringent than what is ideal in clinical practice.

\section{INTRODUCTION}

There are few conditions in interventional pain medicine as controversial as lumbar facet joint pain. Everything from incidence, to diagnostic criteria, patient selection for interventions and the effectiveness of treatment is a source of contention and scientific debate. Regarding prevalence, the cited frequency of lumbar facet joint pain ranges from as low as $4.8 \%$ in the multicenter National Low Back Pain Survey evaluating final diagnoses of 2374 patients with low back pain (LBP) referred to an orthopedic or neurosurgical spine surgeon, to over $50 \%$ in systematic reviews on prevalence studies using varying criteria for diagnostic blocks performed by interventional pain physicians. ${ }^{1-4}$ The wide disparity in reported prevalence raises questions regarding the accuracy of diagnostic testing in the absence of any non-interventional diagnostic reference standard. The poor correlation between facet joint pathology on imaging and LBP further fuels debate. ${ }^{5}$ For diagnostic criteria, research and review articles abound on the ideal cut-off for designating a block as positive, and the optimal number of blocks that should be performed before lumbar facet radiofrequency ablation (RFA) treatment, with no consensus emerging. ${ }^{6-11}$

Lumbar facet interventions comprise the second most common procedure performed in interventional pain practices, with millions per year being performed in the USA alone. ${ }^{12}$ For lumbar RFA, a recent review of the Marketscan commercial claims and encounters databases from 2007 to 2016 demonstrated a $130.6 \%$ overall increase in utilization $\left(9.7 \%\right.$ annually). ${ }^{13}$ Along with increasing utilization, there was also a reciprocal increase in cost, 
Table 1 Levels of evidence for guidelines and recommendations

\begin{tabular}{lllll}
\hline \multirow{2}{*}{$\begin{array}{l}\text { Certainty of } \\
\text { net benefit }\end{array}$} & \multicolumn{4}{l}{ Magnitude of net benefit } \\
\cline { 2 - 5 } & Substantial & Moderate & Small & Zero/Negative \\
\hline High & A & B & C & D \\
Moderate & B & B & C & D \\
Low & Insufficient & & & \\
\hline
\end{tabular}

with the cost per 100000 enrollees increasing from US\$94570 in 2007 to US\$266680 in 2016 (12.2\% annual increase). In addition, the high number of blocks is inconsistent with the most commonly cited prevalence rates, which are generally $<15 \%$ in the non-elderly, but increase with age. ${ }^{14}{ }^{15}$ Increasing utilization alters the risk:benefit ratio of treatments; this, along with inconsistencies in practice, mixed results in mostly small heterogenous trials and the lack of widely accepted consensus guidelines has led to increased scrutiny and confusion on the part of government regulatory agencies and payers. The Spine Intervention Society (SIS; formerly the International Spine Intervention Society) has published guidelines on the performance of lumbar facet blocks and radiofrequency (RF) neurotomy, ${ }^{16}$ but these rigorous criteria have not been followed in recent randomized controlled trials (RCTs), ${ }^{17-19}$ and are not adhered to in domestic and international guidelines. ${ }^{20-22}$ Whereas stringent selection criteria have been anecdotally associated with high RFA success rates, ${ }^{23}$ the increased false-negative rate that inevitably accompanies strict diagnostic criteria, 714 and a host of other factors have resulted in an urgent need for guidelines to inform facet joint interventions in clinical practice and trials. These factors include the absence of safer and more effective alternatives for facetogenic LBP; the publication of large clinical trials that have been widely criticized for poor conduct, and rising utilization, which alters the risk:benefit ratio and calculations of cost-effectiveness. ${ }^{12} 24-27$ Our aim is to develop pragmatic guidelines that can be used to guide clinical care, improve research quality and assist payers with clinical practice pathways and authorization decisions.

\section{METHODS}

The decision to convene a multispecialty working group to develop lumbar facet intervention guidelines was approved by the American Society of Regional Anesthesia and Pain Medicine Board of Directors on 20 November 2018. Stakeholder societies and other organizations (eg, Department of Veteran Affairs) with a vested interest in facet interventions were identified, and formal request-for-participation letters were sent to those societies, who all approved involvement in January 2019. Each society then nominated one or two members to serve on the committee based on their expertise, clinical experience and academic interests (see online supplementary appendix A for a list of participating societies and representatives). For the Department of Defense representative, the US Army Pain Medicine Consultant was selected, who has traditionally represented the Department of Defense in interagency and task force guidelines. ${ }^{28}$

The Lumbar Facet Intervention Guidelines Committee was charged with preparing guidelines on the use of facet blocks and RFA that span the entire spectrum of care to include patient selection, optimizing accuracy, interpreting results and risk mitigation. Questions and formats were developed by the committee chair based on input from the committee, and refined during conference calls. Guidelines for individual study questions were developed by subcommittees (modules) composed of four to five committee members, with one or two persons designated as the 'leads' responsible for task delegation. Once a module came to consensus on an answer, the committee chair assisted with editing and formatting, and the section was sent to the entire committee for open-forum comments and revisions. A modified Delphi method was used to tabulate comments, incorporate changes and converge the answers toward consensus over teleconference or electronic correspondence rounds. At the initial conference call, the committee decided that $>50 \%$ panel agreement was sufficient to report a recommendation, but $\geq 75 \%$ agreement was required for consensus. After the task force completed the guidelines, the document was sent to the organizations' boards of directors for approval, with only minor changes permitted at this stage. For organizational agreement, we determined that consensus required at least $\geq 75 \%$ agreement, with dissensions tabulated for each individual question.

Search engines used during composition of the various sections included MEDLINE, Embase, Google Scholar and Cochrane Database of Systematic Reviews, in addition to examination of the reference sections of all manuscripts. There were no limitations on language or types of articles used to develop the guidelines, such that experimental studies were considered for the sections on physical examination and technical parameters, and case reports were considered for sections pertaining to risk mitigation and complications. Keywords used to address guideline topics were tailored to individual questions and included 'facet', 'low back pain', 'zygapophysial', 'zygapophyseal', 'radiofrequency', 'denervation', 'ablation' and 'arthritis'. Conclusions for each topic were graded on a scale from A to D, or as insufficient, according to the US Preventative Services Task Force

Table 2 What the grades of evidence mean and suggestions for practice

\begin{tabular}{|c|c|c|}
\hline Grade & Definition & Suggestions for practice \\
\hline A & $\begin{array}{l}\text { Our committee recommends this treatment, test or strategy to improve outcomes. There is high certainty that } \\
\text { the net benefit is substantial. }\end{array}$ & Offer or provide this service. \\
\hline B & $\begin{array}{l}\text { Our committee recommends this treatment, test or strategy to improve outcomes. There is high certainty that } \\
\text { the net benefit is moderate or there is moderate certainty that the net benefit is moderate to substantial. }\end{array}$ & Offer or provide this service. \\
\hline C & $\begin{array}{l}\text { Our committee recommends selectively offering or providing this treatment, test or strategy to improve } \\
\text { outcomes to individual patients based on professional judgment and patient preferences. There is at least } \\
\text { moderate certainty that the net benefit is small. }\end{array}$ & $\begin{array}{l}\text { Offer or provide this service for selected patients } \\
\text { depending on individual circumstances. }\end{array}$ \\
\hline I Statement & $\begin{array}{l}\text { Our committee concludes that the current evidence is insufficient to assess the balance of benefits and harms } \\
\text { of the intervention. Evidence is lacking, of poor quality, or conflicting, and the balance of benefits and harms } \\
\text { cannot be determined. }\end{array}$ & $\begin{array}{l}\text { Read the clinical considerations section of the } \\
\text { Recommendation Statement. If the treatment or } \\
\text { service is offered, patients should understand the } \\
\text { uncertainty about the balance of benefits and harms. }\end{array}$ \\
\hline
\end{tabular}




\begin{tabular}{ll}
\hline Level of certainty & Description \\
\hline High & The available evidence usually includes consistent results from well-designed, well-conducted studies in representative populations with suspected lumbar \\
facetogenic pain. The studies assess the effects of the treatment, test or other intervention on treatment or other relevant outcomes. The conclusion is \\
therefore unlikely to be strongly affected by the results of future studies. \\
The available evidence is sufficient to determine the effects of the intervention on outcomes, but confidence in the estimate is constrained by such factors \\
as: \\
The number, size, or quality of individual studies; \\
Inconsistency of findings across individual studies; \\
As more information becomes available, the magnitude or direction of the observed effect could change, and that change may be large enough to alter the \\
conclusion. \\
The available evidence is insufficient to assess effects on treatment and other outcomes of interest. Evidence is insufficient because of: \\
The limited number or size of studies; \\
Important flaws in study design or methods; \\
Inconsistency of findings across individual studies; \\
Gaps in the chain of evidence; \\
High likelihood of bias; \\
More indings not generalizable to individuals with suspected lumbar facetogenic pain; \\
Mormation may allow estimation of effects on treatment outcomes.
\end{tabular}

grading of evidence guidelines, with the level of certainty rated as high, medium or low (tables $1-3) .{ }^{29}$ This system, which has been modified for use in interventional pain management guidelines drafted by the American Society of Regional Anesthesia \& Pain Medicine, American Academy of Pain Medicine, American Society of Anesthesiologists, American Society of Interventional Pain Physicians (ASIPP) and the International Neuromodulation Society, ${ }^{30-33}$ was chosen over others because of its flexibility, ${ }^{34} 35$ which permits high-grade recommendations in absence of highquality level I studies, which are challenging to conduct for invasive procedures. $^{36}$

\section{QUESTION 1: CAN HISTORY AND PHYSICAL EXAMINATION BE USED TO IDENTIFY A PAINFUL FACET JOINT, OR TO SELECT PEOPLE FOR PROGNOSTIC BLOCKS? \\ Overview}

The diagnosis of lumbar facet joint pain relies on the combination of symptomatology, physical examination and confirmation by diagnostic block. Over the past several decades, numerous investigators have attempted to correlate physical signs and symptoms with facet pathology. Considering the high false-positive rate of uncontrolled facet blocks, and their inherent risks and costs, identifying likely responders is an important endeavor. Table 4 summarizes the studies discussed in this section.

\section{Clinical studies evaluating the association of physical examination findings with facet block results}

Fairbank et $a l^{37}$ assessed range of motion in multiple directions, straight leg raising test and tenderness based on digital palpation in 25 patients with acute back and/or leg pain. Based on the site of maximal tenderness, the most painful area was chosen for an IA injection with $1.5 \mathrm{~mL}$ of local anesthetic (LA). A second injection was performed at a level randomly chosen among the nine remaining lumbar facet joints. A positive outcome was designated as subjective relief of symptoms. The patients who experienced pain relief with the verum injection had pain in the back and the upper thigh(s), whereas non-responders were more likely to have pain in their lower leg. A significant improvement in anterior-posterior and lateral movements was also observed in responders.

In a retrospective study by Helbig and Lee performed in 22 patients, ${ }^{38}$ the authors sought to correlate response to an IA facet injection with diagnostic criteria that included pain in the back, buttock, leg or groin, signs of spasms or deformity, paravertebral tenderness, pain with motion and neurological examination. Back pain radiating to the groin or leg, pain worsened with extension-rotation and well-localized paraspinal tenderness were associated with a positive outcome, which was defined as prolonged relief lasting $>6$ months. Pain radiating below the knee was negatively associated with a positive response to facet blocks.

In a prospective study performed by Jackson et al, ${ }^{39}$ IA facet joint injections with $1.5 \mathrm{~mL}$ LA and contrast were done on 454 patients with localized LBP with or without referral into a lower extremity, and a normal neurological examination. The authors studied the change in pain during 10 separate motions and examined 127 variables including tenderness. They found no significant correlation between provocative clinical examination signs and the outcome of the facet joint injection, although the absence of leg pain and pain aggravation with Valsalva maneuver were associated with positive response to the blocks.

Lewinnek and Warfield ${ }^{40}$ performed a small, retrospective study in 21 individuals with refractory LBP, reporting their results with IA LA and steroid injections $(1.5 \mathrm{~mL})$ into the areas of maximal tenderness and pathology identified on X-rays. Patients were selected based on the presence of paraspinal tenderness and negative correlates for other etiologies, such as nerve root tension signs. They found no correlation between any historical or provocative examination sign and immediate or prolonged response to injections.

A prospective study by Lilius et $a l^{41}$ assessed work and disability in 109 patients with LBP who had no signs of radicular pain following an IA injection with either cortisone and LA; a pericapsular injection of the same mixture; or an IA saline injection. They found that psychosocial factors significantly influenced outcome. 
Special article

Table 4 Studies evaluating physical examination findings and facet block results

\begin{tabular}{|c|c|c|c|}
\hline Study & Design/criteria for positive block & Interventions & Findings \\
\hline Fairbank et $a \beta^{37}$ & $\begin{array}{l}\text { Prospective } \\
\mathrm{n}=25 \\
\text { Subjective pain relief }\end{array}$ & $\begin{array}{l}\text { IA (double blocks, one injection at } \\
\text { symptomatic level, another at a random } \\
\text { level) }\end{array}$ & $\begin{array}{l}\text { Responders: pain in the back and thigh; straight leg raising test causes back } \\
\text { pain. } \\
\text { Non-responders: pain in the back and leg; straight leg raising test causes leg } \\
\text { pain }\end{array}$ \\
\hline Lewinnek and Warfield ${ }^{40}$ & $\begin{array}{l}\text { Retrospective } \\
\mathrm{n}=21 \\
\text { Partial or complete pain relief with } \\
\text { resumption of activities immediately and at } \\
3 \text { months }\end{array}$ & IA (single block) & $\begin{array}{l}\text { Patients who had no other cause of LBP or sciatica and had a combination of } \\
\text { facet degeneration, pain and tenderness, were more likely to initially respond } \\
\text { to injection. }\end{array}$ \\
\hline Helbig and Lee $\mathrm{L}^{38}$ & $\begin{array}{l}\text { Retrospective } \\
n=22 \\
\text { Subjective pain relief from hours to months }\end{array}$ & IA (single block) & $\begin{array}{l}\text { A } 100 \text {-point scorecard was developed: } \\
\text { Back pain with groin or thigh pain: }+30 \\
\text { Well-localized paraspinal tenderness: }+20 \\
\text { Reproduction of pain with extension-rotation: }+30 \\
\text { Significant corresponding radiographic changes: }+20 \\
\text { Pain below the knee: }-10 \\
\text { Individuals with high scores }(\geq 60) \text { were likely to be responders but a low score } \\
\text { could not reliably predict negative response to facet joint injections. }\end{array}$ \\
\hline Jackson et $a P^{39}$ & $\begin{array}{l}\text { Prospective } \\
\mathrm{n}=454 \\
\text { Difference in pre- and post-pain scores } \\
\text { associated with lumbar motion }\end{array}$ & IA (single block) & $\begin{array}{l}\text { There were no unique characteristics identified in patients who reported either } \\
\text { no or increased pain after injection. } \\
\text { However, the following factors correlated significantly with greater postinjection } \\
\text { pain relief: older age, a history of LBP, no leg pain, pain not aggravated by } \\
\text { Valsalva maneuver, normal gait, no muscle spasm and pain on extension after } \\
\text { forward flexion. }\end{array}$ \\
\hline Lilius et $a l^{41}$ & $\begin{array}{l}\text { Prospective } \\
\mathrm{n}=109 \\
\text { Outcomes (subjective, work and disability) } \\
\text { were assessed at } 3 \text { months }\end{array}$ & $\begin{array}{l}\text { IA steroid/anesthetic, IA saline or } \\
\text { pericapsular steroid/anesthetic } \\
\text { (single block) }\end{array}$ & $\begin{array}{l}\text { Inappropriate (non-organic physical) signs and symptoms and previous back } \\
\text { surgery were associated with treatment failure. }\end{array}$ \\
\hline Schwarzer et al ${ }^{42}$ & $\begin{array}{l}\text { Prospective } \\
\mathrm{n}=176 \\
\geq 50 \% \text { pain relief after a confirmatory block }\end{array}$ & $\begin{array}{l}\text { IA or MBB } \\
\text { (double comparative diagnostic blocks) }\end{array}$ & $\begin{array}{l}\text { Neither clinical features (range of motion and straight leg raising test) nor pain } \\
\text { referral patterns could predict response to diagnostic blocks. } \\
\text { No patient with central/midline spinal pain responded to a confirmatory block. }\end{array}$ \\
\hline Schwarzer et al ${ }^{43}$ & $\begin{array}{l}\text { Prospective } \\
n=63 \\
\geq 50 \% \text { LBP reduction to bupivacaine } \\
\text { block } \times 3 \text { hours but no response to placebo }\end{array}$ & $\begin{array}{l}\text { IA and placebo } \\
\text { (placebo controlled: normal saline to } \\
\text { superficial muscle) }\end{array}$ & $\begin{array}{l}\text { Similar history and examination features were seen in patients with or without } \\
\text { facet joint pain. }\end{array}$ \\
\hline Revel et $a l^{44}$ & $\begin{array}{l}\text { Prospective } \\
\mathrm{n}=40 \\
\geq 75 \% \text { LBP reduction }\end{array}$ & IA (single block) & $\begin{array}{l}\text { Seven characteristics (Revel's criteria) were more frequent in patients with pain } \\
\text { relief from facet blocks: older age; absence of pain exacerbation by coughing, } \\
\text { absence of pain exacerbation by lumbar hyperextension, absence of pain } \\
\text { exacerbation by forward flexion and rising from forward flexion, absence of pain } \\
\text { exacerbation by extension-rotation and pain relieved by recumbency. }\end{array}$ \\
\hline Revel et $a l^{45}$ & $\begin{array}{l}\text { Prospective, controlled } \\
n=80-42 \text { who received lidocaine } \\
\geq 75 \% \text { LBP reduction }\end{array}$ & IA local anesthetic or placebo (IA saline) & $\begin{array}{l}\text { The presence of at least five of the seven Revel's criteria (above) including pain } \\
\text { reduction by recumbency resulted in } 92 \% \text { sensitivity and } 80 \% \text { specificity. }\end{array}$ \\
\hline Manchikanti et $\left.a\right|^{50}$ & $\begin{array}{l}\text { Prospective } \\
n=120 \\
\geq 75 \% \text { pain reduction }\end{array}$ & $\begin{array}{l}\text { MBB } \\
\text { (double comparative diagnostic blocks) }\end{array}$ & $\begin{array}{l}\text { The prevalence of clinical findings (pain better by sitting/lying, pain worsened } \\
\text { by sitting/standing/walking/coughing/lumbar spine range of motion, positive } \\
\text { straight leg raising test and pain referral pattern) were similar between positive } \\
\text { and negative block groups. Back pain with straight leg raising was weakly } \\
\text { associated with positive blocks. }\end{array}$ \\
\hline Manchikanti et $a P^{52}$ & $\begin{array}{l}\text { Prospective } \\
\mathrm{n}=180 \\
\geq 75 \% \text { pain reduction }\end{array}$ & $\begin{array}{l}\text { MBB } \\
\text { (double comparative diagnostic blocks, } \\
\text { lidocaine } \pm \text { Sarapin } \pm \text { steroid, bupivacaine } \\
\text { alone) }\end{array}$ & $\begin{array}{l}\text { Back or leg pain during straight leg raising was negatively associated with pain } \\
\text { relief from facet blocks. }\end{array}$ \\
\hline Manchikanti et $a P^{51}$ & $\begin{array}{l}\text { Prospective } \\
\mathrm{n}=200 \\
\geq 75 \% \text { pain reduction }\end{array}$ & $\begin{array}{l}\text { MBB } \\
\text { (double comparative diagnostic blocks) }\end{array}$ & $\begin{array}{l}\text { A large number of individual clinical characteristics did not correlate with facet } \\
\text { mediated pain diagnosed by double blocks. }\end{array}$ \\
\hline Young et $a l^{46}$ & $\begin{array}{l}\text { Prospective } \\
n=23 \\
\text { An injection produced concordant pain and } \\
\geq 80 \% \text { pain reduction }\end{array}$ & IA (single block) & $\begin{array}{l}\text { Absence of worsening LBP during rising from sitting was associated with a } \\
\text { positive response to facet injections. } \\
\text { Centralization of pain was associated with negative response to facet injections. }\end{array}$ \\
\hline Laslett et al $\left.\right|^{47}$ & $\begin{array}{l}\text { Prospective } \\
\mathrm{n}=116 \\
\geq 75 \% \text { pain relief or complete eradication of } \\
\text { primary pain }\end{array}$ & $\begin{array}{l}\text { IA or MBB } \\
\text { (single block) }\end{array}$ & $\begin{array}{l}\text { Revel's criteria had low sensitivity and high specificity; therefore, the authors } \\
\text { concluded they are not appropriate for screening purposes. } \\
\text { Age } \geq 65 \text { years reached predictive significance with complete eradication of } \\
\text { primary pain as a reference; no pain with cough/sneezing and no worsening of } \\
\text { pain when rising from flexion approached predictive significance with } \geq 75 \% \text { LBP } \\
\text { relief as a reference. }\end{array}$ \\
\hline Laslett et a $\left.\right|^{48}$ & $\begin{array}{l}\text { Prospective } \\
n=120 \\
\geq 75 \% \text { pain reduction stratified in } 5 \% \\
\text { increments }\end{array}$ & $\begin{array}{l}\text { IA or MBB } \\
\text { (single block) }\end{array}$ & $\begin{array}{l}\text { CPR consist of combinations of seven characteristics: age } \geq 50 \text {; pain is least when } \\
\text { walking/sitting; paraspinal pain; modified somatic perception questionnaire }>13 \text {; } \\
\text { positive extension-rotation test and absence of centralization. } \\
\text { When positive response to facet block is set at } 95 \% \text { pain reduction, four CPRs } \\
\text { have } 100 \% \text { sensitivity, one CPR improved post-test probability by five-fold. }\end{array}$ \\
\hline Cohen et $a F^{54}$ & $\begin{array}{l}\text { Retrospective } \\
\mathrm{n}=192 \\
\text { Patient selection: } \\
\geq 50 \% \text { pain reduction } \\
\text { RFA success: } \\
\geq 50 \% \text { pain relief } \times 6 \text { months }\end{array}$ & $\begin{array}{l}\text { MBB (single block) } \\
\text { RFA }\end{array}$ & $\begin{array}{l}\text { RFA success patients were more likely to have paraspinal tenderness, whereas } \\
\text { positive 'facet loading' (pain worsened by extension-rotation) and chronic opioid } \\
\text { use were more prevalent in RFA failure patients. }\end{array}$ \\
\hline
\end{tabular}




\begin{tabular}{|c|c|c|c|}
\hline Study & Design/criteria for positive block & Interventions & Findings \\
\hline DePalma et $a l^{49}$ & $\begin{array}{l}\text { Retrospective } \\
n=160-52 \text { with lumbar facet joint pain } \\
\geq 75 \% \text { pain reduction }\end{array}$ & $\begin{array}{l}\text { IA (double comparative diagnostic } \\
\text { blocks) }\end{array}$ & $\begin{array}{l}\text { Paraspinal low back pain had a sensitivity of } 95 \% \text { and specificity of } 25 \% \text {. Lack of } \\
\text { paraspinal tenderness suggested the facet joints were unlikely to be the source } \\
\text { of axial LBP. } \\
\text { The diagnostic sensitivity of midline LBP is low for facet joint pain. }\end{array}$ \\
\hline DePalma et a $\left.\right|^{15}$ & $\begin{array}{l}\text { Retrospective, } n=157-49 \text { with lumbar facet } \\
\text { joint pain } \\
\geq 75 \% \text { pain reduction }\end{array}$ & MBB (double comparative blocks) & $\begin{array}{l}\text { Facet joint pain patients were more likely to be older than those with internal } \\
\text { disc disruption, and more likely to be obese than those with sacroiliac joint pain. }\end{array}$ \\
\hline Streitberger et $a l^{55}$ & $\begin{array}{l}\text { Prospective } \\
\mathrm{n}=275 \\
\text { Patient selection: } \\
\text { Pain relief } \geq 50 \% \text {, but one block had to result } \\
\text { in } \geq 80 \% \text { benefit } \\
\text { RFA success: } \\
\geq 50 \% \text { pain relief }\end{array}$ & $\begin{array}{l}\text { MBB (double comparative diagnostic } \\
\text { blocks with lidocaine and bupivacaine) } \\
\text { RFA }\end{array}$ & Only depression was associated with a shorter duration of RFA success. \\
\hline Conger et $a l^{56}$ & $\begin{array}{l}\text { Retrospective } \\
n=111 \\
\geq 80 \% \text { concordant pain relief } \\
\text { RFA success: } \geq 50 \% \text { pain relief at } 6 \text { months }\end{array}$ & $\begin{array}{l}\text { MBB (double comparative diagnostic } \\
\text { blocks with lidocaine and bupivacaine) } \\
\text { RFA }\end{array}$ & Older age and larger Cobb angle associated with RFA treatment success. \\
\hline Cohen et $a F^{57}$ & $\begin{array}{l}\text { Prospective } \\
n=318 \text { ( } 63 \text { with suspected facet joint pain) } \\
\text { Patient selection: } \\
\geq 50 \% \text { pain reduction after a block } \\
\text { RFA success: } \\
\geq 50 \% \text { pain relief } \times 3 \text { months }\end{array}$ & $\begin{array}{l}\text { MBB (single block) } \\
\text { RFA }\end{array}$ & $\begin{array}{l}\text { Number of Waddell signs inversely correlated with treatment outcomes. Factors } \\
\text { associated with treatment success included older age, shorter duration of pain, } \\
\text { lower baseline pain scores and functional disability, absence of secondary gain } \\
\text { and not having concomitant pain and psychiatric conditions. Among concurrent } \\
\text { comorbidities, the presence of pelvic or abdominal pain and depression were } \\
\text { most strongly correlated with negative outcome. }\end{array}$ \\
\hline
\end{tabular}

Double comparative diagnostic blocks refer to two separate blocks with lidocaine and bupivacaine

CPR, clinical prediction rule; IA, intra-articular injection; LBP, low back pain; MBB, medial branch block; RFA, radiofrequency ablation.

Schwarzer et $a l^{42}$ conducted a prospective study attempting to identify presumptive clinical features in 176 patients with chronic LBP using double, comparative LA injections or MBBs. In the $15 \%$ of patients who achieved concordant pain relief with lidocaine and bupivacaine, none of the 16 physical signs or symptoms evaluated was associated with a positive response.

In a smaller prospective study Schwarzer et al conducted in 63 patients, ${ }^{43}$ one or more IA injections of LA produced pain relief in more patients than did injection of saline (32\% vs $40 \%)$. None of the historical features or clinical tests discriminated between patients diagnosed with facet joint pain and those who had negative blocks.

Following up on a prospective study that examined the association between 90 physical examination signs and symptoms and IA LA injections, ${ }^{44}$ Revel et $a l^{45}$ performed a placebocontrolled crossover study in 80 patients based on the presence of five of seven criteria they found in their first study: age $>65$ years, absence of exacerbation with coughing, relief with recumbency, pain not worsened by forward flexion or rising from forward flexion and pain not exacerbated by hyperextension or extension-rotation. Patients were divided into positive $(n=43)$ and negative $(n=37)$ groups based on whether they had at least five of the previously identified seven criteria. Patients randomly received one block, an IA injection with $1.5 \mathrm{~mL}$ of lidocaine and contrast, or saline and contrast into the lowest two or three joints in double-blind fashion. A positive response was $\geq 75 \%$ pain relief after LA block. The presence of at least five of the seven criteria (ie, the positive group) had $90 \%$ sensitivity and $80 \%$ specificity for identifying patients with a positive response to lidocaine.

In a prospective study involving 81 patients with chronic lumbar or lumbopelvic pain who underwent IA facet joint blocks, discograms and sacroiliac (SI) joint injections, Young et $a l^{46}$ sought to identify predictive factors for response to diagnostic injections. Although the group could identify several predictive factors for SI joint and lumbar discogenic pain, the only characteristics associated with a positive IA facet block were lack of pain provocation when rising from sitting, and absence of pain centralization.
In a study involving 116 patients with LBP who underwent comparative LA IA injection or MBB, Laslett et $a l^{47}$ tried to confirm the value of Revel's criteria. ${ }^{44}$ They found that these criteria were associated with low sensitivity $(<17 \%)$ but high specificity (90\%), with only absence of pain by coughing or sneezing reaching predictive significance. The authors concluded that these tests were a poor screening tool to select patients for facet interventions, which require high sensitivity. In a subsequent attempt to better refine clinical prediction rules in 120 patients with $\mathrm{LBP}^{48}$ the same authors performed double blocks, stratifying responses into $5 \%$ intervals from $75 \%$ pain relief to $>95 \%$ relief. At cut-off values $<90 \%$, no clinical findings predicted positive response to facet injections. Using a cut-off value of $95 \%$, the authors found that a negative extensionrotation test, absence of pain centralization, age $\geq 50$ years, pain relief with walking, pain relief with sitting, paraspinal onset and a score on the Modified Somatic Perception Questionnaire suggesting somatization were predictive of facetogenic pain.

DePalma et al $^{49}$ performed a retrospective study in 160 patients (170 axial LBP episodes) that attempted to determine whether the pattern of LBP was associated with the source. The presence of paramedian pain significantly increased the likelihood of SI joint pain and dual MBB-confirmed facet joint pain, while a predominance of midline symptoms was positively associated with internal disc disruption. In a companion study by the same group in 153 patients with axial LBP (157 pain episodes), ${ }^{15}$ older age and higher body mass index were more likely to be associated with a diagnosis of facet joint pain compared with internal disc disruption and SI joint pain, respectively.

Two studies by Manchikanti et $a l^{5051}$ containing 120 and 200 patients, respectively, who presented with axial LBP with or without radiation to the lower extremity, found that neither historical nor physical examination findings correlated with comparative MBB-confirmed lumbar facet joint pain. In the larger study, ${ }^{51}$ the authors were not able to confirm the criteria delineated by Revel et $a{ }^{45}$ In this study, the presence of paraspinal tenderness was associated with non-significant trend toward being predictive of a positive response $(\mathrm{p}=0.188)$. In the smaller study, back pain elicited by straight leg raising 
was weakly associated with a positive block..$^{50}$ The diagnostic criteria in these studies were $\geq 75 \%$ concordant pain relief with comparative LA MBB. A third study from the same group aimed to analyze the duration of effect of dual MBB with LA and LA with either steroid or Sarapin in 180 patients. The only factor that was predictive for a negative outcome was back or leg pain with straight leg raising; none of the other clinical features had a significant correlation with block results. ${ }^{52}$

Dolan $e$ t $a l^{53}$ performed a clinical study in 58 people with clinically diagnosed lumbar facet pain, subjecting them to single photon emission computed tomography(SPECT) and IA steroid injections. SPECT-positive patients $(n=22)$ experienced better outcomes through 3 months than SPECT-negative patients $(n=36)$, but tenderness was not associated with response to injections.

\section{Clinical studies evaluating the association of physical examination findings with RFA results}

Several studies have examined factors associated with RFA treatment outcomes. Although not every patient with facetogenic pain will respond to denervation, the high false-positive rate of uncontrolled blocks and the lack of any confirmatory reference make RF responders an excellent population to use for predictive modeling. In the first study to evaluate factors predictive of lumbar facet RFA outcomes in 192 patients from three different hospitals, Cohen et $a l^{54}$ found that paraspinal tenderness was associated with a positive outcome, while 'facet loading' (pain worsened by extension-rotation) was predictive of a negative outcome. In a smaller, prospective study conducted in 44 patients who underwent RFA after a concordant response to comparative LA MBB, Streitberger et $a l^{55}$ found no association between radiating pain and treatment response; in bivariate analysis, only depression was found to be associated with a shorter duration of treatment response.

More recently, a retrospective review performed in 111 patients who responded with $\geq 80 \%$ concordant pain relief after comparative LA MBB found that older age and a smaller Cobb angle were associated with $\geq 50 \%$ pain reduction 6 months after RFA. ${ }^{56}$ Finally, in a large, prospective study that sought to determine factors associated with interventional treatment outcomes in 318 patients with LBP (63 with suspected facetogenic pain), Cohen et al found that $51.1 \%$ of individual with 0 Waddell signs, $34.1 \%$ with one or two signs, $26.1 \%$ with three or four signs and only $16.7 \%$ of people with five of five Waddell signs experienced a positive treatment outcome. Other variables associated with treatment success included older age, shorter duration of pain, lower baseline pain scores and better function, absence of secondary gain and not having concomitant pain and psychiatric comorbidities. ${ }^{57}$

\section{Experimental studies}

Experimental studies in cadavers have shed light on movements associated with lumbar facet joint stress. In one of a series of experiments designed to determine conditions under which the facet joint capsules were stretched, Ianuzzi $e t a l^{58}$ found that in the upper three facet joints, the greatest strain and joint displacement was associated with lateral bending. In the lowest two joints, the largest degree of strain occurred during forward flexion.

\section{Systematic reviews and guidelines}

Petersen $e$ t $a l^{59}$ performed a systematic review to establish clinical diagnostic rules for various LBP etiologies. For lumbar facet joint pain, the only findings predictive of a negative response to double diagnostic IA injections or MBBs were the absence of relief with recumbency, and the lack of pain centralization.

Finally, guidelines on facet blocks do not support positive physical examination requirements. A systematic review performed by designated members of ASIPP concluded that conventional clinical findings were unreliable in identifying painful lumbar facet joints. ${ }^{60} \mathrm{~A}$ similar view had been previously espoused in guidelines by the SIS, which designated diagnostic injections as the only reliable means for diagnosis. ${ }^{16}$

\section{Recommendations}

In summary, there are no pathognomonic physical examination or historical signs that can reliably predict response to facet joint blocks in individuals with mechanical chronic LBP, although pain that is not predominantly in the midline, and possibly tenderness overlying the facet joints, appear to be weakly associated with a positive response to facet joint interventions. The previous studies that found no association between physical signs and symptoms for the most part did not evaluate this metric. Studies have also shown that maneuvers associated with radicular signs (eg, pain worsened by coughing, pain radiating below the knee) may be predictive of negative diagnostic facet blocks. Similar to other interventions for chronic pain, greater disease burden and psychiatric comorbidities may be associated with definitive treatment failure. When selecting targets for blocks, levels should be determined based on clinical presentation (radiological findings when available, tenderness on palpation performed under fluoroscopy, pain referral patterns); grade C evidence, low level of certainty.

\section{QUESTION 2: IS THERE ANY CORRELATION BETWEEN RADIOLOGICAL FINDINGS AND A PAINFUL FACET JOINT OR RADIOFREQUENCY ABLATION OUTCOMES, AND SHOULD IMAGING BE REQUIRED BEFORE PROGNOSTIC BLOCKS?}

Imaging techniques have been used to identify radiological markers of painful lumbar facet joints. In previous studies, response to IA facet joint injections or MBB has served as the gold standard for confirming that potentially painful lumbar facet joints identified radiologically were sources of LBP. The most widely investigated imaging modality used to detect potentially painful facet joints is SPECT, a nuclear medicine imaging technique that requires intravenous administration of a gammaemitting radioisotope and involves considerable radiation exposure compared with conventional X-rays. Using external detectors, two-dimensional projections are acquired in multiple planes and reconstructed to form a three-dimensional image. The quantity of emissions detected from the radionuclide provides a measure of biological activity; thus, SPECT scans can identify active inflammation involving facet and other joints. Scintigraphy is a similar technique that also requires administration of a gamma-emitting radioisotope and uses external detectors, but only a two-dimensional image is generated. Previous studies in which SPECT, scintigraphy or CT were used in conjunction with confirmatory IA facet joint injections or MBB have reported mixed results regarding their correlation and predictive value. ${ }^{5361-68}$ Table 5 summarizes the studies discussed in this section.

\section{SPECT and confirmatory MBB}

In a randomized, double-blind placebo-controlled trial, 29 patients with LBP completed the research protocol..$^{62}$ In this study, all patients received a SPECT scan after which a pain 
Table 5 Studies evaluating the association between imaging pathology and facet joint block and treatment outcomes

\begin{tabular}{|c|c|c|c|}
\hline Study & Design & Number of subjects & Results \\
\hline Holder et a $\left.\right|^{63}$ & $\begin{array}{l}\text { Prospective study designed to evaluate the } \\
\text { sensitivity and specificity of PS or SPECT } \\
\text { scans in identifying patients responsive to } \\
\text { IA facet injections }\end{array}$ & $\begin{array}{l}43 \text { patients (male }=17 \text {, female } 26 \text { ) } \\
\text { Mean age } 55 \text { years (range } 16-18 \\
\text { years) }\end{array}$ & $\begin{array}{l}\text { PS group: sensitivity }=0.71 \text {, specificity }=0.76,(+) \\
\text { predictive value }=0.38,(-) \text { predictive value }=0.93 \\
\text { SPECT group: sensitivity }=1.0, \text { specificity }=0.71, \\
(+) \text { predictive value }=0.41,(-) \text { predictive } \\
\text { value }=1.0\end{array}$ \\
\hline Schwarzer et a ${ }^{67}$ & $\begin{array}{l}\text { Single-blind, placebo-controlled trial } \\
\text { designed to evaluate the effects of CT- } \\
\text { confirmed facet osteoarthritis on IA facet } \\
\text { joint injections }\end{array}$ & $\begin{array}{l}63 \text { patients } \\
\text { Median age } 59 \text { years (IQR } 51-68) \text {; } \\
\text { Female:male ratio } 3: 1 \\
\text { Median LBP duration } 7 \text { years (IQR } \\
\text { 2-20) }\end{array}$ & $\begin{array}{l}32 \% \text { ( } 95 \% \mathrm{Cl} 20 \text { to } 44 \text { ) with } \geq 50 \% \text { pain } \\
\text { reduction at } 3 \text { hours following IA placebo } \\
\text { injection } \\
40 \% \text { ( } 95 \% \mathrm{Cl} 27 \text { to } 53 \text { ) with } \geq 50 \% \text { pain } \\
\text { reduction at } 3 \text { hours following IA LA injection } \\
\text { No significant group differences in CT joint } \\
\text { scores based on patient response to IA placebo } \\
\text { or IA LA injections }\end{array}$ \\
\hline
\end{tabular}

\begin{tabular}{|c|c|c|c|}
\hline Dolan et a ${ }^{53}$ & $\begin{array}{l}\text { Prospective comparison of IA facet joint } \\
\text { injections between patients with SPECT (+) } \\
\text { and SPECT (-) scans }\end{array}$ & $\begin{array}{l}\text { SPECT (+) group }=22 \\
\text { SPECT (-) group }=36\end{array}$ & $\begin{array}{l}\text { Significant improvement in VAS and McGill pain } \\
\text { scores in SPECT (+) group at months } 1 \text { and } 3 \\
94 \% \text { SPECT (+) group reported improvement } \\
\text { at month } 1 \text { compared with } 47 \% \text { in SPECT (-) } \\
\text { group }\end{array}$ \\
\hline Pneumaticos et al ${ }^{66}$ & $\begin{array}{l}\text { Prospective comparison of IA facet joint } \\
\text { injections between patients with SPECT (+) } \\
\text { and SPECT (-) scans }\end{array}$ & $\begin{array}{l}\text { SPECT }(+) \text { group }=15 \\
\text { SPECT }(-) \text { group }=16 \\
\text { No SPECT comparison group }=16\end{array}$ & $\begin{array}{l}\text { Significant improvement in pain at months } 1 \\
\text { and } 3 \text { in SPECT (+) group vs SPECT (-) and no } \\
\text { SPECT comparison groups } \\
\text { Number of facet joints treated in SPECT (+) } \\
\text { group reduced from } 60 \text { to } 27 \text { with cost savings } \\
\text { of US\$326/patient }\end{array}$ \\
\hline
\end{tabular}

\begin{tabular}{llll} 
Cohen et al ${ }^{69}$ & $\begin{array}{l}\text { Retrospective, multicenter study examining } \\
\text { factors associated with cervical medial } \\
\text { branch RFA outcomes }\end{array}$ & $\begin{array}{l}92 \text { patients, } 44 \text { with significant facet } \\
\text { pathology on MRI }\end{array}$ & $\begin{array}{l}57 \% \text { success rate in overall cohort, } 52 \% \text { in } \\
\text { individuals with significant MRI pathology } \\
(p=0.75)\end{array}$ \\
\hline Cohen et $a F^{54}$ & $\begin{array}{l}\text { Retrospective, multicenter study examining } \\
\text { factors associated with lumbar medial } \\
\text { branch RFA outcomes }\end{array}$ & $\begin{array}{l}192 \text { patients, } 117 \text { with significant } \\
\text { facet pathology on MRI }\end{array}$ & $\begin{array}{l}54 \% \text { success rate in overall cohort, } 52 \% \text { in } \\
\text { individuals with significant MRI pathology } \\
\text { ( } \mathrm{p}=0.75)\end{array}$
\end{tabular}

\begin{tabular}{|c|c|c|c|c|}
\hline Ackerman and Ahmad ${ }^{61}$ & $\begin{array}{l}\text { Randomized, double-blind trial of MBB vs } \\
\text { IA facet joint injections in patients with } \\
\text { SPECT (+) scans }\end{array}$ & $\begin{array}{l}\text { IA facet injection group }=23 \\
\text { (male }=14, \text { female }=9) \\
\text { MBB group }=23(\text { male }=12, \\
\text { female }=11) ; \\
\text { Median age }=39.3 \text { years } \\
\text { Mean symptom duration }=7.6 \text { weeks }\end{array}$ & $\begin{array}{l}61 \% \text { had } \geq 50 \% \text { pain relief at week } 12 \text { in IA } \\
\text { facet injection group vs } 26 \% \text { in MBB group } 26 \% \\
\text { Sensitivity/specificity of SPECT in the IA facet } \\
\text { joint injection group } 0.79 \text { and } 0.70 \text {, respectively } \\
\text { Pain rating and ODI scores significantly less in } \\
\text { the IA facet group vs MBB group at week } 12\end{array}$ & $\begin{array}{l}\text { All patients in the IA facet injection } \\
\text { and MBB groups received lidocaine and } \\
\text { triamcinolone. }\end{array}$ \\
\hline Stojanovic et $a^{68}$ & $\begin{array}{l}\text { Retrospective review of correlations } \\
\text { between MRI and outcomes of MBB and } \\
\text { RF denervation }\end{array}$ & $\begin{array}{l}127 \text { consecutive patients } \\
\text { Male }=52 \% \\
\text { Mean age }=52.9 \text { years }\end{array}$ & $\begin{array}{l}\text { Facet joint degeneration or hypertrophy on } \\
\text { MRI significantly correlated with } \geq 50 \% \text { pain } \\
\text { reduction following MBB but not RF } \\
\text { Younger patients significantly more likely to fail } \\
\text { MBB but not RF }\end{array}$ & $\begin{array}{l}\text { Prospective studies recommended to } \\
\text { confirm study findings. }\end{array}$ \\
\hline Koh et $a l^{65}$ & $\begin{array}{l}\text { Prospective comparison of MBB between } \\
\text { patients with SPECT }(+) \text { and SPECT (-) } \\
\text { scans }\end{array}$ & $\begin{array}{l}\text { SPECT }(+) \text { group }=28 \text { (male }=12 \text {, } \\
\text { female }=16) ; \\
\text { SPECT }(-) \text { group }=5 \text { (male }=2 \text {, } \\
\text { female }=3) \\
\text { Mean age SPECT }(+) \text { group }=60.4 \\
\text { Mean age SPECT }(-) \text { group }=51.8 \\
\text { years }\end{array}$ & $\begin{array}{l}85.7 \% \text { with }>50 \% \text { pain reduction at week } 2 \text { in } \\
\text { SPECT (+) group vs } 20 \% \text { in the SPECT (-) group } \\
78.6 \% \text { with }>50 \% \text { pain reduction at week } 4 \text { in } \\
\text { SPECT (+) group vs } 0 \% \text { in the SPECT (-) group } \\
\text { No significant between-group differences in ODI }\end{array}$ & $\begin{array}{l}\text { All MBB performed with ultrasound } \\
\text { guidance using lidocaine and } \\
\text { triamcinolone. }\end{array}$ \\
\hline Freiermuth et $a l^{62}$ & $\begin{array}{l}\text { Randomized, double-blind, placebo- } \\
\text { controlled trial to determine the sensitivity/ } \\
\text { specificity of SPECT/CT to identify patients }\end{array}$ & $\begin{array}{l}29 \text { patients }(\text { male }=16 \text {, female }=13) \\
\text { age range }=38-83 \text { years }\end{array}$ & $\begin{array}{l}\text { SPECT/CT; sensitivity } 0.57 \text { ( } 95 \% \mathrm{Cl} 0.18 \text { to } 0.90 \text { ), } \\
\text { specificity } 0.77(95 \% \mathrm{Cl} 0.55 \text { to } 0.92 \text { ) } \\
\text { Diagnostic accuracy }=0.72 \text { (ideal value } 1.0 \text { ) }\end{array}$ & $\begin{array}{l}\text { SPECT/CT not recommended as first-line } \\
\text { diagnostic tool prior to IA facet joint } \\
\text { injections. }\end{array}$ \\
\hline
\end{tabular}

Slightly higher success rate in the younger patients (ie, with less facet joint pathology) treated at Walter Reed may have contributed to findings. Slightly higher success rate in the younger patients (ie, with less facet join pathology) treated at Walter Reed may have contributed to findings.

No significant improvements evident at $47 \%$ of SPECT (+) patients had osteoarthritic facet joints compared with $\%$ of SPECT (-) group.

No significant group differences at month 6 . injections. Other evaluation of facet pain.

The authors concluded that the high sensitivity and (-) predictive value mad symptomasic . 
a joint that was not blocked. Following completion of the first series of blocks, $24 \%$ (7 of 29) of patients had a positive response and $76 \%$ (22 of 29) had a negative response. Among individuals who had positive blocks, 4 of 7 also had positive SPECT scans (sensitivity $=0.57$ ), and 17 of 22 (specificity $=0.77$ ) had negative SPECT scans. A second series of blocks was performed in six patients, two of whom had a positive response. Although a power analysis was not performed, the authors concluded that SPECT should not be recommended as a first-line diagnostic tool prior to MBB. ${ }^{62}$

In a second study, a randomized, double-blind controlled trial was conducted that involved 80 patients with LBP. ${ }^{64}$ Patients were randomized to receive SPECT scans prior to diagnostic blocks (SPECT scan group, $\mathrm{n}=40$ ) or no scan prior to receiving blocks (control group, $n=40$ ). The block recommendations of patients randomized to the SPECT scan group was modified based on the scan results, but block recommendations for patients randomized to the group who did not receive a scan were based solely on clinical evaluation. For patients diagnosed with facet pain at the L4-L5 or L5-S1 levels, fluoroscopically guided MBB were performed using $0.6 \mathrm{~mL}$ of LA. A positive block was defined as $\geq 50 \%$ pain reduction 4 hours after the block was completed. In the SPECT scan group, 7 of 40 patients were diagnosed with facet arthropathy, while 14 of 40 patients in the control group had a similar diagnosis. In the SPECT scan group, $71 \%$ (5 of 7) had a positive MBB compared with 43\% (6 of 14) in the control group. The between-group response rate to MBBs was statistically significant $(\mathrm{p}<0.05){ }^{64}$

In a third study, an observational, open-label design was used to compare the outcomes of MBB in patients with chronic LBP $(n=30)$ with and without facet joint-positive SPECT scans. ${ }^{65}$ The primary outcome measure was $>50 \%$ pain reduction on the visual analog scale (VAS) at weeks 2 and 4 following the MBB. A secondary outcome measure was the Oswestry Disability Index (ODI) score. All MBB were performed using ultrasound guidance, and the injectate consisted of $2 \mathrm{~mL}$ of lidocaine $1 \%$ and triamcinolone $30 \mathrm{mg}$. At week 2 follow-up, 85.7\% (24 of 28) of patients in the SPECT scan-positive group reported $>50 \%$ pain reduction compared with $20 \%$ ( 1 of 5) in the SPECT-negative group. At week 4 follow-up, $78.6 \%$ (22 of 28 ) in the SPECTpositive group reported $>50 \%$ pain reduction compared with none (0 of 5$)$ in the SPECT-negative group. No significant group differences in ODI scores were reported. ${ }^{65}$

\section{SPECT and confirmatory IA facet joint injections}

Two prospective, open-label studies compared the effects of IA facet joint injections in patients with facet joint-positive and joint-negative SPECT scans. In the first study, a randomized open-label design was used to investigate the effects of IA facet joint injections in patients with facet joint-positive and jointnegative scans. ${ }^{66}$ Patients with LBP $(\mathrm{n}=47)$ were randomized in a 2:1 ratio to receive a SPECT scan prior to fluoroscopically guided IA facet injections (group A) or no scan prior to IA injections (group B). Patients randomized to group A who had positive SPECT scans were further categorized as group A1, and patients with negative SPECT scans were categorized as group A2. The primary outcome measure was change in pain scores at months 1,3 and 6 following the injections. All facet joint injections were fluoroscopically guided, and the injectate consisted of $2.5 \mathrm{~mL}$ of bupivacaine $0.5 \%$ and $0.5 \mathrm{~mL}$ of betamethasone (total dose of $3 \mathrm{mg}$ ). At 1-month follow-up, the change in pain scores was significantly greater $(\mathrm{p}<0.008)$ in group A1 $(\mathrm{n}=15)$ compared with group A2 $(n=16)$ and group $B(n=16)$. Similarly, at month
3 follow-up, the change in pain scores was significantly greater $(\mathrm{p}<0.001)$ in group A1 compared with group A2 and group B. A greater proportion of patients in group A1 (87\%, 13 of 15) reported improvement in pain at 1-month follow-up compared with group A2 (13\%, 2 of 13) and group B (31\%, 5 of 16$)$. In patients randomized to group $\mathrm{A} 1$, the number of facet joints injected decreased from 60 indicated by the referring physician to 27. This translated to a cost-per-patient reduction, based on Medicare reimbursement rates, from US\$2191 to US $\$ 1865$, inclusive of imaging costs. ${ }^{66}$ Follow-up cost-effectiveness studies have yet to be conducted, and calculating cost-effectiveness depends on many factors including patient selection, interpretation of imaging, designation of outcomes and local cost variances, among others.

In the second study, 58 patients with a clinical diagnosis of facet joint pain received SPECT scans; 22 had facet joint-positive scans and 36 had joint-negative scans. ${ }^{53}$ Outcome measures at months 1, 3 and 6 included the VAS pain score, Present Pain Intensity score and the modified McGill Pain Questionnaire (MPQ). All IA injections were performed using fluoroscopic guidance, and the injectate consisted of $1 \mathrm{~mL}$ of lidocaine $1 \%$ and methylprednisolone $40 \mathrm{mg}$. At 1-month follow-up, patients with SPECT-positive scans experienced significantly greater reductions $(\mathrm{p}<0.05)$ in VAS pain scores compared with patients with SPECT-negative scans. Similarly, at 1-month and 3-month follow-ups, patients with SPECT-positive scans experienced significantly greater reductions (month $1, \mathrm{p}=0.005$; month 2 , $\mathrm{p}=0.001)$ in MPQ scores compared with patients with SPECTnegative scans. Compared with patients with SPECT-negative scans, a significantly greater proportion of patients with SPECTpositive scans reported improvement at 1 -month ( $94 \%$ vs $47 \%$; $\mathrm{p}<0.0005)$ and 3 -month $(79 \%$ vs $42 \%, \mathrm{p}<0.001)$ follow-ups. ${ }^{53}$

\section{SPECT and confirmatory IA facet joint injections versus MBB} A randomized, double-blind trial was performed to compare the effects of IA facet joint injections $(n=23)$ and MBB $(n=23)$ at 12-week follow-up in patients with chronic LBP who had lumbar facet joint-positive SPECT scans. ${ }^{61}$ The primary outcome was $\geq 50 \%$ pain reduction on the numeric rating pain scale at 12 weeks. A secondary outcome was the ODI score. All injections were performed using fluoroscopic guidance, and the injectate for the IA facet joint injections and MBB consisted of $0.1 \mathrm{~mL}$ of lidocaine $1 \%$ and $0.2 \mathrm{~mL}$ of triamcinolone (total dose $2 \mathrm{mg}$ ). At the 12-week follow-up visit, 61\% (14 of 23) experienced $\geq 50 \%$ pain reduction in the IA group compared with $26 \%$ (6 of 23 ) in the MBB group. The sensitivity and specificity of a facet joint-positive SPECT scan in the IA group were 0.79 and 0.70 , respectively. No significant group differences in ODI scores were reported. ${ }^{61}$

\section{SPECT, planar scintigraphy and confirmatory IA facet joint injections}

A prospective open-label design was used to investigate the sensitivity and specificity of SPECT compared with planar scintigraphy for identifying patients likely to respond to IA facet joint injections. ${ }^{63}$ A consecutive series of patients with a clinical presentation suggestive of facet pain $(n=43)$ received planar scintigraphy and SPECT scans. All patients received fluoroscopically guided IA facet joint injections with bupivacaine and steroid. The follow-up time periods were not specified. Forty-one patients were included in the sensitivity and specificity analyses. The sensitivity and specificity of planar scintigraphy for identifying IA injection-confirmed facet pain were 0.71 and 
0.76 , respectively. The positive predictive and negative predictive values were 0.38 and 0.93 , respectively. For SPECT, the sensitivity and specificity were 1.0 and 0.71 , respectively, and the positive and negative predictive values were 0.41 and 1.0, respectively. ${ }^{63}$

\section{MRI, therapeutic facet injections and radiofrequency denervation}

In a retrospective study, facet joint pathology was categorized in 127 patients and correlated with $\mathrm{MBB}$ and RF denervation outcomes. ${ }^{68}$ A positive $\mathrm{MBB}$ was defined as $\geq 50 \%$ pain reduction concordant with the duration of the LA, and a positive RF outcome was defined as $\geq 50 \%$ pain relief at month 3 follow-up. The presence of facet joint degeneration or hypertrophy correlated with a positive response to MBB (71\% vs 51\% in individuals with normal facet joint morphology; $\mathrm{p}=0.04)$, but no correlation was observed between facet joint pathology and RF outcomes. Younger age was correlated with a negative response to $\mathrm{MBB}(\mathrm{p}=0.04)$, but no significant correlation was found between younger age and RF outcomes. ${ }^{68}$

Cohen et al performed studies in the lumbar $(n=192)$ and cervical $(n=92)$ spine regions designed to determine factors predictive of RFA outcome. In both studies, no association was found between the presence of significant facet joint pathology on MRI and denervation results. ${ }^{5469}$

Finally, a small retrospective study performed in 10 patients with chronic neck pain sought to determine whether positron emission tomography (PET)/MRI could be used to identify patients for therapeutic cervical MBB performed with high volumes of LA and steroid. ${ }^{70}$ Increased 18 F-fluoro-deoxyglucose uptake along with facet arthrosis was observed in six joints in six patients. These patients exhibited better pain relief 3 hours after the blocks, which persisted through 3-month follow-up.

\section{CT and confirmatory IA facet joint injections}

In a single-blind, placebo-controlled trial, 63 patients underwent CT scans followed by a series of IA facet joint injections at the L3-L4, L4-L5 and L5-S1 levels. ${ }^{67}$ The CT scans were independently reviewed in random order by three radiologists blinded to the clinical status of the patient. Each facet joint was scored ( $0-3$ scale) based on the extent of joint space narrowing, sclerosis, subchondral erosions, cysts and osteophytes. All facet joint injections were fluoroscopically guided and the injectate consisted of up to $1.5 \mathrm{~mL}$ of bupivacaine $0.5 \%$. The placebo injections consisted of $0.5 \mathrm{~mL}$ of normal saline. A positive IA injection was defined as a $\geq 50 \%$ reduction in VAS scores maintained for a minimum of 3 hours. A positive response to placebo injections was observed in 32\% (20 of 63) of patients, and $40 \%$ reported a positive response to the bupivacaine injections. No significant association was observed between radiological grading of facet joint pathology and response to IA facet joint injections. ${ }^{67}$

\section{Recommendations}

In summary, there is moderate evidence supporting the use of SPECT for identifying painful lumbar facet joints prior to MBB (grade $\mathrm{C}$ recommendation, moderate level of certainty). Weak evidence exists supporting the use of SPECT for identifying painful lumbar facet joints prior to IA facet joint injections (grade D recommendation, low level of certainty). Regarding the costeffectiveness of SPECT, further study is required. For scintigraphy, MRI and CT, there is weak or no evidence supporting the use of these imaging modalities for identifying painful lumbar facet joints prior to MBB or IA facet joint injections (grade D recommendation, low level of certainty).

\section{QUESTION 3: SHOULD PHYSICAL THERAPY AND/OR PRIOR CONSERVATIVE TREATMENT BE A PREREQUISITE BEFORE PROGNOSTIC FACET BLOCKS? IF SO, FOR HOW LONG SHOULD THEY BE CONTINUED, AND SHOULD THEY BE CONCURRENT?}

\section{Rationale for conservative care, and duration of care, before} facet blocks

Existing clinical practice guidelines (CPGs) for LBP consistently recommend care that is patient-centered, screens for psychosocial factors, provides back pain education and promotes exercise and physical therapy (PT). ${ }^{2171-74}$ As a result, the timing and duration of LBP treatments remain highly individualized. If primary care and acute care providers follow guideline recommendations, patients will present to pain specialists already having trialed many conservative treatments. Since adherence to these guidelines is poor, ${ }^{75} 76$ pain specialists should confirm whether or not conservative treatment was received before considering invasive treatments. It is important to note that the order of treatment is not based on studies showing better outcomes with conservative care; rather, it is based on the fundamental medical principal of starting with less invasive treatments even when more invasive options may be more efficacious.

The North American Spine Society coverage guidelines recommend failure of at least 3 months of conservative therapy (defined to include exercise, PT, chiropractic care and/or analgesics) before consideration of diagnostic facet joint blocks and nerve ablation. ${ }^{77}$ Accordingly, insurance authorizations for facet joint interventions increasingly mandate a trial of conservative management prior to authorization of the procedure. ${ }^{78}$ Despite consistent evidence of only small effect sizes for conservative treatments (including PT) in chronic LBP, ${ }^{79} 80$ proponents still recommend conservative care trials due to their relatively lower costs and risks. This position appears to be supported by interventional pain researchers since the inclusion criteria within prospective studies of facet joint interventions usually, 1819 81-83 but not always, ${ }^{84} 85$ include a preceding trial of conservative treatment. Yet, there is no existing evidence that demonstrates the appropriate timing or optimal duration of conservative treatments for chronic LBP.

\section{Rationale for continued or concurrent conservative care and PT and clinical trials}

A common rationale for combined therapy is that therapeutic interventions can reduce pain and create an opportunity to engage in exercise and other healthy behaviors, and ultimately motivate patients toward self-care. Although this is common in clinical practice, few studies have examined the role of combination therapies. A recent high-profile randomized trial compared exercise for LBP with exercise with RF denervation of the facet joints and reported no significant difference in average improvement in pain intensity between groups. ${ }^{17}$ However, clinically meaningful improvement was only observed in the group that received exercise plus RF denervation of the facet joints. ${ }^{24}$ Additional evidence is available from the broader spine intervention literature. For example, Cohen et $a l^{86}$ compared cervical epidural steroid injections, conservative treatment (ie, PT and/or adjuvants) and combined treatment, and found that combination therapy provided better improvement in several outcomes than either stand-alone treatment. One explanation provided by the authors for these findings was that the intermediate-term benefit 
afforded by injections created a therapeutic window in which the effectiveness of PT could be maximized. International guidelines also support multimodal and interdisciplinary treatment, with recently published guidelines from the National Institute for Health and Care Excellence ${ }^{87}$ and the Belgian Federal Healthcare Institute ${ }^{88}$ recommending lumbar facet RFA as part of an interdisciplinary care pathway for LBP. In addition to physicianprescribed treatments, self-care strategies for low back health that should be implemented or continued include exercise, smoking cessation, weight loss, healthy diet, mood and stress management and sleep hygiene. ${ }^{89} 90$

\section{Recommendations}

We recommend a 3-month trial of different conservative treatments before facet joint interventions. Conservative therapies may include medications (eg, non-steroidal anti-inflammatory drugs, antidepressants), physical treatments (exercise, heat or cold therapy, massage), integrative treatments (acupuncture, spinal manipulation if indicated) and others (nutrition, weight loss, sleep hygiene). Although current research does not provide clear answers regarding the optimal timing of facet joint blocks for chronic LBP, or the appropriate duration of conservative care before consideration of facet interventions, prospective studies of facet joint interventions have generally required a trial of conservative treatment before study enrollment. This is consistent with the recommendations of multiple CPGs; grade C recommendation, low level of evidence.

\section{QUESTION 4: IS IMAGE GUIDANCE NECESSARY FOR LUMBAR FACET BLOCKS AND RADIOFREQUENCY ABLATION? \\ Theoretical concerns: accuracy and safety}

Image guidance has become an essential component of performing spinal procedures in pain management. ${ }^{91}$ For MBB and IA facet joint injections, fluoroscopy and to a lesser degree, CT guidance are most commonly used. The use of imaging allows accurate needle placement ensuring the lowest volume of anesthetic is administered, thereby reducing spread to surrounding tissues which may lead to false-positive test results. Image guidance also improves safety through direct visualization of bony elements of the neuraxis, thus avoiding structures in proximity including pleura, neural foramina and vascular supply. An oftencited study evaluating the accuracy of 45 nonimage-guided paravertebral somatic nerve blocks found that in only $18 \%$ of cases was contrast confined to the paravertebral area. Epidural spread was noted in $70 \%$ of injections. ${ }^{92}$ In addition, a case report in an active duty service member described a spinal headache requiring an epidural blood patch following a blind lumbar facet block. ${ }^{93}$

\section{Guidelines and insurance coverage}

The SIS guidelines state 'fluoroscopy is mandatory for the conduct of lumbar medial branch blocks' as it provides an overview of the bony anatomy as well as the ability to confirm contrast spread. ${ }^{16}$ For MBB, the nerve is not directly visible with fluoroscopy, but its location is inferred based on accepted landmarks. Fluoroscopy is also a familiar technology that most pain providers are comfortable with. Nevertheless, fluoroscopy - and particularly CT-have considerable costs associated with them, including purchase price, maintenance and dedicated facilities. Furthermore, both modalities expose patient and provider to radiation, which may have cumulative health effects.

Guidelines released by the US Department of Health and Human Services in 2008 asserted that radiographic guidance is typically employed during facet injections to ensure accurate needle placement and to avoid unnecessary injury. ${ }^{94}$ In 2018, Noridian, a major carrier for the Centers for Medicare and Medicaid Services, provided a local coverage determination for Medicare that asserted facet joint interventions must be performed under fluoroscopic or CT guidance and that interventions performed under ultrasound would not be reimbursed..$^{95}$ Multiple insurance companies have pursued similar requirements, including BlueCross BlueShield, ${ }^{78} \mathrm{Cigna}^{96}$ and UnitedHealthcare, ${ }^{97}$ determining that facet blocks performed without fluoroscopy (ie, using ultrasound only) were medically inappropriate.

\section{Validity and accuracy of fluoroscopic and CT-guided blocks}

Fluoroscopy is the gold standard for facet blocks and is recommended or required by multiple insurance companies. ${ }^{78} 9697$ With regard to MBB, although a randomized study in the cervical spine found the incidence of 'missed nerves' to be 7\% using fluoroscopic guidance with $0.25-0.5 \mathrm{~mL}$ of injectate, ${ }^{98}$ an earlier study performed in 15 healthy volunteers reported that a $0.5 \mathrm{~mL}$ injectate bathed the target lumbar medial branch in $100 \%$ of 120 nerve blocks. ${ }^{99}$ For lumbar IA injections, studies have reported high rates of failed blocks, ranging between $29 \%$ and $38 \%$ per joint using fluoroscopy. ${ }^{18}{ }^{100}$ However, the precise anatomical osseous resolution afforded by CT imaging may yield higher success rates. In one retrospective study, Weininger et al reported a $94 \%$ success rate for 85 lumbar IA facet blocks. ${ }^{101}$ Success rates exceeding $90 \%$ have been reported by other investigators as well. ${ }^{102}$

Despite its high-resolution compared with plain radiographs, the use of CT blocks for MBB and RFA has not been demonstrated in randomized clinical trials. For MBB, CT precludes the use of real-time contrast injection or digital subtraction angiography to detect intravascular uptake. Regarding RFA, the use of CT is limited because of imaging constraints and radiation exposure. Fluoroscopy allows for the placement of electrodes in an orientation parallel to the nerve, whereas this is less likely with CT. In one cadaveric study $(n=10)$ that compared fluoroscopy with CT for RF neurotomy in the lumbar spine, the use of CT was associated with less overlap of the electrode with the medial branch (ie, was oriented less parallel), more instances $(30 \%)$ where the electrode was positioned proximal to the medial branch and two cases (10\%) where the ventral ramus was inadvertently reached. ${ }^{103}$ The authors concluded that in current practice, CT should not be used for thermocoagulation of the lumbar medial branches.

\section{Use of ultrasound in the lumbar spine}

The use of ultrasound may provide an alternate imaging modality for performance of MBB and IA injections. This modality has widespread acceptance in regional anesthesia and can visualize soft tissue anatomy, neural structures and vascular supply. ${ }^{104} 105$ In addition, ultrasound is portable, can be used in pregnancy and does not require use of protective garments. However, there are disadvantages of using ultrasound for lumbar spine interventions, including limited visualization of the field, lengthy learning curve and potential for inadvertent vascular uptake, which can be reliably detected using realtime contrast injection or digital subtraction angiography. ${ }^{106}$ Furthermore, needle visibility can be impaired by body habitus and depth to target. 


\section{Use of ultrasound for lumbar medial branch blocks}

Greher et al performed 50 bilateral ultrasound-guided lumbar facet nerve injections on five cadavers. ${ }^{107}$ The target point was the groove of the cephalad margin of the transverse process of the L1-L5 vertebrae (T12-L4 medial branches) adjacent to the superior articular process. After needle placement with ultrasound, axial transverse CT scans were performed with and without contrast. Forty-five of the 50 needle tips were located at the target point, with the remaining five needle tips within $5 \mathrm{~mm}$ of the target. The authors reported 94\% accuracy, but noted contrast spread in the paraforaminal region in $14 \%$, epidural spread in $10 \%$, and intravascular spread in $4 \%$ of cadavers.

In a similar three-part study, Greher et al performed an ultrasound-based anatomical analysis on one fresh, nonembalmed cadaver to define necessary landmarks, views and estimated distances. ${ }^{108}$ In the second part of the study, delineation of sonographic landmarks was tested in vivo in 20 healthy volunteers for the L2-L4 medial branches. Using this information, the authors performed 28 ultrasound-guided MBB in five patients who had suspected bilateral lumbar facet joint pain, an average body mass index (BMI) of $23 \mathrm{~kg} / \mathrm{m}^{2}$ and an average age of 36 years. Fluoroscopy was used to confirm localization. Based on dissection, needle position was correctly located at all three levels in the cadaver. In the volunteers, landmarks were reported as good in 19 patients and sufficient in 1 patient with obesity. In the five patients with suspected lumbar facetogenic pain, 25 of 28 needles were determined to be accurately placed, with the remaining three needle tips within $5 \mathrm{~mm}$ of the target. Of note, the L5 dorsal ramus was not blocked.

In a retrospective study, Han et al compared ultrasoundguided and fluoroscopically guided lumbar MBB for lumbar facet joint pain in 214 patients. ${ }^{109}$ Among the 146 patients for whom follow-up information was available, no differences were noted between groups for complications, pain reduction and functional improvement through 6-month follow-up. However, the performance time for ultrasound-guided $\mathrm{MBB}$ was shorter.

Wu et al screened 103 RCTs and non-RCTs comparing the effectiveness of ultrasound guidance with fluoroscopically or CT-guided injection techniques for lumbar facet joint pain. ${ }^{110}$ Among these trials, three were included involving 202 patients. The authors found no significant difference between groups for pain scores, functional capacity or procedure time. They concluded that ultrasound-guided injections were feasible and reduced radiation exposure.

\section{Use of ultrasound for lumbar IA facet injections}

In a two-part study, Galiano et al performed 50 ultrasoundguided lumbar facet joint injections on five cadavers to assess the feasibility and accuracy of this modality. ${ }^{111}$ The authors reported that 8 of 50 attempts were not feasible due to reduced visibility from trapped air during cadaver conservation; however, for the 42 approaches performed, only 2 were outside the joint space. Ultrasound and CT showed the same mean depth and lateral distance to the reference point. Pearson's correlation coefficient was $0.86(\mathrm{p}<0.001)$ between ultrasound and CT, including the two failed measurements. In a follow-up study, the same group enrolled 40 patients in a trial comparing ultrasound with CT-guided lumbar facet joint injections. ${ }^{112}$ Among the 20 patients in the ultrasound group, 16 had clearly defined anatomic landmarks and 100\% accurate needle placement was achieved. In two patients with BMI $>28 \mathrm{~kg} / \mathrm{m}^{2}$, the lumbar facet joints could not be clearly visualized. The authors concluded that both groups showed benefit, but that procedure time and radiation exposure were less in the ultrasound-guided group.

Gofeld et $a l^{113}$ published an ultrasound-guided lumbar facet joint injection study using fluoroscopy as a control. IA facet joint injections were performed on five cadavers using an in-plane ultrasound approach. For the 50 injections performed, IA contrast spread was clearly observed in 44 cases. In the other six injections, however, contrast flow was noted in the surrounding soft tissue. In four of the six failed injections, the facet joint was not visible on ultrasound imaging. Using a similar approach, $\mathrm{Ha}$ et $a l^{114}$ retrospectively compared the outcomes of 105 patients with lumbar spinal pain who received fluoroscopically guided $(\mathrm{n}=51)$ and ultrasound-guided $(\mathrm{n}=54)$ IA facet blocks. Both groups demonstrated similar pain relief, functional improvement and complication rates through 6-month follow-up, but costs and procedure time were slightly higher for the ultrasoundguided procedures. Flaws in this study include the retrospective nature of the study, the absence of information regarding technical success rate, and the relatively low prevalence of obesity in the cohort (the Korean population in which this study was conducted has a lower prevalence of obesity than in non-Asian populations).

\section{Limitations of ultrasound}

One of the chief limitations for ultrasound guidance in lumbar spinal procedures is reduced visibility of the neuraxis in patients with obesity. As the prevalence of obesity in the USA approaches $40 \%,{ }^{115}$ the utility of this approach would be limited in a large portion of the population. Rauch et al evaluated use of ultrasound in 84 MBBs performed in 20 patients with a BMI exceeding $30 \mathrm{~kg} / \mathrm{m}^{2}{ }^{116}$ The authors found that while visualization was sufficient to identify anatomical targets with ultrasound, the success rate was only $62 \%$. Most failed blocks occurred at L5, which innervates the most commonly clinically affected facet joint, due to poor visibility from surrounding adipose tissue and artifacts from the iliac bone and sacral ala. ${ }^{117}$ In order to overcome some of the limitations of targeting the L5 dorsal ramus with ultrasound, an oblique out-of-plane technique in a rotated across axis view has been proposed. In a cadaveric study (10 cadavers with significant degenerative spondylosis, 20 L5 blocks), Greher et al reported an overall success rate of $80 \%$; when the five cadavers with moderate-to-severe spondylolisthesis were excluded, there was a $100 \%$ success rate in the 10 blocks. ${ }^{118}$

A second drawback of ultrasound is the possibility of targeting the wrong segment without fluoroscopic confirmation, which is potentially problematic at upper lumbar vertebrae. For example, a study performed in the thoracic spine found that misidentification of the targeted spinal level occurred between $16 \%$ and $43 \%$ of the time depending on the scanning technique, with $<50 \%$ accuracy in patients with obesity. ${ }^{119}$ Consequently, when midlumbar and upper lumbar levels are targeted, care must be taken to count up from the sacrum, or down from the lowest thoracic level, ensuring the identification of individuals with transitional anatomy (eg sacralized L5) which may theoretically increase the likelihood of lumbar facetogenic pain. ${ }^{120}$

Another consideration is the lack of studies assessing ultrasound-guided RFA of the lumbar medial branches. A proofof-concept cadaveric study was performed by Gofeld et al examining the use of a magnetic positioning system and ultrasound guidance for lumbar medial branch RF neurotomy. ${ }^{121}$ When using this visualization system with internally cooled electrodes, the ultrasound-guided procedural accuracy rate reached 97\%, with one failed placement at the L5 dorsal ramus. Of note, 
four of six L5 dorsal ramus injections required an out-of-plane caudad-to-cephalad approach because of acoustic interference produced by the iliac crest. It is important to recognize that internally cooled electrodes were used for this study, which do not require the steep caudad-cephalad angulation necessary to position the electrodes parallel to the neural target (cooled electrodes are placed perpendicular to the target).

\section{Recommendations}

We recommend that CT or preferably fluoroscopy (lower costs, faster time and less radiation exposure than CT) be used for lumbar MBB, although ultrasound may be useful in patients in whom radiation exposure may be associated with potential harm (eg, pregnant), or in patients without obesity when radiographic or radiological imaging is unavailable; grade $\mathrm{B}$ recommendation, moderate level of certainty. For IA injections, we recommend the use of CT scanning to enhance accuracy, although fluoroscopy using contrast injection to confirm IA placement can also be considered in certain cases (eg, a thin person without minimal joint narrowing) given the lower costs and radiation exposure; grade C recommendation, low level of certainty. For lumbar medial branch RFA, we recommend that fluoroscopy be used, as the inaccuracies with placement and additional radiation exposure from CT compared with fluoroscopy preclude any theoretical benefit; grade $\mathrm{B}$ recommendation, low level of evidence.

\section{QUESTION 5: ARE FACET BLOCKS 'DIAGNOSTIC', 'PROGNOSTIC' OR BOTH?}

\section{Premise of diagnostic facet interventions}

The terms diagnostic, prognostic and predictive are commonly used interchangeably in the chronic LBP literature, although they are not the same. Diagnosis refers to the 'process of identifying a disease, condition or injury from its signs and symptoms'. ${ }^{122}$ Prognosis most commonly refers to the forecasting of the likely course of a disease (which may include the effects of treatment), while predictive provides specific information about the likely effect of a therapeutic intervention. Whereas these terms may overlap in some scenarios, they refer to different concepts.

Diagnostic injections can be used to isolate the anatomical structures that are the source of pain. They are a critical but potentially flawed element in the practice of pain and spine medicine. The lack of a clear and accepted historical or physical examination finding, diagnostic test and/or spine imaging finding indicative of pain of facetogenic origin (ie, a reference standard) results in reliance on these indirect methods of diagnosis. Although the administration of LA into the joint itself or on the nerves supplying the facet joint with diagnostic intent has face validity, it is based on the assumption that there are no other factors (ie, activity, natural course, psychological stress) that will alter the pain, and relies on the patient's report of pain relief, which is subject to bias and cannot be independently verified. ${ }^{123}$ Therefore, the possibility of false-positive or falsenegative reporting is an inherent risk with facet blocks that can only be identified through placebo injections (for false-positive) and careful control of confounding factors.

\section{Limitations of diagnostic injections}

The limitation of facet interventions in providing diagnostic information is confounded by the placebo response, which is robust for procedures. ${ }^{124} 125$ The placebo response experienced by the patient receiving either IA facet joint injections or MBB should never be interpreted to mean the patient is not experiencing pain of pathophysiological origin. However, the placebo response is, without question, a factor in some percentage of patients reporting pain relief after diagnostic blocks. How clinicians approach patients prior to or after the procedure undoubtedly affects how prevalent and robust the placebo response is. Furthermore, one cannot discount the effect that LAs may have either on surrounding tissue or possibly systemically, if given in sufficient volume. As stated previously, placebo injections may help sort out some of the placebo response, although there are ethical issues to consider. It is important to note that even placebo injections may not entirely address the placebo response, as sham interventions (eg, the injection of saline into a joint after superficial anesthetic) may actually exert a therapeutic effect in some people. ${ }^{36}$

The accuracy of a diagnostic block is contingent on several technical and anatomical factors. First, it assumes the procedure is performed in manner that results in anesthesia of the intended, but not unintended, structure(s) ${ }^{14}$ MBBs are unlikely to achieve this level of specificity due to the close proximity of the intermediate and lateral branches of the dorsal rami, resulting in non-selective neural blockade. ${ }^{14} 99$ Second, a successful diagnostic block assumes that the anesthetized nerve supplies a single anatomical target and that the ensuing pain relief results from anesthetization of only that structure. In the case of an MBB of the dorsal primary ramus, this is not the case since it also innervates the multifidus muscle, interspinal muscle and ligament and periosteum of the neural arch. ${ }^{126}$ An appropriately performed IA facet joint injection, in which the LA remains within the joint capsule, would theoretically meet this specificity assumption. Third, for an injection to have diagnostic or construct validity assumes that the diagnostic target (the facet joint) receives single-source innervation. Kaplan et al ${ }^{127}$ found that one in nine patients (11\%) who underwent image-guided MBB did not experience relief from experimentally induced facet pain from capsular distention. The authors stated that this could indicate a false-negative rate as high as 31\%, and the result supports other studies finding aberrant facet joint innervation. ${ }^{128}$ A similar argument has been made for the lack of diagnostic validity of lateral branch blocks in the context of diagnosis of SI joint pain. ${ }^{129}$ MBBs do not meet these expectations; therefore, an MBB may more accurately be referred to as a test block. ${ }^{130} \mathrm{An}$ IA facet joint injection, in which the LA is contained within the joint, does meet the assumptions; therefore, it could be classified as a diagnostic intervention. However, practically, there is a high rate of failed IA injections ranging between $29 \%$ and $38 \%$ per joint, and $46 \%$ and $64 \%$ per patient. ${ }^{18100}$

\section{Limitations of prognostic injections}

Prognostic injections can be used in risk stratification and treatment planning. Prognosis is closely aligned in medicine to predictability. A patient may appropriately ask his/her clinician, "What are the chances that I will get 50\% pain relief from this intervention?" Similarly, a patient may ask, "What is my prognosis or expectation if I get 70\% relief from the diagnostic block and then undergo radiofrequency denervation?" These are not easily answered questions. Evidence-based medicine may provide outcome estimates from interventions, but this is not the same as providing a prognosis or prediction.

IA joint and medial branch injections have been used to assess the probable response of medial branch and dorsal primary ramus RFA. The rationale is that if MBB relieves pain, then a treatment capable of physically interrupting conduction along the same nerve(s) should provide comparable relief, but last longer depending on the expected duration of disrupted signaling (ie, 
until nerve regeneration or reinnervation occurs). The use of these interventions as a surrogate measure for outcome prediction carries the same limitations as their use as a diagnostic tool. The accuracy of a prognostic test also depends on how success or failure is defined. For instance, success of RFA might be expressed simply as pain relief at the point in time at which the LA is no longer active and the patient has recovered from procedural pain (days or weeks), or it could be defined as alleviation of pain at some predesignated distant time point (months) following the procedure. Depending on the time period chosen, the prognostic power of the initial intervention will be different.

The accuracy of prognostic interventions depends on the accuracy of diagnosis, including identification of the anatomic structure responsible for the pain and the correlation between the prognostic injection and treatment effect, which in turn is contingent on the efficacy of the procedure. The use of MBB as a prognostic tool for medial branch denervation outcome has very high face validity; however, the risks of false-positive and falsenegative results negatively impact the quality of prediction. ${ }^{123}$ The use of the lumbar facet joint injection as a prognostic injection for medial branch ablation carries the same limitations as the use of an SI joint injection to predict response from lateral branch ablation, ${ }^{129}$ although unlike for SI joint pain, extraarticular (eg, ligamentous) facet joint pathology is uncommon.

\section{Evidence for diagnostic and prognostic utility}

The prevalence of facet joint pain has an exceptionally wide range of $5 \%-90 \%$ when using history, physical examination and radiological examination for diagnosis. ${ }^{131}$ In light of the lack of objective measures of facet-mediated pain, MBB and IA facet joint injections with LA remain the most widely accepted approach to diagnosis, and a surrogate measure for prognosis. In a randomized trial assessing the effect of superficial LA and saline infiltration on double lumbar $\mathrm{MBB}$ and IA injections, a diagnosis of facet pain ( $\geq 75 \%$ pain relief 30 min postinjection) was conferred in $12 \%$ and $13 \%$ of patients with paraspinal tenderness, respectively. ${ }^{132}$ Of note, the positive block rate increased significantly on the second diagnostic injection in individuals who received saline infiltration from the skin down to the facet joints or medial branches, but not those who received LA tissue infiltration. In those who received superficial tissue infiltration with LA but no facet or MBB, the percentage of positive blocks was higher after the first injection than the second $(73 \%$ vs $12 \%)$. These findings support other findings that suggest that LA treatment of myofascial pain significantly contributes to falsepositive blocks. ${ }^{133}$

In a multicenter case-control study by Cohen et al ${ }^{134}$ which treated 511 patients with axial LBP who underwent RFA following either MBB, IA blocks or IA injections followed by $\mathrm{MBB}$, the authors found a higher success rate with $\mathrm{MBB}$ than IA with injections (70.3\% vs $60.8 \%)$. MBB remained a significant predictor for positive treatment response even when controlling for confounding factors. In the subsequent randomized, three-arm FACTS study by Cohen et al, ${ }^{18}$ the authors found a false-positive rate of $30 \%$ when defined as significant pain relief following a lumbar $\mathrm{MBB}$ with saline. The proportions of positive responders to RFA in the IA and medial block diagnostic groups were $51 \%$ and $56 \%$, respectively. Those treated who did not experience prolonged pain relief from saline medial branch injection had a positive response rate of $24 \%$. This indicates that IA injections and MBB were significantly more prognostic than saline when long-term placebo responders were excluded.
Two studies have sought to evaluate the correlation between pain relief during a diagnostic $\mathrm{MBB}$, and pain relief after RFA. In a prospective study by Cohen et $a l^{6}$ performed in 61 patients who underwent lumbar RFA after MBB, the authors reported no difference in denervation success rates between $10 \%$ incremental cut-off intervals ranging from $50 \%$ to $100 \%$ relief after prognostic blocks, although patients who underwent ablation after experiencing $<50 \%$ pain relief fared worse. In a retrospective analysis by Holz and Sehgal ${ }^{135}$ conducted in 112 patients who experienced positive comparative LA MBB before lumbar and cervical RFA, the authors found no significant correlation between pain reduction after MBB and RFA.

Few studies have calculated the predictive value of lumbar MBB before RFA. In a retrospective review by Derby et $a l^{9}$ in 229 patients who underwent single or double lumbar MBB with bupivacaine, the authors reported a sensitivity of $55 \%$, a specificity of $77 \%$, a positive predictive value of $78 \%$ and a negative predictive value of $53 \%$.

\section{Recommendations}

IA facet joint injections meet criteria for diagnostic interventions for facet-mediated pain but are less predictive than MBB for response to medial branch RFA and are characterized by a high technical failure rate. As diagnostic tools, MBBs suffer from limitations related to aberrant lumbar facet joint innervation. Compared with saline controls, both IA and medial branch injections with LA provide better predictive information for medial branch RFA; grade B recommendation, low level of certainty.

\section{QUESTION 6: ARE MEDIAL BRANCH BLOCKS PREFERABLE TO INTRA-ARTICULAR INJECTIONS TO SELECT PATIENTS FOR RADIOFREQUENCY ABLATION?}

It has previously been written that lumbar MBB and IA injections are comparable in identifying painful facet joints, and selecting patients for RFA. ${ }^{60136137}$ However, this assertion is based on two small studies, ${ }^{138} 139$ neither of which preselected patients with screening facet blocks (ie, few likely had facetogenic pain) or performed RFA (ie, there is no predictive value), and only one of which assessed pain relief shortly ( $<1$ hour) after the blocks. ${ }^{138}$

\section{Pathophysiological and anatomical considerations}

The argument supporting MBB over IA injections before RFA might appear to be intuitive. This is supported by an experimental study performed in 18 healthy individuals, 15 of whom experienced pain during facet joint capsular distention and returned for the second and third study phases. ${ }^{127}$ In these individuals, five received saline injections while 10 received LA blocks of the two medial branches innervated by their initially injected joint. In the nine subjects who received LA MBB in whom intravascular uptake was avoided, eight could not feel repeat capsular distention, while all five subjects who received saline MBB perceived pain with capsular infiltration. This suggests that approximately $11 \%$ of individuals who receive technically successful MBB will continue to experience pain from facet joint pathology, which the authors attributed to aberrant, non-medial branch innervation.

Technically, MBBs are easier to perform and less painful than IA injections, which have a documented technical failure rate ranging between $29 \%$ and $38 \%$ per joint, and from $46 \%$ to $64 \%$ per procedure. ${ }^{18100}$ Since excessive procedure-related pain is a potential cause of false-negative blocks, a less painful procedure might be associated with a lower false-negative rate, though this has not been studied. ${ }^{14}$ The technical failure rate for IA injections is highest at L5-S1, which is the most common clinically 
Table 6 Studies and reviews comparing lumbar medial branch blocks and intra-articular injections as prognostic tools before denervation therapy

\begin{tabular}{|c|c|c|c|c|c|}
\hline Study & Design/Study type & Number of patients & Diagnostic interventions & Results & Comments \\
\hline Birkenmaier et al ${ }^{145}$ & Randomized & $\begin{array}{l}41,26 \text { (13 in each group) who } \\
\text { had a positive block and received } \\
\text { cryodenervation }\end{array}$ & $\begin{array}{l}\text { MBB with } 1 \mathrm{~mL} \text { bupivacaine or } \\
\text { pericapsular injections with } 2 \mathrm{~mL} \\
\text { before lumbar facet cryodenervation }\end{array}$ & $\begin{array}{l}M B B>I A \text { at } 6 \text { weeks and } 3 \\
\text { months }\end{array}$ & $\begin{array}{l}\text { Differences favoring MBB non- } \\
\text { significant at } 6 \text { months. }\end{array}$ \\
\hline Cohen et al ${ }^{134}$ & Case-control & $\begin{array}{l}511 \text { who under MBB }(n=212), I A \\
(n=212) \text { or } M B B \text { and IA }(n=87) \\
\text { before RFA }\end{array}$ & $\begin{array}{l}\text { MBB with } 0.5-0.75 \mathrm{~mL} L A \text { or IA with } \\
0.5-1 \mathrm{~mL} L A+\text { steroid }\end{array}$ & $\begin{array}{l}\mathrm{MBB}>\mathrm{IA} \text { or } \mathrm{MBB}+\mathrm{IA} \text { at } \\
3 \text { months }\end{array}$ & $\begin{array}{l}\text { In patients who received double- } \\
\text { blocks, } M B B>\mid A+M B B \geq I A \text {. }\end{array}$ \\
\hline Cohen et al ${ }^{18}$ & $\begin{array}{l}\text { Two-phase, } \\
\text { randomized }\end{array}$ & $\begin{array}{l}228 \text { who underwent prognostic } \\
\text { blocks, } 135 \text { who received RFA }\end{array}$ & $\begin{array}{l}0.5 \mathrm{~mL} M B B \text { with } L A \text { and steroid, } \\
0.5 \mathrm{~mL} \text { IA injection or saline injection }\end{array}$ & $\begin{array}{l}\text { Both } M B B \text { and } I A>\text { saline } \\
\text { through } 6 \text { months, but no } \\
\text { difference between MBB } \\
\text { and IA injections }\end{array}$ & $\begin{array}{l}\text { Those in the MBB and IA groups } \\
\text { with a (+) prognostic block } \\
\text { received RFA, while everyone in } \\
\text { the saline group was treated. }\end{array}$ \\
\hline van Zundert et al ${ }^{142}$ & Narrative review & $\begin{array}{l}7 \text { randomized studies, } 349 \\
\text { patients }\end{array}$ & $\begin{array}{l}\text { Indirect comparison of studies using } \\
\text { IA and MBB blocks as screening tests } \\
\text { before RFA }\end{array}$ & $\begin{array}{l}M B B>I A \text { as screening test } \\
\text { before lumbar facet RFA }\end{array}$ & Did not perform meta-analysis. \\
\hline $\begin{array}{l}\text { Practice Guidelines, } \\
\text { Bogduk, ed }\end{array}$ & Guidelines & Not noted & $\begin{array}{l}\text { Indirect comparison of studies using } \\
\text { IA and MBB blocks as screening tests } \\
\text { before RFA }\end{array}$ & $\begin{array}{l}\text { MBB }>\mid A \text { as screening test } \\
\text { before lumbar facet RFA }\end{array}$ & $\begin{array}{l}\text { Based on lack of validation for IA } \\
\text { injections. }\end{array}$ \\
\hline
\end{tabular}

IA, intra-articular; LA, local anesthetic; MBB, medial branch block; RFA, radiofrequency ablation

affected facet joint (L4-5 is the most frequently radiologically degenerated joint). ${ }^{43117140141}$ In contrast, lumbar MBB rarely $(<2 \%)$ miss the targeted nerve, ${ }^{99}$ although intravascular uptake, which occurs in between $4 \%$ and $19 \%$ of injections, can lead to false-negative results. ${ }^{106142143}$ In the study by Kaplan et al. ${ }^{127}$ evaluating the ability of MBB to anesthetize facet joints, among the six subjects in whom intravascular uptake was appreciated, three were still able to perceive pain during capsular distention despite repositioning the needle to avoid intravascular contrast uptake. This indicates that false-negatives may occur from intravascular uptake even with real-time contrast injection.

\section{Previous guidelines}

In the relative absence of large, prospective studies comparing the prognostic value of IA and MBBs before RFA, experts have relied on indirect comparisons to draw conclusions, which are fraught with limitations. After reviewing the results of randomized trials based on the type of prognostic block, van Zundert et al concluded, 'Based on the evaluation of studies, IA injection of LA no longer can be recommended as a diagnostic test for prediction of response to RF treatment'. ${ }^{142}$ In a review, Cohen et $a l^{14}$ cited aberrant innervation, higher procedure-related pain and technical difficulties in recommending MBB over IA blocks as an RFA screening procedure. According to the Greater Manchester EUR Policy Statement on Facet Injections, released in October 2018 by the UK's National Health Service in Greater Manchester, 'facet injections for low back pain are no longer commissioned', and "all patients who are suitable for RF denervation should be considered for a diagnostic medial branch block'. ${ }^{144}$ In 2012 guidelines from ASIPP, the authors concluded there is evidence to support the diagnostic utility of MBB, but fail to mention IA injections. Finally, in the SIS practice guidelines on lumbar MBBs, the organization concluded that '... MBB should replace IA injections for the diagnosis of lumbar zygapophysial joint pain'. ${ }^{16}$

\section{Evidence from clinical studies}

Three published studies to date compare the predictive values of MBB and joint injections before ablative therapy (table 6). In a case-control study by Cohen et al ${ }^{134}$ involving 511 patients who received RFA after either IA blocks, MBBs or both blocks, the authors reported a higher success rate with $\mathrm{MBB}$ than with IA injections (70.3\% vs $60.8 \%)$, which remained a significant outcome predictor in multivariable analysis. Birkenmaier et $a l^{145}$ performed a randomized trial in 26 individuals (out of 41) with a positive facet block comparing the prognostic value of pericapsular lumbar facet injections with $2 \mathrm{~mL}$ of LA against MBB with $1 \mathrm{~mL}$. Those who received MBB fared better for pain throughout the 6-month follow-up, with the difference between groups reaching statistical significance at 6 weeks and 3 months. A major flaw in this study is that pericapsular injections, unlike technically successful low-volume IA blocks, lack diagnostic specificity and face validity. Finally, in a two-phase study designed to determine the therapeutic efficacy of lumbar MBB and IA injections and their predictive value before RFA, Cohen et $a l^{18}$ found no difference in RF outcomes through 6-month follow-up in the 93 people who proceeded to denervation after positive prognostic blocks. However, there was a significant difference in some outcomes when both groups were compared with the 42 people who received saline control blocks before ablation, which persisted for the duration of the study.

The diagnostic value of IA injections was called into question by a blinded, triple crossover study comparing IA lumbar facet injections with LA (verum), normal saline (placebo) and extra-articular needle placement (sham). ${ }^{146}$ Schütz et $a l^{146}$ found that the differences between response rates, defined as $\geq 2$-point reduction in back pain, between the different groups was clinically and statistically non-significant, with slightly more responders in the verum group than in the placebo group, which in turn was associated with a marginally higher response rate than in the sham group. Overall, the authors concluded that a single IA injection was not a valid means to detect a painful lumbar facet joint.

\section{Recommendations}

Overall, we conclude that MBB should be the prognostic screening test of choice before lumbar facet RFA. IA injections of corticosteroids may, however, be of therapeutic value for certain populations in which there is suspected inflammatory facetogenic pain, and in whom denervation may be relatively contraindicated. In these cases, they may concomitantly serve as prognostic blocks. These individuals may include the young, athletic person in whom denervation of the multifidus and other spinal muscles (eg, intertransversarii, longissimus, iliocostalis) may result in muscle atrophy that can adversely impact their condition (eg, spondylolisthesis) or activities of daily living, ${ }^{147} 148$ and individuals who may be at risk for complications with RF treatment (eg, pacemaker-dependent patients and those with automatic 
implantable cardioverter-defibrillators). ${ }^{149} 150$ Although RFA has been successfully employed in individuals with implantable devices, we are aware of at least two cases of a defibrillator discharging despite following precautions (personal communication from LTC Ron White (ret), Travis Air Force Base). Younger individuals may be more likely to present with acute inflammatory facetogenic pain, which has been shown in one small randomized trial to be responsive to IA steroids, ${ }^{61}$ and to have a lower technical failure rate (ie, less osteoarthritic changes that can impede joint entry); grade $\mathrm{C}$ evidence, moderate level of certainty.

\section{QUESTION 7: WHAT IS THE EFFECT OF SEDATION ON THE ACCURACY OF DIAGNOSTIC OR PROGNOSTIC INTRA- ARTICULAR FACET JOINT BLOCKS AND MEDIAL BRANCH BLOCKS?}

\section{Background for the use of sedation for diagnostic or prognostic injections}

The use of sedation before diagnostic facet blocks is a subject of substantial debate. This controversy is predicated on the question of whether sedating and/or providing analgesic medications will alter the patient's 'true' response to the intervention. We will refer to procedural sedation in the manner it is commonly used as the provision of a sedative and/or an analgesic (eg, benzodiazepine and/or opioid, respectively), not based on the physiological response to the medication. The 'true' response to the injection is one that helps inform the physician in making the diagnosis or determining the likely prognosis from therapeutic interventions. The diagnostic or prognostic value of these blocks is discussed in a different section and will not be revisited here.

Sedation for these procedures has been justified using a patientcentric perspective (by decreasing procedure-related discomfort or anxiety) to reduce the risk of a false-negative response, as well as from a physician perspective (to increase patient satisfaction with the procedure, decrease body movements that can make the procedure difficult to complete, decrease the chance that the patient does not show up for the RFA and expedite workflow). ${ }^{151-153}$ Although these benefits may exist, the use of sedation can also increase the false-positive rate and therefore have a negative effect on the diagnostic or prognostic accuracy of these procedures. ${ }^{117}$ Benzodiazepines produce skeletal muscle relaxation and amnesia, which may result in a false-positive response (ie, alleviate baseline back pain). ${ }^{154}$ Although they are not analgesics, they have been found to reduce pain tolerance, which may in turn reduce the pain relief associated with the procedure (false-negative response). ${ }^{155}$ Fentanyl is an analgesic and could potentially accentuate the pain-relieving effect of the facet injection, resulting in false-positive results. Any sedative or opioid may interfere with postblock activity levels, thereby providing a spurious reflection of benefit.

\section{Direct evidence: sedation for MBBs or IA injections}

No studies were identified.

Indirect evidence: sedation prior to medial branch injections Several studies published by the same group of investigators purported to examine the effects of sedation on the diagnostic validity of blocks; however, no postblock outcome measures were included in any group (table 7). ${ }^{156-159}$ Sedation was achieved with saline in up to half of the individuals, ${ }^{159}$ and the authors concluded that saline, midazolam or fentanyl can all produce false-positive results, with fentanyl $>$ midazolam $>$ saline.
However, these studies suffer from many methodological flaws, including the lack of power estimation, absence of a clinically relevant group of patients receiving the benzodiazepine in combination with the opioid and a biased patient sampling that included a high proportion of opioid users and individuals with prior spine surgery. The authors also excluded any patient who did not respond to 'therapeutic' MBBs, which likely selects for placebo responders. Importantly, the authors did not assess the effect of sedation on postblock pain relief, but instead assessed sedation and pain relief before and after the drugs were administered. The authors did, however, assess the effect of sedation on the ability to perform previously painful maneuvers, and found that midazolam, fentanyl, and saline all resulted in sufficient ability to perform these movements. ${ }^{159}$ The lack of difference is likely due to insufficient sample size.

Indirect evidence: sedation for diagnostic interventional pain and spine injections

One study examined the effect of sedation on SI joint and lumbar sympathetic injections using a randomized crossover study design. ${ }^{160}$ In the primary crossover analysis, procedures done with light sedation using midazolam and/or fentanyl had a higher probability of a positive diagnostic block using $\geq 50 \%$ pain relief as the cut-off (OR 2.2; 95\% CI 1.07 to $4.46 ; \mathrm{p}=0.031$ ) or $\geq 80 \%$ (OR $3.0 ; 95 \%$ CI 1.32 to $6.98 ; \mathrm{p}=0.009$ ). A similar increase in the positive rate of the diagnostic block was noted for the parallel and omnibus (all sedation vs all no sedation) analyses. Sedation decreased procedure-related pain but did not affect satisfaction scores or 1 month outcomes. Although this study did not directly address the question of the influence of sedation on diagnostic or prognostic facet intervention outcomes, it supports the conclusion that the validity of diagnostic injections can be affected by the use of sedation.

A retrospective study by Erdek et al examining predictive factors associated with celiac plexus neurolysis in 50 individuals with cancer pain supports this contention. Among those who did not receive sedation during the prognostic block done with LA, 73\% experienced a positive outcome after neurolysis, which favorably compared with a $39 \%$ success rate in individuals who received intravenous sedation. ${ }^{161}$

\section{Indirect evidence: sedation for pain-relieving procedures}

In a prospective observational study, Dreyfuss et $a l^{162}$ set out to determine the effect of sedation on therapeutic epidural steroid injections performed without LA. The authors found no difference in immediate postprocedure pain scores between those who received sedation with midazolam and/or fentanyl and those who did not. Approximately $25 \%$ of patients experienced $>80 \%$ pain relief immediately following the epidural steroid injection despite the injectate containing no LA, and this did not differ between groups. This high rate was attributable to placebo effects in both groups.

\section{Need for sedation}

Kubulus et $a l^{163}$ used a large database to retrospectively examine the influence of sedation on patient satisfaction for regional anesthetic injections. Unlike Cohen et al, ${ }^{160}$ the authors found that sedation improved satisfaction with the procedure. Although this study has the strength of a very large sample size, it is limited by its retrospective nature and the confounding anxiety produced by the impending surgical procedure. 
Special article

Table 7 Studies evaluating sedation during diagnostic or prognostic IA facet joint blocks and MBBs

\begin{tabular}{|c|c|c|c|c|c|}
\hline Study & Design & Patients & Medications & Results & Comments \\
\hline Manchikanti et al ${ }^{159}$ & $\begin{array}{l}\text { Randomized, double-blind, } \\
\text { three-arm parallel group } \\
\text { Measured pain relief } \\
\text { before the block }\end{array}$ & $\begin{array}{l}60 \text { patients with neck } \\
\text { pain and LBP who were } \\
\text { obtaining long-term relief } \\
\text { with serial MBBs }\end{array}$ & $\begin{array}{l}\text { From } 1-5 \mathrm{~mL} \text { of saline, } \\
\text { midazolam }(1 \mathrm{mg} / \mathrm{mL}) \text { or } \\
\text { fentanyl }(50 \mu \mathrm{g} / \mathrm{mL})\end{array}$ & $\begin{array}{l}10 \% \text { in the saline group, } 20 \% \text { in the } \\
\text { midazolam group and } 25 \% \text { in the } \\
\text { fentanyl group obtained } \geq 50 \% \text { pain } \\
\text { relief. For } \geq 80 \% \text { pain relief, these } \\
\text { proportions were } 10 \%, 15 \% \text { and } 10 \% \text {, } \\
\text { respectively. }\end{array}$ & $\begin{array}{l}\text { Light sedation used. No } \\
\text { combinations of benzodiazepine } \\
\text { and opioid were included; } \\
>40 \% \text { had prior surgery. Did not } \\
\text { measure the effect of sedation } \\
\text { on block results. It is unlikely } \\
\text { patients were blinded. }\end{array}$ \\
\hline Manchikanti et al ${ }^{158}$ & $\begin{array}{l}\text { Randomized, double-blind, } \\
\text { three-arm parallel group } \\
\text { Measured pain relief } \\
\text { before the block }\end{array}$ & $\begin{array}{l}360 \text { patients with neck } \\
\text { pain and LBP who were } \\
\text { obtaining long-term relief } \\
\text { with serial MBBs }\end{array}$ & $\begin{array}{l}\text { From } 1-5 \mathrm{~mL} \text { of saline, } \\
\text { midazolam }(1 \mathrm{mg} / \mathrm{mL}) \text { or } \\
\text { fentanyl }(50 \mu \mathrm{g} / \mathrm{mL})\end{array}$ & $\begin{array}{l}13 \%-15 \% \text { in the saline group, } \\
15 \%-20 \% \text { of the midazolam group and } \\
18 \%-30 \% \text { of the fentanyl group had } \\
\text { a placebo response ( } \geq 80 \% \text { back pain } \\
\text { relief) to diagnostic MBBs. A nocebo } \\
\text { (worse pain) effect was observed in } \\
5 \%-8 \% \text { of the saline group, } 8 \% \text { of the } \\
\text { midazolam group and } 3 \%-8 \% \text { of the }\end{array}$ & $\begin{array}{l}\text { Light sedation used. No } \\
\text { combinations of benzodiazepine } \\
\text { and opioid were included. } \\
\text { Did not measure the effect of } \\
\text { sedation on block results. It is } \\
\text { unlikely patients were blinded. } \\
\text { Re-analysis of patients from two } \\
\text { earlier studies. }\end{array}$ \\
\hline
\end{tabular}

\begin{tabular}{|c|c|c|c|}
\hline Manchikanti et al ${ }^{156}$ & $\begin{array}{l}\text { Randomized, double-blind, } \\
\text { three-arm parallel group } \\
\text { Measured pain relief } \\
\text { before the block }\end{array}$ & $\begin{array}{l}180 \text { patients with LBP } \\
\text { who were obtaining } \\
\text { long-term relief with } \\
\text { serial MBBs }\end{array}$ & $\begin{array}{l}\text { From } 1-5 \mathrm{~mL} \text { of saline, } \\
\text { midazolam }(1 \mathrm{mg} / \mathrm{mL}) \text { or } \\
\text { fentanyl }(50 \mu \mathrm{g} / \mathrm{mL})\end{array}$ \\
\hline Manchikanti et al ${ }^{157}$ & $\begin{array}{l}\text { Randomized, double-blind, } \\
\text { three-arm parallel group } \\
\text { Measured pain relief } \\
\text { before the block }\end{array}$ & $\begin{array}{l}180 \text { patients with neck } \\
\text { pain who were obtaining } \\
\text { long-term relief with } \\
\text { serial MBBs }\end{array}$ & $\begin{array}{l}\text { From } 1-5 \mathrm{~mL} \text { of saline, } \\
\text { midazolam }(1 \mathrm{mg} / \mathrm{mL}) \text { or } \\
\text { fentanyl }(50 \mu \mathrm{g} / \mathrm{mL})\end{array}$ \\
\hline
\end{tabular}

\begin{tabular}{|lll}
\hline Cohen et al ${ }^{160}$ & $\begin{array}{l}\text { Randomized crossover } \\
\text { study }\end{array}$ & $\begin{array}{l}73 \text { patients with } \\
\text { suspected sacroiliac } \\
\text { joint pain or complex } \\
\text { regional pain syndrome } \\
\text { received sacroiliac joint or } \\
\text { sympathetic blocks with } \\
\text { or without sedation }\end{array}$ \\
Dreyfuss et al $\left.\right|^{162} \quad$ Prospective, observational & $\begin{array}{l}\text { Midazolam and fentanyl, } \\
\text { titrated to effect }\end{array}$ \\
& $\begin{array}{l}102 \text { patients with cervical, Midazolam and fentanyl, } \\
\text { thoracic or lumbosacral titrated to effect } \\
\text { radiculopathy receiving } \\
\text { epidural steroid injections }\end{array}$
\end{tabular}

fentanyl group.

$7 \%$ in the saline group, $5 \%$ in the Light sedation used. No midazolam group and $13 \%$ in the fentanyl group obtained $\geq 50 \%$ pain relief. For $\geq 80 \%$ pain relief, these proportions were $2 \%, 5 \%$ and $7 \%$, respectively.

$8 \%$ in the saline group, $13 \%$ in the midazolam group and $27 \%$ in the fentanyl group obtained $\geq 50 \%$ pain relief. For $\geq 80 \%$ pain relief, these proportions were $5 \%, 8 \%$ and $8 \%$, respectively.

combinations of benzodiazepine and opioid were included. Did not measure the effect of sedation on block results. It is unlikely patients were blinded.

Light sedation used. No combinations of benzodiazepine and opioid were included.

Did not measure the effect of sedation on block results. It is unlikely patients were blinded.

In the primary crossover analysis, procedures done with sedation had a higher probability of a positive Light sedation used. A similar increase in the positive rate of the diagnostic block was noted (O) 2.2; for the parallel and omnibus $95 \% \mathrm{Cl} 1.07$ to $4.46 ; \mathrm{p}=0.031$ ) or $\geq 80 \%$ (all sedation vs all no sedation) (OR $3.0 ; 95 \% \mathrm{Cl} 1.32$ to $6.98 ; \mathrm{p}=0.009$ ) analyses. Sedation decreased pain relief as the cut-off. procedure-related pain but did not affect satisfaction scores or 1 month outcomes.

In the sedation group, $49 \%$ reported Light sedation employed based $>50 \%$ immediate relief of axial pain on patient preference. Epidural and $41 \%$ reported $\geq 50 \%$ relief of limb steroid injections are not a pain. In the no-sedation group, the diagnostic procedure. corresponding proportions were $43 \%$ and $37 \%$.

\begin{tabular}{|c|c|c|}
\hline Kubulus et $a l^{163}$ & $\begin{array}{l}\text { Retrospective, } \\
\text { observational }\end{array}$ & $\begin{array}{l}42654 \text { receiving neuraxial Opioids and benzodiazepines } \\
\text { and peripheral nerve } \\
\text { blocks for surgery }\end{array}$ \\
\hline
\end{tabular}

Improved patient satisfaction in sedated Sedation with opioids and patients

benzodiazepines improved patient satisfaction with the procedure. The regional anesthetic blocks were performed in patients with and without preblock pain and were not diagnostic procedures. Patients were not blinded.

$\begin{array}{lll}\text { Cucuzzella et al }{ }^{152} & \text { Survey study } & \begin{array}{l}500 \text { patients who received } \\ \text { an epidural steroid } \\ \text { injection or facet block }\end{array}\end{array}$

$17 \%$ requested sedation before initial injection, with $28 \%$ stating they would request sedation before a second procedure.

Sedated patients reported slightly higher pain ratings. Factors associated with requesting sedation for a second injection included depression, anxiety and greater pain during initial injection.

\begin{tabular}{|c|c|c|c|c|c|}
\hline Kim et $a l^{153}$ & Prospective, observational & $\begin{array}{l}301 \text { patients who } \\
\text { underwent an epidural } \\
\text { steroid injection or facet } \\
\text { block }\end{array}$ & $\begin{array}{l}\text { Oral sedation: diazepam } \\
5-10 \mathrm{mg} \\
\text { intravenous sedation: } \\
\text { diazepam } 5 \mathrm{mg}\end{array}$ & $\begin{array}{l}58 \% \text { of patients requested sedation, } \\
\text { with } 96 \% \text { of these choosing intravenous } \\
\text { administration. }\end{array}$ & $\begin{array}{l}\text { Request for sedation associated } \\
\text { with greater anxiety. Among } \\
\text { those who did not request } \\
\text { sedation, } 93 \% \text { were satisfied } \\
\text { with their decision while } 1.5 \% \\
\text { wished they had received } \\
\text { sedation; } 90 \% \text { of patients who } \\
\text { received sedation stated their } \\
\text { anxiety was controlled. }\end{array}$ \\
\hline
\end{tabular}

IA, intra-articular; LBP, low back pain; MBB, medial branch block.

Two studies performed in the same private practice setting found different results on the need for sedation before epidural steroid injections or facet blocks. ${ }^{152} 153$ In a survey study by Cucuzzella et al, ${ }^{152} 17 \%$ of patients requested intravenous sedation with diazepam before their initial procedure, with $28 \%$ reporting that they would request it before repeating the procedure. A history of anxiety, depression and higher pain during the initial procedure was associated with a patient requesting 
sedation for anticipated follow-up injections. In a prospective follow-up study in which patients were offered oral or intravenous sedation with diazepam, 58\% requested sedation, with $90 \%$ of these individuals being satisfied with the anxiolytic effect. Among those who did not request sedation, 93\% were satisfied with their decision. ${ }^{153}$

\section{Guidelines}

Neither the American Society of Anesthesiologists ${ }^{164}$ nor the SIS $^{165}$ recommend routine sedation for facet blocks, with scenarios that might warrant sedation including the need to lie still for prolonged periods of time (eg, a bilateral procedure in a patient with obesity with altered anatomy, difficulty lying prone secondary to pain) and debilitating anxiety. In contrast, 2009 guidelines by the ASIPP ${ }^{166}$ that predated the randomized crossover study by Cohen et $a l^{160}$ (ie, they considered only the earlier studies by Manchikanti et al) found sedation with midazolam or fentanyl had minimal effect on the evaluation of cervical and lumbar facet joint pain when stringent cut-off values were used.

\section{Recommendations}

Overall, we conclude that sedation should not be routinely administered for diagnostic or prognostic facet injections in the absence of reasonable indications. When sedation is used, patients should be educated on the increased risk of a falsepositive block, and the lowest doses of short-acting sedatives, ideally without opioids, should be given; grade B evidence, lowto-moderate level of certainty.

\section{QUESTION 8: WHAT IS THE IDEAL VOLUME FOR PROGNOSTIC FACET INJECTIONS?}

Factors affecting injectate spread and rationale for considering injectate volume

The spread of fluid after injection into an anatomical space can theoretically be affected by several parameters including fluid viscosity, injection velocity, direction of the bevel tip and fluid volume, which may interact with one another. Studies performed for both MBB and epidural injections have found that injection velocity does not affect the degree of cephalad spread, while those evaluating the effect of bevel direction have been mixed. ${ }^{167-169}$ Regarding composition, the viscosity of different LAs is roughly equivalent, but is less than that of contrast, which may underestimate spread (ie, higher viscosity is associated with less spread). ${ }^{170}$

Not surprisingly, the factor that most affects the degree of injectate spread, and therefore specificity, is volume. For procedures such as selective nerve root blocks and SI joint injections, lower volumes have been shown to enhance specificity. ${ }^{171}$ Assuming appropriate needle position, the volume of the injectate is the most modifiable and predictable factor affecting injectate distribution. As noted in other sections, the validity and reliability of facet interventions is contingent on precision injections. ${ }^{99}$ Injectate spread to structures other than the medial branch nerve or within the facet joint capsule, including the surrounding musculature, ligaments, intermediate/lateral branches, spinal nerve and epidural space, can undermine the specificity and positive predictive value of RFA.

\section{Extrapolation from non-facetogenic clinical studies}

There are no studies evaluating the effect of prognostic block volume on lumbar facet RFA, but several studies support the use of lower block volumes. In a large retrospective study examining predictive factors for pulsed RF of the occipital nerves, lower block volumes were associated with higher pulsed RF success rates. ${ }^{172} \mathrm{~A}$ higher success rate was also found in patients who received a lower prognostic block volume in a study examining prognostic factors for celiac plexus neurolysis in patients with cancer pain. $^{161}$

\section{Medial branch blocks}

In RCTs examining the efficacy of RFA of the lumbar medial branches, the volumes used for prognostic MBBs have varied to include $0.3 \mathrm{~mL},{ }^{83} 0.5 \mathrm{~mL}^{18} 0.75 \mathrm{~mL}^{81}$ and $1.0 \mathrm{~mL},{ }^{82}$ with no detectable differences in outcomes stratified by injectate volume. For clinical trials evaluating therapeutic $\mathrm{MBB}$, the volumes range between $0.5 \mathrm{~mL}^{18}{ }^{173-175}$ and $2 \mathrm{~mL} .^{138} 139$ In a two-part study assessing the effect of the target point on 120 lumbar MBBs performed in 15 volunteers, Dreyfuss et a $l^{99}$ found that a fluoroscopically guided $0.5 \mathrm{~mL}$ injection of contrast dye at the base of the superior articular processes of L2 through L5 resulted in spread to the neural foramen or epidural space in $16 \%$ of cases, and diffused into the posterior back muscles $100 \%$ of the time. When it occurred, the degree of epidural spread was believed to be clinically insignificant based on assessment with postinjection CT scanning. Aberrant spread was reduced when a more caudad location midway between the upper border of the transverse process and the mamillo-accessory ligament was targeted, rather than at the superomedial border of the transverse process. The authors also found that the medial branch was bathed during all nerve blocks and concluded that a smaller volume would be sufficient.

In a small $(n=6)$ cadaveric study that sought to assess optimal MBB volumes, Wahezi et al ${ }^{176}$ found that both 0.25 and $0.5 \mathrm{~mL}$ of contrast bathed the targeted nerves $(n=18)$ in all injections, but that using lower volumes significantly reduced aberrant spread to adjacent structures, specifically more superficial muscles and distal segments of the dorsal rami. They concluded that the lower volume was more specific and should ideally be used for prognostic blocks before medial branch RFA. ${ }^{176}$

In a randomized study performed in 24 patients by Cohen et $a l^{98}$ in the cervical spine, injection of $0.25 \mathrm{~mL}$ was found to bathe the target nerve at approximately the same (93\%) rate as a $0.5 \mathrm{~mL}$ injection, although with a lower rate of aberrant spread. Paradoxically, more people who received blocks with $0.25 \mathrm{~mL}$ obtained $\geq 50 \%$ relief ( $50 \%$ vs $25 \%$ ), although the difference was not statistically significant. The most common pattern of aberrant spread was to an adjacent, non-targeted spinal level, which occurred in $57 \%$ of cases at C3. Whereas this is the only clinical trial evaluating MBB outcome differences between injectate volumes, anatomical differences between the lumbar and cervical spine regions warrant caution with generalization.

\section{Intra-articular facet joint injections}

The facet joint is a true synovial joint with a capsule that has a reported capacity of $1.0-2.0 \mathrm{~mL}$ of fluid. ${ }^{177}$ Yet in RCTs examining the efficacy and prognostic value of lumbar facet IA injections, a wide range of volumes have been used including $0.25-0.50 \mathrm{~mL}^{84} 0.3 \mathrm{~mL},{ }^{178} 0.5 \mathrm{~mL},{ }^{18} 0.7 \mathrm{~mL},{ }^{61} 1.0 \mathrm{~mL},{ }^{179} 180$ $1.5 \mathrm{~mL},{ }^{53} 1381393.0 \mathrm{~mL}^{66}$ and $8.0 \mathrm{~mL}^{41}$ Whereas high volumes may result in rupture of the joint capsule and inadvertent spread to other potential pain generators, thereby undermining specificity, using an insufficient volume may conversely fail to anesthetize the joint, resulting in a false-negative block. Considering the high failure rate of IA blocks and poor long-term efficacy, ${ }^{14} 18100$ it is not surprising that there is little correlation between IA block volume and pain relief. 
In a study involving 70 IA injections performed in 30 patients, most of whom had osteoarthritis, Dory ${ }^{181}$ found that rupture of the facet joint capsule was very common, occurring with between 1.0 and $3.0 \mathrm{~mL}$ of injectate. In another study, capsule rupture and extravasation into the epidural space occurred when volumes exceeding $1.5 \mathrm{~mL}$ were injected into the joint. ${ }^{182}$ When capsular rupture did not occur, only $17 \%$ of the patients had pain relief, leading the authors to conclude that high volume injections overestimate the prevalence of lumbar facet joint pain. When leakage occurs laterally, branches of the dorsal ramus can be anesthetized. If the capsule is ruptured or leakage occurs medially, the injectate often spreads into the epidural space and/or intervertebral foramen, which can lead to false-positive results. ${ }^{181} 182$ Theoretically, capsular disruption can also lead to worsening pain and stiffness.

\section{Recommendations}

Lumbar MBBs should be performed with $\leq 0.5 \mathrm{~mL}$ (total volume) to reduce spread to adjacent structures; grade $\mathrm{C}$ recommendation, low level of certainty. Lumbar IA facet joint injections should be performed with a volume of $<1.5 \mathrm{~mL}$ to prevent capsular rupture and reduce spread to adjacent structures; grade $\mathrm{C}$ recommendation, low level of certainty.

\section{QUESTION 9: ARE INTRA-ARTICULAR FACET OR MEDIAL BRANCH BLOCKS WITH STEROIDS THERAPEUTIC? Rationale for corticosteroids}

The use of IA corticosteroid injections for facet joint pain is controversial and predicated on the belief that an inflammatory component that may respond to local steroids is responsible for a predominance of symptoms. For MBB, the theoretical foundation is weaker, and is based on the observation that the medial branches may be trapped beneath the mamillo-accessory ligament, which is most common at L5 (20\%) but may also occur at higher levels. ${ }^{183} 184$ This entrapment neuropathy has been implicated as a source of LBP. ${ }^{183}$

\section{Randomized controlled trials evaluating intra-articular steroids}

In a large randomized study involving 109 patients, no difference was found between large-volume $(8 \mathrm{~mL})$ IA saline injections, IA corticosteroid and LA, and the same mixture injected around two facet joints. ${ }^{41}$ Two studies published in the New England Journal of Medicine that prescreened patients who responded to previous diagnostic IA lumbar facet injections and cervical MBB also failed to demonstrate benefit for lumbar and cervical IA facet joint injections, respectively. ${ }^{180}{ }^{185}$ In the randomized controlled study performed in 101 patients with lumbar facet joint pain, only small, non-significant differences between the injection of saline and depo-corticosteroid were observed throughout the study, with $22 \%$ in the steroid group and $5 \%$ in the placebo group obtaining meaningful benefit at 6 months. ${ }^{180}$ In the smaller of the two studies performed in 41 individuals with whiplash injury, Barnsley et $\mathrm{al}^{185}$ found no significant differences between cervical IA bupivacaine and depo-steroid, with the median time to return of pain to $50 \%$ of baseline being 3 days in the steroid group and 3.5 days in the control group. Kennedy et $a l^{186}$ performed a small double-blind study comparing the effect of lumbar facet IA steroids versus saline on the need for RFA in 24 patients prescreened with MBB. The authors found no difference in either the need for denervation or the time that elapsed before the denervation between treatment groups. In stage 1 of a two-stage randomized, double-blind trial, Cohen et al found no significant differences for pain relief or functional outcome between lumbar facet IA injections with steroid and bupivacaine, $\mathrm{MBB}$ with steroid and bupivacaine or saline control MBB for up to 6 months postinjection. ${ }^{18}$

Although these studies provide evidence against the use of IA steroids, a small randomized, double-blind study by Ackerman and $\mathrm{Ahmad}^{61}$ suggests that individuals with acute, inflammatory pain may benefit from IA steroids. Among 46 patients with clinical symptoms consistent with acute lumbar facet joint pain (mean age 39.3 years, median duration 7.6 weeks) and positive SPECT scans, $61 \%$ who received IA facet LA and steroid injections obtained $\geq 50 \%$ relief 12 weeks post-treatment vs $26 \%$ of those who received therapeutic MBB. Observational studies also suggest intermediate-term relief in individuals with positive SPECT. ${ }^{53} 66117$ Two older randomized studies compared MBB with IA injections containing LA and steroid in patients who were not prescreened with facet blocks, finding little difference between groups. ${ }^{138} 139$ Marks et $a l^{138}$ found only marginally longer relief with IA steroids in 86 patients with axial LBP, with only 7 patients in the IA group and 6 in the MBB group reporting persistent relief at 3 months. In an earlier study by $\operatorname{Nash}^{139}(\mathrm{n}=67)$, the authors reported that comparable numbers of patients obtained significant relief at 1 month after MBB and IA injections with steroid and LA. In a more recent double-blind randomized study comparing IA and intramuscular steroids in patients with axial LBP who were not prescreened for facetogenic pain $(\mathrm{n}=60)$, Ribeiro $e a^{187}$ found that IA steroids were slightly better than intramuscular steroids on some, but not most, outcomes through 6-month follow-up. These studies demonstrating a lack of evidence for IA facet injections in patients with chronic LBP are consistent with evidence-based guidelines, ${ }^{1621}$ which recommend against the injections. One caveat with placebo-controlled trials that is not commonly appreciated is that the IA injection of saline or LA may itself provide prolonged therapeutic benefit. ${ }^{188}$

\section{Randomized controlled trials evaluating MBB}

Dias da Rocha et al ${ }^{173}$ performed a non-randomized placebocontrolled study in 104 individuals with suspected facet joint pain, injecting saline around the medial branches followed by lidocaine injection in those who failed to benefit after $10 \mathrm{~min}$. The authors found that $16.3 \%(\mathrm{n}=17)$ of individuals responded to placebo, while $31.7 \%(\mathrm{n}=33)$ failed to obtain at least $50 \%$ relief from lidocaine. Among the 54 lidocaine responders, two-thirds maintained pain relief at 3 months. In phase I of a three-arm double-blind study that compared IA LA and steroid lumbar facet injections, MBB with LA and steroid, and saline control blocks, Cohen et al ${ }^{18}$ found no significant differences in any outcome measure at any time point in the 6-month follow-up (1 month success rates of $12 \%, 11 \%$ and $6 \%$, respectively, which declined at subsequent visits). In a systematic review that evaluated two trials by the same group of investigators that included a total of 204 patients treated with serial lumbar MBB with lidocaine, lidocaine and steroid, lidocaine and Sarapin, or lidocaine, steroid and Sarapin, the authors found strong evidence for benefit which lasted over 6 months in most people. ${ }^{189}$ One of these randomized studies evaluating patients who received MBB with LA or LA and steroid for 2 years found that patients received significant relief $(\geq 50 \%$ reduction in pain score) and functional improvement for between 82 and 84 weeks out of 104 weeks, requiring approximately five to six treatments, with each treatment producing an average 19 weeks duration of relief. ${ }^{174}$ Flaws in these studies include the high proportions of 
patients taking opioids and having had previous back surgery, and the lack of control groups and absence of blinding.

\section{Unique issues for steroid injections}

Although one study supports the use of IA facet joint steroid injections in individuals with acute pain, this study was small, did not prescreen patients with diagnostic blocks and used SPECT scans to identify candidates, which is expensive and exposes patients to a substantial amount of radiation. ${ }^{61}$ There is also a high failure rate associated with IA facet injections, which ranges between 29\% and $38 \%$ per joint, and $46 \%$ and $64 \%$ per patient (ie, percentage of patients in whom there was at least one failed injection). ${ }^{18}{ }^{100} \mathrm{In}$ two studies that examined the correlation between IA spread and outcomes, only the uncontrolled study showed a higher success rate with successful arthrography. ${ }^{100}$ In the subset of individuals who do respond to facet injections, there is some evidence that repeat injections are associated with poorer treatment response, ${ }^{40}$ and may be associated with long-term consequences such as immunosuppression, increased diabetes risk and osteoporosis. ${ }^{190-192}$

\section{Recommendations}

We recommend against the routine use of therapeutic facet injections, although we acknowledge that in patients who may be at risk of adverse consequences from RFA (eg, young athletes, older individuals on anticoagulation therapy or with implantable cardiac devices) or in whom there is a strong likelihood of success (eg, individuals who obtained prolonged relief from previous diagnostic injections with or without steroids), it may reasonable to add steroids to a block in the hope of deriving intermediate-term relief; grade $\mathrm{D}$, moderate level of certainty.

\section{QUESTION 10: WHAT SHOULD THE CUT-OFF BE (IE, PER CENT RELIEF) FOR DESIGNATING A BLOCK AS 'POSITIVE', AND IS THERE ANY BENEFIT IN USING NON-PAIN SCORE OUTCOME MEASURES? \\ Guidelines}

Numerous studies have been devoted to determining the optimal cut-off for proceeding to RFA. The SIS guidelines on lumbar facet denervation specify that complete relief in a distinct topographical area is necessary for a particular block to be positive (though some pain may persist from other sources), ${ }^{16}$ while the ASIPP guidelines note that there is stronger evidence for a cut-off of $75 \%$ than $50 \%$. Both guidelines recommend that these cut-offs be used for dual blocks. Initiative on Methods, Measurement, and Pain Assessment in Clinical Trials (IMMPACT) guidelines propose that a $30 \%$ or greater reduction in pain be considered a moderately clinically important improvement and that reductions of $50 \%$ or greater can be considered a substantial improvement. ${ }^{193}$ Although this cut-off was intended to categorize the response to pain treatments, given the implicit (although imperfect) correlation between the block and definitive treatment, in certain circumstances these cut-offs may also provide a benchmark for prognostic information despite not being validated in this context (personal communications from Robert Dworkin, Robert Kerns and Srinivasa Raja). High cut-offs may also be difficult to achieve physiologically given that facet degeneration almost never occurs in isolation. For example, radiological studies indicate that disc degeneration almost always precedes and is greater in magnitude than facet degeneration, and that muscle pathology accompanies facet joint inflammation. ${ }^{194-196}$

\section{Factors that can affect pain relief}

Whereas it may appear to be axiomatic or self-evident that higher cut-off values should translate into higher success rates (ie, individuals in whom facetogenic pain represents a greater contribution to their back pain burden than other sources should do better), it is difficult or impossible to tease out the proportion of pain relief due to the block itself and factors such as inadvertent spread of LA to other pain-generating structures, the effect of superficial anesthesia on myofascial pain, sedation and the placebo response, which is generally higher than the intrinsic effect of therapies for chronic pain. ${ }^{1499} 132197$

\section{Studies comparing different pain relief cut-offs}

Most randomized studies evaluating lumbar facet RFA have used $\geq 50 \%$ pain relief from a prognostic block as an inclusion criterion, ${ }^{77-19698384198}$ and several studies have compared prognostic block cut-off values of $50 \%-70 \%$ or $80 \%$ for lumbar facet and other denervation procedures ${ }^{6-8} 6869135172$ 199-201 (see table 8 for study details). The first study to examine this question was a retrospective study in 262 patients that found no difference in 6-month lumbar facet RFA outcomes between individuals who experienced at least $50 \%$ but $<80 \%$ vs $\geq 80 \%$ relief with MBB. ${ }^{199}$ A similar study that sought to examine the effect of MRI findings on lumbar facet RF outcomes found identical success rates in a high index group that obtained $\geq 80 \%$ relief after two MBBs and those who had either one block done or obtained $\geq 80 \%$ pain on only one of two blocks. ${ }^{68} \mathrm{~A}$ recent study by Holz and Sehgal ${ }^{135}$ found no correlation between the percent pain relief after either the first or second MBB and lumbar and cervical RFA outcomes at 3 months. In the only prospective study $(n=61)$ to examine the effect of lumbar MBB pain relief on RFA outcomes, Cohen et $\mathrm{al}^{6}$ found no difference in $10 \%$ incremental cut-offs between $50 \%$ and $100 \%$ relief, with patients who obtained $<50 \%$ relief with their diagnostic block faring worse. Of note, the predesignated cut-off for a successful RFA outcome was $50 \%$ so that some patients who experienced $<50 \%$ pain relief on their MBB but felt subjective improvement and proceeded to RFA, experienced similar improvement after RFA but were considered treatment failures. Several other studies examining differences in diagnostic block cut-off points and RF outcomes for cervical facet joint pain, SI joint pain and occipital neuralgia also found no benefit for using threshold values above 50\%. ${ }^{69} 172200$

Not all studies have reported comparable relief with lower cut-offs. A retrospective study by Manchikanti $e t a l^{201}$ found that for up to 2 years, individuals who experienced $\geq 50 \%$ pain relief but $<80 \%$ relief with one or two blocks had poorer outcomes than those who experienced at least $80 \%$ relief ( $89.5 \%$ vs $51 \%)$. At 1 -year follow-up, the reported success rates in the $\geq 50 \%$ and $\geq 80 \%$ relief groups were $75 \%$ and $93 \%$, respectively, indicating that three-fourth of the people who would have been denied treatment because of implementation of the higher cut-off threshold actually benefitted. The main shortcoming of this study is that not all patients underwent RFA (number not provided). In another retrospective study, Derby et $a l^{8}$ found a higher proportion of patients who obtained $\geq 80 \%$ relief with single and double diagnostic blocks experienced over 50\% relief after RFA compared with those who obtained between $50 \%$ and $80 \%$, although a direct statistical analysis was not performed. In the group with $\geq 80 \%$ relief, $84 \%$ experienced a positive RFA outcome, defined as $\geq 50 \%$ pain relief, vs $56 \%$ who obtained $\geq 50 \%$ but $<80 \%$ relief on their diagnostic blocks.

\section{Non-pain relief measures of benefit}

Whereas pain relief (eg, mean reduction in average pain) is by far the most common primary outcome measure in interventional and analgesic pain trials, two studies evaluating epidural 


\begin{tabular}{|c|c|c|c|c|}
\hline Study & Design & Number of patients & Results & Comments \\
\hline Cohen et al ${ }^{6}$ & Prospective & 61 & $\begin{array}{l}54 \% \text { success rate, with no difference in categorical } \\
\text { outcomes or correlation in } 10 \text { percentage point increments. } \\
\text { Only one in six people who underwent RFA after obtaining } \\
<50 \% \text { relief on MBB had positive outcome. }\end{array}$ & $\begin{array}{l}\text { Cut-offs at } 10 \% \text { increments from } 50 \% \text { to } 100 \% \text { relief. Poorer } \\
\text { outcomes in six individuals who had }<50 \% \text { relief with single } \\
\text { block; } \geq 50 \% \text { pain relief } 6 \text { months after RFA designated as } \\
\text { positive response. }\end{array}$ \\
\hline Cohen et al ${ }^{199}$ & Retrospective & 262 & $\begin{array}{l}52 \% \text { success rate in } \geq 50 \% \text { cut-off group vs } 56 \% \text { in } \geq 80 \% \\
\text { group. }\end{array}$ & Multicenter study evaluating single blocks. \\
\hline Holz and Sehgal, ${ }^{135}$ & Retrospective & 50 & $\begin{array}{l}53.1 \% \text { relief in individuals with } \geq 70 \% \text { relief on both } \mathrm{MBB} \\
\text { vs } 44.4 \% \text { relief in those with } \geq 70 \% \text { relief on only one of } \\
\text { twio MBB. }\end{array}$ & $\begin{array}{l}\text { Included both lumbar and cervical facet RFA. Sixty patients } \\
\text { lost to follow-up. Greatest pain relief in patients with }>8 \text { hours } \\
\text { of pain relief after lidocaine blocks. }\end{array}$ \\
\hline Cohen et $a^{69}$ & Retrospective & 92 & $\begin{array}{l}56 \% \text { success rate in } \geq 50 \% \text { cut-off group vs } 58 \% \text { in } \geq 80 \% \\
\text { group. }\end{array}$ & $\begin{array}{l}\text { Evaluated cervical facet RFA. Multicenter study evaluating } \\
\text { single blocks. }\end{array}$ \\
\hline Stojanovic et al ${ }^{68}$ & Retrospective & 77 & $\begin{array}{l}47 \% \text { success rates in both high index group who obtained } \\
\geq 80 \% \text { pain relief on two blocks and those who received one } \\
\text { block, or had } \geq 80 \% \text { relief on only one of two blocks. }\end{array}$ & Seventeen people in 'high index' group. \\
\hline Cohen et $\mathrm{al}^{134}$ & $\begin{array}{l}\text { Retrospective, case- } \\
\text { control }\end{array}$ & 511 & $\begin{array}{l}74 \% \text { pain relief from diagnostic facet blocks in individuals } \\
\text { with a positive RF outcome vs } 72 \% \text { in those with a negative } \\
\text { outcome. }\end{array}$ & $\begin{array}{l}\text { Multicenter study designed to determine whether IA or MBB } \\
\text { are superior as prognostic tests. }\end{array}$ \\
\hline Derby et $a l^{8}$ & Retrospective & 51 & $\begin{array}{l}\text { Success in } 22 \% \text { ( } 2 / 9) \text { of patients with } \geq 50 \% \text { but }<70 \% \text { relief } \\
\text { vs } 79 \%(33 / 42) \text { in those with } \geq 70 \% \text { relief. }\end{array}$ & $\begin{array}{l}\geq 50 \% \text { relief designated as success. Patients had both single } \\
\text { and double blocks. }\end{array}$ \\
\hline Manchikanti et al ${ }^{201}$ & Retrospective & $\begin{array}{l}110 \text { to } 152 \text { in control } \\
\text { comparison group }\end{array}$ & $\begin{array}{l}\text { At } 1 \text {-year follow-up, } 93 \% \text { in } 80 \% \text { cut-off group had a } \\
\text { positive outcome vs } 73 \% \text { in the } 50 \% \text { cut-off group. At } \\
2 \text { years, success rates were } 89.5 \% \text { and } 51 \% \text {, respectively. }\end{array}$ & $\begin{array}{l}\text { Compared double block outcomes with their own historical } \\
\text { controls. Patients treated with both 'therapeutic' MBB and RFA } \\
\text { (breakdown not provided). Since MBB have not been shown to } \\
\text { provide long-term benefit, validity is questionable. }\end{array}$ \\
\hline McCormick et al ${ }^{205}$ & Prospective & $\begin{array}{l}55,28 \text { who had } 2 \text { blocks and } \\
27 \text { who had a single block }\end{array}$ & $\begin{array}{l}\text { In the single block group, } 43 \% \text { and } 46 \% \text { had } \geq 50 \% \\
\text { improvement in pain and function vs } 59 \% \text { and } 63 \% \text { in those } \\
\text { who had two blocks. }\end{array}$ & $\begin{array}{l}\text { Those who had } 50 \%-74 \% \text { relief on the initial block underwent } \\
\text { a confirmatory block, while those who obtained } \geq 75 \% \text { relief } \\
\text { proceeded to RFA. }\end{array}$ \\
\hline Derby et $a l^{206}$ & Retrospective & 182 & $\begin{array}{l}\text { Single block group: } \geq 50 \\
<80 \% \text { relief } 50 \% \text { RFA success rate; } \geq 80 \% \text { relief: } 72 \% \text { RFA } \\
\text { success rate. } \\
\text { Double block group: } \geq 50<80 \% \text { relief: } 85 \% \text { RFA success } \\
\text { rate; } \geq 80 \% \text { relief: } 100 \% \text { success rate }(13 / 13) \text {. }\end{array}$ & $\begin{array}{l}\text { Unclear why some patients underwent single vs double blocks. } \\
\text { Excluded some patients with suspected multiple sources of } \\
\text { pain. }\end{array}$ \\
\hline
\end{tabular}

IA, intra-articular; MBB, medial branch block; n, number; RFA, radiofrequency ablation.

steroid injections published in the New England Journal of Medicine used LBP functional capacity as the primary outcome measure. $^{202203}$ In individuals with chronic pain, improving function may be a more realistic benchmark than pain relief, and both the Roland-Morris Disability Questionnaire and ODI are meant to provide a cross-sectional measure of function. However, in practice the parameters assessed in these instruments (sitting and standing tolerance, walking distance, ability to travel, dressing, lifting, sex, sleep, etc) preclude their use over the brief 2-4-hour therapeutic window after facet blocks. The same holds true for medication reduction, as long-acting medications cannot be tapered over a period of 3 hours, and withholding opioids may elicit hyperalgesia. In the prospective study by Cohen et $a l^{6}$ evaluating the effect percent pain relief on prognostic blocks has on RFA outcomes, when the six patients with $<50 \%$ pain relief on their diagnostic block underwent RFA based on their subjectively reported functional improvement and satisfaction, only one experienced a positive 6-month categorical outcome, which was defined as $\geq 50 \%$ relief.

Since patient recall is subject to error and expectation bias, the most objective means to measure benefit is by the use of 'real-time' pain diaries. But pain relief must be assessed in the context of analgesic consumption and function, so that the use of pain diaries to assess response after prognostic injections should evaluate function as well as analgesic requirements. In accordance with the US Food and Drug Administration (FDA) guidelines on identifying responders, ${ }^{204}$ a clinically significant need for increased analgesic consumption for the index condition (ie, LBP) after a block would preclude that block from being designated 'positive'. For the same reasons, a modest reduction in pain that is attributed to a decrease in activity levels should be considered evidence against proceeding to RFA. Because the limitations in using non-pain-related measures as the benchmark for designating a prognostic block as positive are related to the relatively short duration of action of LAs, should sustainedrelease or ultra-long-acting formulations of LA become standard of care, the use of objective measures of function (eg, use of a pedometer, medication reduction, functional capacity) to assess block success will become an area ripe for investigation.

\section{Predictive modeling}

As noted elsewhere, clinical prediction tools might someday be used to achieve personalized medicine. In this scenario, the amount of pain relief from a block might be used as part of an algorithm to select patients for RFA. For instance, in a young athlete with subacute back pain and an equivocal presentation, $50 \%$ pain relief on an initial block might warrant a confirmatory block, while the same person who obtains $75 \%$ relief might benefit from proceeding to RFA. This model is supported by preliminary evidence. A clinical study by McCormick et al ${ }^{205}$ used the amount of pain relief on an initial block to decide whether a second block was warranted (ie, those with 50\%-74\% relief), finding no difference in outcomes between those who had single versus double blocks. In a retrospective analysis by Derby et al, ${ }^{206}$ the authors reported a 50\% RFA success rate in 100 patients who underwent a single block that afforded between $50 \%$ and $79 \%$ relief versus a $72 \%$ success rate in those who obtained $\geq 80 \%$ relief from a single block. However, among 33 patients who obtained between $50 \%$ and $79 \%$ pain relief following two MBBs, the success rate was $85 \%$.

\section{Recommendation}

In summary, this committee recommends that a $\geq 50 \%$ reduction in pain be considered a positive block, although we recognize 
that studies should be performed to determine whether lower cut-offs may prove to be optimal. Although there are studies showing that patients with $\geq 80 \%$ relief are more likely to have a positive response to RFA than those with less relief, a significant proportion of patients who achieve a threshold of $50 \%$ but $<70 \%$ or $80 \%$ relief will benefit from RFA. In the absence of any reliable treatment options for patients who obtain $\geq 50 \%$ but $<80 \%$ relief, the committee opts to maximize access to care in a clinical context. Secondary outcomes such as medication usage, activities during the duration of the block, and satisfaction may be considered when deciding whether or not to proceed with RFA (ie, a 50\% reduction in pain that is attributed to decreased activity, residual sedation or an increase in analgesic consumption should not be considered a positive block). It is also possible that future clinical prediction modeling will result in different cut-off values for different clinical scenarios; grade B recommendation, moderate level of certainty.

\section{QUESTION 11: HOW MANY PROGNOSTIC BLOCKS SHOULD ONE PERFORM BEFORE RADIOFREQUENCY ABLATION?}

\section{Basis for multiple blocks and false-positive rate}

The number of blocks that should be performed before lumbar medial branch RFA is a subject of great controversy. In the only guidelines espoused by pain organizations, SIS and the ASIPP both advocate two blocks before RFA, with the latter concluding that the evidence for diagnostic accuracy is poor ( $<75 \%$ relief) to limited ( $\geq 75 \%$ relief) when single blocks are used. ${ }^{116}$ The rationale for performing either placebo-controlled blocks, or 'blinded' comparative LA blocks, in which two LAs with different durations of action are used for blocks on two separate occasions, and longer relief from the longer-acting agent is necessary for diagnosis, is that it reduces the placebo effect. However, the placebo effect is only one of several causes of falsepositive blocks, which include leakage of the injectate into adjacent pain-generating structures such as muscles and the epidural space; excessive use of superficial anesthesia; the use of sedation and not participating in one's normal activities after the injection. 1499132

The false-positive rate for IA injections and MBB is estimated at between $17 \%$ and $41 \%$, and may be higher for individuals with previous surgery and psychopathology. 50117133207208 However, most of these studies have calculated the false-positive rate based on comparative LA blocks, which suffer from low sensitivity $(<60 \%) .{ }^{209}$ In the absence of any reference standard for diagnosis, estimates of sensitivity and specificity are always speculative, with few studies having examined the false-positive rate based on placebo-controlled blocks (table 9). In these studies, which examined both MBB and IA injections, the false-positive rate varies from $16 \%$ to upward of 30\%. ${ }^{1845146210}$

There are certain contexts in which a screening test with high specificity and positive predictive value is warranted. These include when the definitive treatment is associated with high risks and/or costs (eg, multilevel spine fusion). Such tests can also be warranted in conditions that have relatively low prevalence. This is due to the fact that the diagnostic confidence of a test is predicated on the sensitivity and specificity, and on disease prevalence (ie, pretest probability). Specifically, since isolated facetmediated pain may have a lower prevalence in certain patient populations than the reported false-positive rate of a single $\mathrm{MBB}$ (eg, very young, sedentary people), some have advocated for a more rigorous diagnostic criterion such as dual MBB.

Conversely, others argue that the relative risks of RFA are less than those of alternative treatments (eg, surgery, opioids) in people who have already failed conventional therapies. In this setting, a prognostic block associated with high sensitivity and negative predictive value is desired. Otherwise, individuals with a false-negative injection may be denied treatment, referred for surgery or started on expensive and less effective treatments such as chronic opioid therapy.

\section{False-negative blocks}

There are several reasons for false-negative blocks, including failure to envelop the target nerve (infrequent since $0.5 \mathrm{~mL}$ of LA spreads to an area $>6 \mathrm{~cm}^{2}$ ), intravenous uptake (incidence range 4\%-19\%, with digital subtraction being the reference standard for detection), inability to access the joint for IA injections (incidence 29\%-38\%), aberrant, non-medial branch innervation (approximately 11\%), excessive procedure-related pain including muscle pain and spasm, failure to adequately assess pain relief, comorbid spinal conditions and opioid-hyperalgesia from abrupt cessation of opioids, among others. ${ }^{14} 100106127143211$

Table 9 Randomized studies evaluating a placebo response rate using saline control injections

\begin{tabular}{|c|c|c|c|c|c|}
\hline Study & $\begin{array}{l}\text { Number of } \\
\text { patients }\end{array}$ & Study design & Type of blocks (placebo arm) & $\begin{array}{l}\text { Placebo response or false- } \\
\text { positive rate* }\end{array}$ & Comments \\
\hline Revel et $a l^{45}$ & $\begin{array}{l}80-38 \text { who } \\
\text { received placebo }\end{array}$ & Randomized, parallel group & $\mathrm{IA}$ with $1 \mathrm{~mL}$ saline & $18 \%$ placebo response & Response defined as $\geq 75 \%$ relief. \\
\hline Cohen et al ${ }^{18}$ & $\begin{array}{l}229-47 \text { who } \\
\text { received placebo }\end{array}$ & $\begin{array}{l}\text { Randomized, three-arm } \\
\text { parallel group }\end{array}$ & MBB with $0.5 \mathrm{~mL}$ saline & $30 \%$ placebo response & Response defined as $\geq 50 \%$ relief. \\
\hline Lord et $\left.a\right|^{209}$ & $\begin{array}{l}50 \text { patients with } \\
\text { whiplash }\end{array}$ & $\begin{array}{l}\text { Randomized, three-period } \\
\text { crossover }\end{array}$ & $\begin{array}{l}\text { Cervical MBB with } 0.5 \mathrm{~mL} \text { bupivacaine, } \\
\text { lidocaine and saline }\end{array}$ & $\begin{array}{l}40 \% \text { placebo response, false- } \\
\text { positive rate (concordant relief } \\
\text { with LA blocks but positive } \\
\text { response to placebo) } 19 \%\end{array}$ & $\begin{array}{l}\text { Response defined as longer pain relief } \\
\text { (complete or profound) with bupivacaine than } \\
\text { lidocaine, and a negative response to saline. } \\
\text { False-negative rate (positive but discordant } \\
\text { response to LA injections but negative } \\
\text { response to placebo) } 32 \% \text {. Sensitivity } 54 \% \text {, } \\
\text { specificity } 88 \% \text {. }\end{array}$ \\
\hline $\begin{array}{l}\text { Dias da Rocha et } \\
\text { al }\end{array}$ & 104 & $\begin{array}{l}\text { Patient-blinded, one-way } \\
\text { crossover }\end{array}$ & $\begin{array}{l}\text { Lumbar MBB with } 0.5 \mathrm{~mL} \text { saline, and if } \\
\text { negative, lidocaine }\end{array}$ & $16 \%$ placebo response & $\begin{array}{l}\text { Response defined as } \geq 50 \% \text { relief. All patients } \\
\text { received saline and if negative, lidocaine MBB } \\
\text { after } 10 \mathrm{~min} \text {. }\end{array}$ \\
\hline Schütz et al ${ }^{146}$ & 60 & $\begin{array}{l}\text { Single-blind, three-way } \\
\text { crossover }\end{array}$ & $\begin{array}{l}\text { Bilateral lumbar IA injections with } \\
1.5 \mathrm{~mL} \text { of mepivacaine (verum), saline } \\
\text { (placebo) or extra-articular needle } \\
\text { placement without injection (sham) }\end{array}$ & $\begin{array}{l}\text { Sham and placebo groups had } \\
20 \% \text { and } 38 \% \text { response rates, } \\
\text { respectively, at } 1 \text { hour }\end{array}$ & $\begin{array}{l}\text { Response defined as }>2 \text {-point decrease in } \\
\text { back pain. Non-inferiority shown between } \\
\text { placebo and verum injection. }\end{array}$ \\
\hline
\end{tabular}


Several studies have sought to determine the incidence of falsenegative blocks, via repeat blocks and RFA response to negative MBB responders. In a retrospective chart review by Derby et al ${ }^{9}$ using $\geq 70 \%$ pain relief as the criterion for a positive response, the estimated false-negative rate was $46.7 \%$ in individuals who obtained $<50 \%$ relief following an initial block, $47.1 \%$ in those with $50 \%-69 \%$ relief and $<10 \%$ in those with $\geq 70 \%$ relief. In those who underwent RFA, $100 \%$ (four of four) of those who had $<50 \%$ relief on their first block, and $50 \%$ (two of four) who had between $50 \%$ and $69 \%$ relief had a positive outcome. When attempting to identify a subset of patients prone to false-negative blocks, the authors found that individuals with 'delayed' (ie, discordant) relief based on the expected duration of action of the LA were most likely to respond to RFA among those with negative blocks (three of four, 75\%). The investigators reported sensitivity, specificity, positive predictive and negative predictive rates of $55 \%, 77 \%, 78 \%$ and $53 \%$, respectively. These results, along with the low reported sensitivity and negative predictive values, indicate that comparative LA blocks will result in a substantial proportion of patients who would otherwise be denied a beneficial treatment. The results are consistent with another retrospective analysis by Holz and Sehgal ${ }^{135}$ that found no significant difference in pain relief or function following lumbar or cervical RFA between patients who obtained longer pain relief $(\geq 70 \%)$ with bupivacaine than lidocaine, and those with discordant responses to comparative LA MBB $(53.1 \%$ vs $44.4 \%)$.

\section{Indirect comparison of studies using different numbers of blocks}

The two randomized, controlled studies evaluating facet joint RFA (including one in the cervical spine) that used multiple blocks, both yielded positive findings, ${ }^{82} 212$ while those that employed single blocks have yielded mixed results. ${ }^{17} 198183-85213$ However, there were numerous other differences between these studies and other publications. In the study $(n=24)$ by Lord et $a l^{212}$ evaluating cervical medial branch RFA, the authors performed three screening blocks with lidocaine, bupivacaine and saline, requiring concordant relief with lidocaine and bupivacaine and no benefit with placebo. They defined a positive block as complete alleviation of pain, and created four to six lesions per level. In the study by Nath et al $(\mathrm{n}=40),{ }^{82}$ the authors required $\geq 80 \%$ pain relief from comparative LA blocks, and created six empirical lesions per level. This study group screened 376 patients to enroll 40 participants. A clinical audit by Dreyfuss et $\mathrm{al}^{23}$ reported that $87 \%$ of patients experienced at least $60 \%$ pain relief 12 months following lumbar medial branch RFA. However, in addition to selecting patients with comparative LA blocks, investigators required at least $80 \%$ pain relief; screened all patients with imaging, electromyography to establish intact multifidi, and Beck Depression Inventory scores; used 16-gauge electrodes for denervation and confirmed the technical success of the procedure via confirmation of multifidus denervation. In contrast, the negative study by Leclaire $e t a l^{85}$ required 'significant relief' for at least 24 hours after IA lidocaine injections, which is a LA with an elimination half-life of $<2$ hours. This study also employed an ablation technique that resulted in small lesions that likely missed target nerves, and screened only 76 patients to obtain 70 study participants. Thus, excluding individuals with non-facetogenic sources of pain and maximizing the chance for a technically successful procedure appear to be critical components for a 'successful' study. Overall, studies that reported clear-cut or equivocally positive results ${ }^{18} 818284$ used more stringent selection criteria than those studies that reported unequivocally negative results ( $14 \%$ vs $34 \%$ enrollment rate among screened study candidates). ${ }^{17} 1985$

\section{Studies comparing different numbers of blocks}

There has been only one randomized trial in the peer-reviewed literature comparing outcomes stratified by different prognostic block paradigms. Cohen et $a l^{7}$ randomized 151 patients to receive either lumbar medial branch RFA based on clinical findings without prognostic blocks, RFA after a single positive MBB with bupivacaine (defined as $\geq 50 \%$ pain relief lasting at least 3 hours) and RFA only after positive comparative LA blocks with both lidocaine and bupivacaine performed in random order. In the group that received RFA without a block, 17 of 51 patients (33\%) experienced a positive categorical outcome, which was designated as $\geq 50 \%$ reduction in average back pain at 3 months coupled with a positive global perceived effect. In the single block group, $16 \%$ of the 50 randomized patients achieved a positive categorical outcome ( 7 from RFA, 1 from prolonged effect from LA), while in the double-block group, $11(22 \%)$ attained a positive outcome ( 9 from RFA). However, when only individuals who underwent RFA were considered, the success rates in the zero, one and double-block groups were 33\%, 39\% and $64 \%$, respectively. When the authors calculated costs, the zero-block group had the lowest cost-per-effective procedure rate, and the lowest overall cumulative cost. The explanation behind these findings was that the zero-block group included all placebo responders and excluded no false-negative blocks, while the double-block group excluded most placebo responders and also some false-negatives (ie, true positives). This indicates that at the reported Medicare reimbursement rates, performing prognostic lumbar MBB will decrease the overall number of responders, and increase costs, with multiple blocks resulting in even lower numbers of responders and higher costs. Yet for scenarios where maximizing the positive predictive value MBB is desired, including studies designed to assess RFA efficacy and unproven facet arthrodesis procedures, multiple blocks could be indicated since they effectively screen out false-positives.

In a retrospective study, Stojanovic et $a l^{68}$ designed to determine the association between imaging findings and RFA outcomes, the authors also examined the effects the number of blocks and the pain relief experienced had on treatment results. Among the 17 patients who obtained $\geq 80 \%$ pain relief from dual $\mathrm{MBB}$, the $47 \%$ success rate was identical to those who had either one block, or obtained $<80 \%$ pain relief from at least one of two blocks. In a larger $(n=511)$ case-control study designed to determine the relative predictive value of $\mathrm{MBB}$ and IA blocks before lumbar medial branch RFA, Cohen et al ${ }^{134}$ reported no significant differences in success rates based on numbers of blocks (63\% in individuals who received one prognostic block vs $70 \%$ in those who received two or more). There was no difference in outcomes based on whether the blocks were both MBB, both IA blocks or combination blocks (IA followed by MBB), with only undergoing MBB being associated with a positive outcome. Derby et $a l^{8}$ performed a retrospective study in 51 patients, 13 of whom underwent double MBBs, both with bupivacaine. The authors defined a positive block as $\geq 50 \%$ pain relief lasting at least $45 \mathrm{~min}$ postprocedure. Two-thirds of the patients were on opioids. The authors reported that $63.2 \%$ of single-block patients experienced a positive 3 -month RFA outcome vs $84.6 \%$ in those who received double blocks.

For other conditions treated with RFA, the use of screening blocks is also of questionable utility. For example, van Eerd 
et $a l^{214}$ reported a $55 \%$ success rate when evaluating a new approach for cervical medial branch RFA without the use of a screening block. In a randomized study evaluating the utility of a single prognostic block before RFA for knee osteoarthritis in 54 individuals, McCormick et $a l^{215}$ reported 6-month success rates of $64 \%$ in the no-block group and $59 \%$ in the single-block group. Yet, the lower relative prevalence rate of facetogenic pain in individuals with LBP compared with those with neck pain, and arthritis in those with knee pain, suggests there is a higher likelihood for false-positive diagnostic blocks in the lumbar spine compared with the cervical spine or knee.

\section{Weighing false-positives versus false-negatives}

There is evidence in the form of observational studies that the success rate for medial branch RFA will increase with the number of blocks, but this will inevitably occur at the expense of patients who are deprived of treatment. The proportion of the higher success rate that is attributable to a higher placebo response rate with multiple blocks is unclear; the only way to obviate this dilemma would be to perform placebo-controlled blocks, which are difficult to justify for a relatively safe procedure. Two observational studies illustrate the high success rates that can be achieved with stringent selection. As noted above, the prospective cohort study by Dreyfuss et $a l^{23}$ reported that $87 \%$ of 15 patients who experienced at least $80 \%$ relief with dual-comparative LA MBB obtained at least $60 \%$ pain relief maintained at 1 year after RFA, with $60 \%$ obtaining at least $90 \%$ relief. However, along with double blocks, the authors screened 460 patients for the study, with 138 presenting for full physical examinations, suggesting a low prevalence of isolated facetogenic pain, a high false-negative rate or a combination of the two. In a more recent study using similar selection criteria and RF parameters, MacVicar et $a l^{216}$ reported that 56\% of 106 patients obtained complete pain relief and functional restoration lasting a median of 15 months. Whereas the authors were not able to determine the exact number of patients screened, they estimated it to be around 575. In a meta-analysis performed by Lee et $a l^{217}$ evaluating five randomized controlled studies and 423 patients with 6-month follow-up data who underwent either lumbar medial branch RFA or a control procedure (sham or epidural steroid injection), the authors found a statistically and clinically significant 1.5 -point difference in back pain scores favoring denervation. Notably, all studies in this review used either 1 or $0(n=1)$ block, and one included patients with 'equivocal' relief. In a prospective, observational study, McCormick et $a l^{205}$ performed double blocks in individuals who experienced between $50 \%$ and $75 \%$ relief $(n=28)$, but proceeded to RFA following single blocks if the pain relief obtained was $\geq 75 \%$ $(n=27)$, and found no significant differences in outcomes.

\section{Clinical prediction tools}

It is possible that in the future, predictive modeling programs based on large-scale registries or complex trial designs may find that different people require different RFA selection paradigms (personalized medicine). Proceeding straight to RFA without blocks is preferred in situations where costs and number of procedures are the primary concerns. Potential examples include an elderly person who is on anticoagulation therapy and presents with paraspinal tenderness, marked facet arthropathy on MRI and no psychopathology or those in whom blocks could pose significant risks or hardships (eg, a person with extreme needle phobia who might require sedation that could undermine the accuracy of a block, or a service member deployed at a forward operating base). Double MBBs provide an advantage and are preferred when maximizing the success rate of medial branch RFA is the primary concern. Examples include a person with minimal imaging pathology, an equivocal physical examination or multiple risk factors for treatment failure; a young athlete in whom denervating spinal muscles could affect performance and someone with spondylolisthesis or other risk factors for spinal instability in whom denervation could theoretically worsen their clinical condition.

\section{Recommendation}

The committee recommends a single block. We found moderate evidence that dual blocks result in a higher subsequent success rate for medial branch RF, but that the use of a zero-block paradigm results in the highest overall number of patients with a positive response to the RFA. This has led some, including this committee, to a clinical compromise of accepting the results of a single MBB for identifying denervation candidates, with some data suggesting that higher RF treatment response rates occur in those reporting a higher degree of relief with a single block. In an era of personalized medicine, the committee believes that known variables should be used to tailor care to the needs of the individual patient and to the goals of the practice environment; grade $\mathrm{C}$ recommendation, low-to-moderate level of certainty.

\section{QUESTION 12: IS THERE EVIDENCE FOR LARGER LESIONS TO IMPROVE OUTCOME MEASURES FOR RADIOFREQUENCY ABLATION? IF SO, HOW CAN LESION SIZE BE INCREASED?} Rationale for lesion size for lumbar facet denervation

In order to effectively perform RFA of the medial branches and dorsal rami innervating the lumbar facet joints, it critically important that physicians understand the electrophysiological principles, technical and anatomic aspects of RFA. ${ }^{14} 218-220$ Procedural challenges exist for lumbar RFA based on the need to balance limiting the size of thermal lesions to avoid lesioning non-targeted tissues and enhancing lesion size to increase the likelihood of capturing the targeted small-diameter nerve fibers. The diameter of lumbar medial branches is $<2 \mathrm{~mm}$ and the L5 dorsal ramus transverse diameter has been measured at $0.5 \mathrm{~mm} .{ }^{221} 222$

The main rationale for expanding lesion size is to increase the maximal tolerable margin of error for coagulating the targeted medial branch or dorsal rami, which can vary in location and in the number of branches that innervate the facet joint. ${ }^{223}$ The margin of error is the maximum distance that an RF cannula can be placed from a targeted structure and still create a lesion that envelops the structure. ${ }^{224}$ With limited-sized lesions and small diameter nerves, the tolerable margin of error is small.

It is important to emphasize that whereas patient selection is the most effective way to improve RFA success rate, because withholding treatment from individuals who are at high risk for failure but could greatly benefit from ablation may severely curtail access (ie, high-risk, high reward category such as those on opioids or who are unable to work because of back pain), decreasing the technical failure rate by increasing lesion size should be a relatively non-controversial endeavor that most people can agree on.

\section{The physics of radiofrequency ablation}

Traditional thermal RFA involves the use of high-frequency alternating current $(300000-500000 \mathrm{~Hz})$, which results in ionic agitation and friction generating focal heating in tissue (ie, the tissue surrounding the electrode becomes the primary source 
Table 10 Factors affecting radiofrequency lesion generation

\begin{tabular}{|c|c|}
\hline Radiofrequency element & Electrophysiological principle \\
\hline Distance from active tip & $\begin{array}{l}\text { Heat generation }=1 /(\text { radius from active tip })^{220} \\
\text { Tissue heating decreases rapidly with increasing } \\
\text { distance from the active tip. }\end{array}$ \\
\hline RFA current intensity* & $\begin{array}{l}\text { Heat generation=(current density) })^{14} \\
\text { Heat generated from RFA is directly proportional to } \\
\text { current density. } \\
\text { Current intensity has a strong influence on tissue } \\
\text { heating. }\end{array}$ \\
\hline Duration of RF application & The duration of heating influences lesion size. \\
\hline
\end{tabular}

* Tip size as determined by the gauge of the needle and the length of the active tip influences RF current intensity.

$\mathrm{RF}$, radiofrequency; RFA, radiofrequency ablation

of the heat). Irreversible cellular damage can occur from focal temperatures above $42^{\circ} \mathrm{C}$, although for most mammalian tissues damage occurs between $46^{\circ} \mathrm{C}$ and $49^{\circ} \mathrm{C} .{ }^{225} 226$ Such temperatures applied to a nerve result in local destruction and Wallerian degeneration of nerve axons. ${ }^{226}$ Although both impedance-controlled and temperature-controlled systems exist, for interventional pain medicine temperature-controlled RFA systems are typically employed. The 'bio-heat' equation governing RF-induced heat transfer through tissue was initially described over 70 years ago by Pennes, ${ }^{227}$ and has since been simplified as follows ${ }^{228}$ :

Coagulation necrosis $=($ heat generated $\times$ local tissue interactions)-heat lost

The ability to ablate specific tissues while limiting destruction to non-targeted tissues depends on local physiological tissue characteristics and factors that influence energy delivery. In a simplified thermal RFA system, three primary factors determine heat generation and lesion size (table 10): distance from the cannula's active tip, RF current density and duration of current application. ${ }^{229-231}$ Specifically, peak power and total energy delivered directly correlate with lesion size. ${ }^{232}$ Duration of RF application affects lesion size and influences lesion variability. ${ }^{233}$ Although a substantial amount of lesion growth occurs within the first $60 \mathrm{~s}$ after the set temperature $\left(\mathrm{eg}, 80^{\circ} \mathrm{C}\right)$ is achieved ( $~ 87 \%$ of the maximal surface area), lesion growth continues after this threshold is surpassed. Consequently, as the lesioning time increases lesion size variability decreases. ${ }^{233}$

\section{Methods to enhance lesion size}

Multiple methods have been studied to increase lesion size in both in vivo and ex vivo models. It is important to recognize that studies performed in ex vivo models do not necessarily simulate in vivo conditions (ie, may have different tissue properties). When examining ex vivo and in vivo models used to assess lesion size, it is imperative to understand the medium in which the testing was performed. For example, substantial differences exist between fluid egg white and solid animal tissue. ${ }^{234}$ Although egg white heats faster than muscle, lesions performed in egg white typically underestimate lesion size and are not consistently reproducible. ${ }^{230234}$ Ex vivo models of RFA lesion size can also underestimate in vivo lesion size secondary to the lower baseline tissue temperature. ${ }^{232} 235236$ The lower baseline temperature requires higher energy deposition to attain the same ablation zone. The presence of bone also alters lesion geometry, with the maximal effective radius approximately doubling against bone compared with a muscle-only model. ${ }^{237}$

In clinical practice, common techniques that have been shown to enhance tissue ablation include increasing the set temperature, increasing the diameter of the electrode cannula, increasing size of the active tip and increasing lesion time. The major limitation of high temperatures is disruption of conductivity at the electrode-tissue interface. When tissue boils, desiccates or chars, it becomes a high impedance insulator, which may result in an RFA generator fault and/or a smaller lesion size. The temperature at which this takes place, known as the 'electrode interface disruption temperature', typically occurs near $100^{\circ} \mathrm{C}$. $^{218}$ Therefore, with traditional systems, increasing set temperature beyond $90^{\circ} \mathrm{C}$ is not recommended.

Perhaps the most efficient and reliable means to amplify lesion size is to increase RF cannula diameter. For example, when the cannula diameter is increased from 22-gauge to 16-gauge at RFA settings of $80^{\circ} \mathrm{C}$ and $2 \mathrm{~min}$, the average lesion width increases $58 \%-65 \%$, which correlates to a lesion that is $3-4 \mathrm{~mm}$ larger. Similarly, increasing lesion time from 1 to $3 \mathrm{~min}$, without changing cannula size or temperature, results in a lesion that is $23 \%-32 \%$ larger. $^{230}$

Additional methods that can be used to increase lesion size include fluid pre-injection, modification of the electrode tip and the use of internally cooled electrodes ('cooled RFA'). ${ }^{218} 232233238239$ For internally cooled electrodes, an internal perfusate serves as a heat sink that removes heat closest to the electrode. Therefore, heating of the tissue nearest to the electrode is reduced and greater current deposition occurs, resulting in larger lesions. ${ }^{240}$ Significant tissue ablation occurs distal to the tip of the cannula with internally cooled electrodes, whereas standard electrodes produce minimal lesioning beyond the cannula tip. ${ }^{241}$

\section{Fluid modulation}

Both ex vivo and in vivo data with traditional thermal RFA have demonstrated amplification of lesion size with the injection of increasing concentrations of saline. 232233238239 Based on the Bioheat equation, injecting specific fluids modulates local tissue interactions. The pre-injection of hypertonic saline (ie, saline with concentration $>0.9 \%$ ) increases conductivity (thereby decreasing resistance), resulting in higher peak power and total energy output. In vivo data demonstrate that when $1 \mathrm{~mL}$ of $8 \%$ saline is injected after $1 \mathrm{~mL}$ of $1 \%$ lidocaine prior to RF lesioning, the lesion width increases by $>3 \mathrm{~mm}$, and the calculated volume increases by $>50 \%$, in comparison to no additional fluid. ${ }^{232}$ The pre-injection of hypertonic saline also alters the histological composition, increasing to the largest degree the size of the outermost ablation zone, which is associated with coagulative necrosis and edema. ${ }^{232} 242243$ When injecting hyperosmolar solutions such as hypertonic saline, caution must be exercised to minimize inadvertent spread to non-targeted neural tissue because of theoretical concerns for neurotoxicity ${ }^{244}$. The geometry of the RFA lesion associated with $\mathrm{NaCl}$ pre-injection is altered as well, with the maximum width of the lesion shifted more toward the distal end of the active tip. ${ }^{232}$

In ex vivo models, saline solutions, and other solutions have been shown to enhance lesion size with traditional thermal RFA, with more conductive solutions (ie, less impedance) having a greater effect. ${ }^{239} 245$ For example, the pre-injection of $1 \%$ lidocaine in $0.7 \% \mathrm{NaCl}$, which is often used to increase procedure tolerability, has been shown to increase the area of ablation in ex vivo models. ${ }^{238} 239$ However, this relationship was not reproduced in an elegant in vivo experiment examining the effect of pre-injection fluid on lesion size using traditional thermal RFA. ${ }^{232}$ Conversely, the pre-injection of corticosteroids prior to lesioning has been shown to reduce lesion size. ${ }^{246}$ 
When using internally cooled electrodes, fluid modulation using LA and $\mathrm{NaCl}$ concentrations of $0.9 \%$ and $7.3 \%$ have not been shown to increase lesion size. ${ }^{240} 247$

There are theoretical reasons to increase lesion size for lumbar RFA, including optimizing the chance of incorporating the targeted structure into the area of tissue ablation, and possibly increasing the duration of pain relief; yet, no clinical data exist to verify these assumptions. Whereas anecdotal evidence suggests robust treatment effects when lesion-amplifying techniques are used, comparative-effectiveness studies are needed to confirm these observations.

\section{Larger lesions and duration of benefit}

The effect of larger lesions on duration of pain relief in individuals with a successful outcome is unclear. It is not entirely understood how RFA exerts its benefit, but it may occur via damaging nerves such that they cannot transmit nociceptive information, or transecting the nerves; in one review, it is postulated that RFA results in third-degree peripheral nerve injury to the myelin, axon and endoneurium without disrupting the fascicular arrangement. ${ }^{248}$ If analgesia resulted from complete nerve bisection, nerve regrowth would not be expected to occur faster with a larger transected area, provided the nerve was completely severed in both scenarios and Wallerian degeneration occurred. If larger lesions resulted in a greater likelihood of completely transecting a nerve rather than axonotmesis, then that could theoretically result in a longer duration of benefit. In one placebo-controlled study that examined the duration of pain relief with internally cooled RFA, which results in a larger lesion diameter than traditional RFA, the authors reported a mean duration of relief of 7.9 months after lateral branch RFA for SI joint pain. ${ }^{241}$ The lack of longer pain relief in this study compared with that achieved with conventional RFA may be due to the nerves targeted (the SI joint is more extensively innervated, and requires more ablations, than lumbar facet joint pain), the blinding of participants and close surveillance, or myriad other factors, and warrants further examination of this issue.

\section{Risk mitigation}

When creating larger lesions, care must be taken to avoid collateral damage to surrounding tissues. One of the most feared complications is damage to surrounding non-targeted spinal nerves. ${ }^{249}$ Methods to prevent this complication include precise anatomic placement of the RFA cannula with fluoroscopic imaging checked in multiple views, physiological testing with sensorimotor stimulation and a detailed understanding of lesion dimensions. In addition, the risk of toxicity to non-targeted tissues, including central and peripheral nervous system structures, should be considered before injecting specific fluids (ie, high saline concentrations).

\section{Recommendations}

Based on the current limitations of traditional thermal RFA and the small size of the targeted structures (ie, lumbar medial branches and dorsal rami), creating larger lesions with reduced lesion variability may increase the likelihood of capturing the targeted structure. If larger lesions are used, care should be taken to limit damage to non-targeted structures; grade $\mathrm{C}$ recommendation with low level of certainty for using larger lesions to improve the ability to capture the targeted nerves; grade I with low level of certainty for the ability of larger lesions to increase the duration of pain relief.
QUESTION 13: SHOULD ELECTRODES BE POSITIONED IN A CERTAIN ORIENTATION, AND IF SO, WHAT IS THAT ORIENTATION?

\section{Background}

Relief of lumbar facetogenic pain by thermal RFA of the medial branch rests on the premise that pain transmission can be interrupted if the nerve is coagulated by heat. ${ }^{250}$ One might infer that if a longer a section of the nerve is destroyed, longer pain relief may ensue because it takes more time for the injured nerve to regain the ability of pain transmission. In humans, nerve regrowth occurs at a variable rate, from 1 to $2 \mathrm{~mm}$ per day in small nerves, and up to $5 \mathrm{~mm}$ per day in larger nerves, with factors such as electrical stimulation, less scar tissue, hormonal factors, favorable genetics, shorter distance of the origination of the nerve to the lesion site, and exercise enhancing regenerative ability. ${ }^{251-253}$ However, when a nerve is completely severed (which may or may not happen with RFA), Wallerian degeneration distal to the lesion occurs, such that the width of transection plays a relatively minor role in regrowth. Currently, there are two prevailing methods to achieve medial branch ablation, which differ based on the orientation of the placement of electrodes. According to the one technique, curved electrodes are inserted tangentially along the course of the nerve, allowing longitudinal contact between the cannula and nerve; if the curved tip is rotated, a further increase in lesion size is realized. ${ }^{254}$ This technique has been described as 'parallel', although geometrically this term refers to two lines extending in the same direction, everywhere equidistant and never meeting. In one variation of the parallel technique, a large, straight cannula is inserted at a steep caudo-cephalad angle, approximately $20^{\circ}$ in a lateral to medial direction, allowing the electrode to embrace the anterolateral aspect of the base of the superior articular process. In the perpendicular technique, cannulas are inserted using an oblique fluoroscopic view perpendicular to the course of the nerve, such that the length of the active tip is less important. ${ }^{254}$ Is one method better than the other? The following discussion is restricted to conventional thermal RF medial branch ablation, as the use of internally cooled electrodes, which generate a circular lesion that extends distal to the electrode tip (approximately $40 \%$ of the lesion occurs distal to the tip) rather than a spherical lesion that envelops the electrode, are typically inserted in a perpendicular fashion to optimize lesion characteristics and minimize tissue trauma.

\section{Anatomy}

The lumbar facet joints are paired, true synovial joints. ${ }^{255}$ Each joint is innervated by the medial branches of the primary dorsal rami from that level and the level above (figure 1). The L1-L4 medial branches of the dorsal rami run across the superior portion of the subjacent transverse process, under the mamillo-accessory ligament at the junction of the superior articular process and the root of the transverse process, and then course onto the lamina. On the lamina the nerve divides, giving off branches to the joint below, the joint at that level, the interspinous ligament and muscle and the multifidus muscle. For the purposes of medial branch neurotomy, the nerve can be considered to hug the superior articular process by the mamillo-accessory ligament. In some people, the nerve may be trapped beneath a calcified ligament, which occurs most commonly at the fifth lumbar vertebra, but can occur at more cephalad levels. ${ }^{184}$ At L5, it is the dorsal ramus itself that is amenable to ablation, which runs in the groove between the superior articular process of S1 and the sacral ala (figure $1 \mathrm{~A}-\mathrm{C}) .{ }^{255}$ 

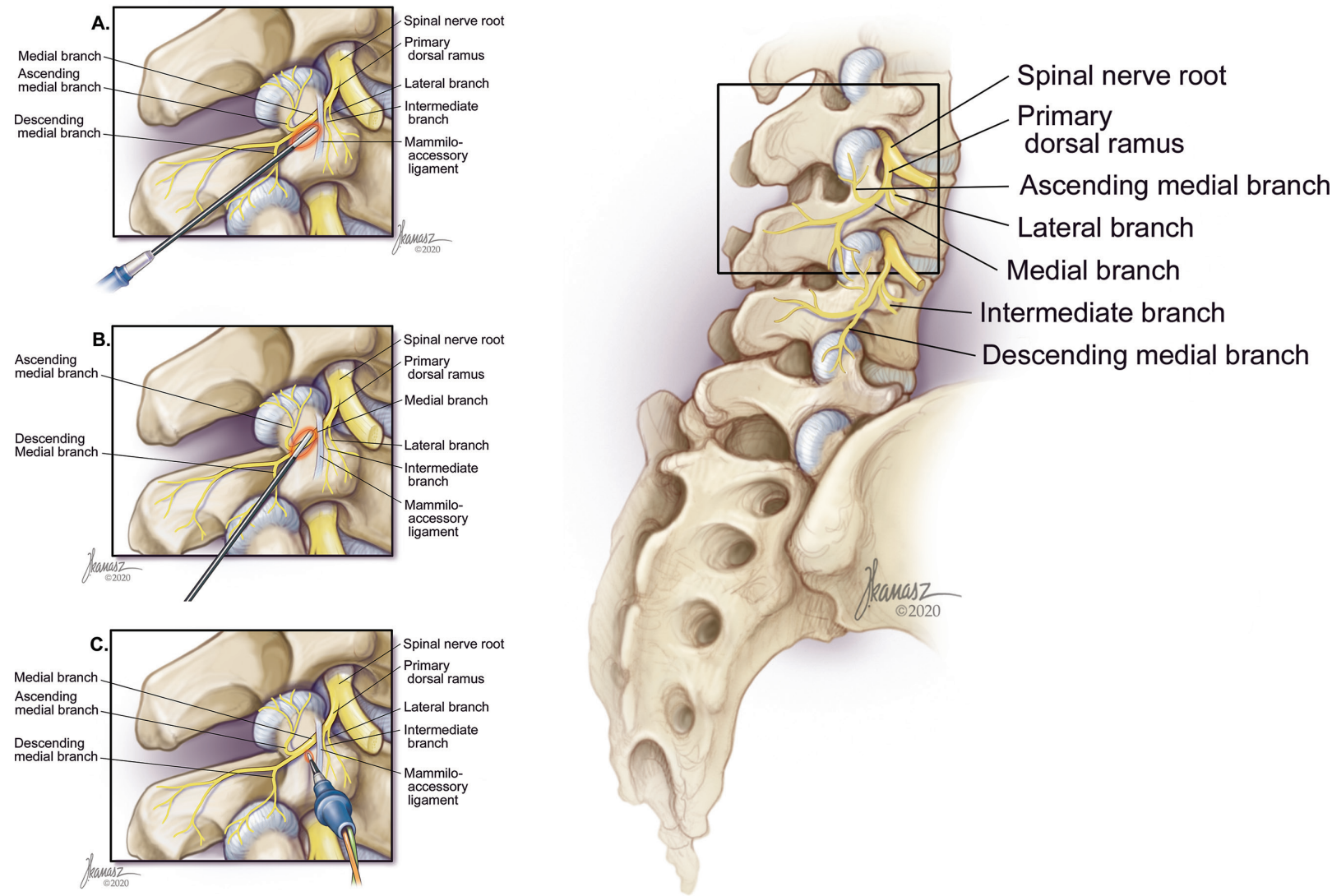

Figure 1 Representational drawing depicting the lumbosacral facet joints and accompanying neural anatomy. Insets illustrate closeup views of the bony and neural anatomical landmarks and a schematic representation of the effect electrode orientation has on nerve ablation. Artistic renditions by Joe Kanasz (joekanasz@att.net). (A) Parallel insertion of electrodes. Parallel placement may result in a higher likelihood of missing the nerve than with near-parallel orientation. (B) Near-parallel insertion of electrodes. This may result in the highest likelihood of medial branch nerve ablation. (C) Perpendicular insertion of electrodes. This theoretically results in the highest chance of missing the nerve, which may be more likely when the medial branch is entrapped beneath the mammilo-accessory ligament.

\section{History and preclinical studies}

The concept of denervation of facet joints has undergone much evolution since it originated from the neurosurgeon Rees's technique that described severing the articular nerves supplying the zygapophysial joints through surgical incisions. ${ }^{256}$ A less traumatic approach, using RF electrodes, was subsequently described by another neurosurgeon, Norman Shealy. ${ }^{257} \mathrm{He}$ recommended placing the electrodes lateral to the articular processes with the tip of the electrode reaching the intertransverse ligament. Subsequently, a cadaveric study by Bogduk and Long ${ }^{258}$ found that it was the medial branches of lumbar dorsal rami and not articular branches that should be targeted, which led to major changes in electrode positions.

In the early days of RFA, it was common practice to place electrodes perpendicular to the target nerve(s). However, further investigations were prompted by varying degrees of success and short-lived pain relief. ${ }^{257}$ Experimental lesions were created in egg white and meat using 18-gauge electrodes heated to temperatures of $80^{\circ}$ and $90^{\circ} \mathrm{C}$. In egg white, lesions extend slightly proximal to the active tip, but never distal. Lesion expansion occurs in the radial direction, circumferentially around the electrode in an oblate spheroid shape. In meat, the tissue surrounding the active tip is denatured longitudinally in an elliptical shape, with the lesions extending for a short distance distal to the electrode tip. Such observations were confirmed by other independent investigators. 230238259260 This led researchers to conclude that electrodes inserted parallel to the course of the nerve were more likely to envelop the target, and that inserting the electrodes in a perpendicular trajectory can lead to non-capture and clinical failure (partial relief or limited duration of benefit).

Eckmann et $a l^{237}$ reported that lesions created ex vivo in muscle, and especially egg white, do not represent physiological conditions during in vivo medial branch ablation, whereby the electrode is placed adjacent to bone and surrounding soft tissue. The authors conducted an experiment by placing the electrodes either apposed to bone with muscle on the other side or fully embedded in muscle. In the bone-muscle model, they found that the lesions remained elliptical with the long axis aligned with that of the electrode. Yet the lesions expanded to a greater extent perpendicularly from the needle axis when compared with those created in pure muscle. The authors did not draw conclusions about how their findings could be used to optimize lesion size in vivo, although they suggested that placing an electrode perpendicular to the nerve would result in a larger horizontal lesion on bone than would be expected in a pure muscle model.

In a cadaveric study, Lau et $a l^{261}$ placed electrodes either parallel or perpendicular onto the L4 medial branch and L5 dorsal ramus nerves in situ under direct vision. Radiographs of anteroposterior, lateral and declined views were taken. Ellipses were drawn based on the average size of lesions generated and expressed as electrode-widths. Investigators observed that the nerves might not be captured by lesions produced by electrodes 
oriented perpendicular to the targets, because the nerves were situated at the tapering end of the elliptical lesions. To improve the likelihood that the nerves are incorporated into RF lesions, they recommended that electrodes be placed parallel to the nerves, against the neck of the superior articular process.

\section{Theoretical issues}

Transecting a nerve anywhere results in Wallerian degeneration distal to the lesion location. ${ }^{262}$ Similar to cutting down a tree trunk or branch with a chainsaw, orienting the instrument used to cut the nerve perpendicular to the target in the same plane should theoretically maximize the chance of a complete transection (which may or may not be necessary for analgesia). However, the distance between the area of needle insertion (ie, skin) and the bony target (ie, the junction between the superior articular and transverse processes), and the posteriorly concave curvature of the transverse processes, preclude this. Theoretically, if an electrode could be inserted in the same plane as a target nerve, and a lesion extended circumferentially around the electrode tip, then positioning the electrode parallel to the nerve would actually minimize the likelihood of nerve ablation. In order to maximize lesion area on bone, where the medial branches reside, the electrode should ideally be inserted in a medial-cephalad direction, obliquely parallel to the nerve course. This could also result in a higher likelihood of nerve ablation in cases where the medial branch is trapped beneath a calcified mamillo-accessory ligament. ${ }^{184}$

The use of curved electrodes has recently gained popularity for lumbar medial branch RFA, whereby the depth from skin to the transverse process precludes positioning the electrode juxtaposed on bone, unlike with a posterior approach in the cervical spine. In order to maximize the lesion area on bone where the medial branches reside, practitioners typically position the convex surface of the curved active tip anteriorly on the transverse process. ${ }^{18}$ To further enhance the lesion area, many doctors will then advance the cannula and rotate it $180^{\circ}$, such that the concave surface hugs the inferior part of the posterior foraminal wall. Although this makes intuitive sense, there are no studies to support or refute this practice.

\section{Comparison of parallel versus perpendicular electrode orientation on RFA outcome in clinical practice}

Only one study to date has addressed the effect of electrode placement on the outcome of lumbar medial branch ablation. Loh et $a l^{263}$ performed a single-center, retrospective chart review in 323 patients comparing two different techniques used by multiple practitioners over a 4 -year period. A perpendicular approach, in which cannulas were inserted perpendicular to the medial branch in a different plane targeting a point on the transverse process just caudal to the supero-medial edge of the transverse process, was used in 241 patients. A later technique, which used near-parallel electrode insertion, was employed in 82 patients. The authors reported lower pain scores (mean 3.64 vs $4.27 ; p=0.06)$ at 1 -month postprocedure and a longer duration of relief (median duration 4 vs 1.5 months; $p=0.02$ ) in patients who received near-parallel electrode placement. However, differences in selection criteria, technical parameters and patient expectations (ie, different physicians use different approaches) limit the generalizability of these results.

In another retrospective study performed in the cervical spine, Cheng et $a l^{264}$ found no difference in pain reduction at 1 and 3 months following RFA between individuals treated using perpendicular (ie, lateral approach) electrode insertion $(n=38)$ and those who were treated using a parallel (ie, from the posterior neck) approach $(n=44)$, but those treated using the lateral approach fared better at 6 and 12 months. Along with the anatomical differences between the cervical and lumbar spine regions, the same limitations in the study by Loh et $a l^{263}$ undermine external validity in this study which was never published in a peer-reviewed journal.

\section{Indirect comparisons of outcomes in studies using different approaches}

The two placebo-controlled trials that used parallel electrode insertion both yielded positive results, ${ }^{82} 83$ while only one ${ }^{81}$ of three 198184 that inserted the electrodes perpendicular to the targeted nerves reported positive findings. The negative, randomized MINT study ${ }^{17}$ was also widely criticized for using a perpendicular needle approach. ${ }^{25-27}$ However, the heterogeneity of the patient populations, and differences in selection criteria, other technical aspects of RFA (eg, fluid modulation, cannula size, lesioning temperature and duration) and outcome measures preclude any meaningful conclusions from indirect comparisons of electrode insertion.

\section{Recommendation}

Based on anatomical descriptions and the available literature, near-parallel placement of traditional (eg, non-internally cooled and variations designed to increase lesion area) electrodes is recommended to increase the likelihood of medial branch nerve RFA by increasing the margin of error; grade B evidence, low level of certainty (figure 1).

\section{QUESTION 14: SHOULD SENSORY AND/OR MOTOR STIMULATION BE PERFORMED BEFORE RADIOFREQUENCY ABLATION?}

\section{Rationale for sensory stimulation and evidence}

The success of RFA of lumbar medial branch nerves is dependent on correctly identifying patients whose pain is mediated via the medial branch nerves and by providing a thermal lesion that adequately coagulates the nerves, thereby preventing conduction of nociceptive information along the nerves. Integral to this second point is that the RF cannula must be in close enough proximity to the intended target nerves to result in ablation. Additionally, to avoid or minimize complications, the procedure should avoid coagulation of the ventral ramus or other unintended structures. Although some physicians believe that these goals can be accomplished through appropriate needle placement to the intended anatomical target based on fluoroscopic landmarks, others advocate for the use of sensory and/or motor testing in addition to anatomic landmarks to achieve optimal placement. The justification for this is based on anatomical variations in the location of the medial branches and the multiple articular branches emanating from each nerve. ${ }^{261} 265-267$

Sensory stimulation is typically carried out at $50 \mathrm{~Hz}$. Patients are asked to inform the treating physician when they identify a sensory change (eg, tingling, buzzing, vibration, pain). Traditionally, an acceptable threshold is $\leq 0.5 \mathrm{~V}^{7} 18{ }^{81} 84$ If sensory threshold is in fact being used to determine optimal placement, however, the cannula should be advanced in all three dimensions (anterior-posterior, cephalad-caudal and medial-lateral) to determine exactly where the stimulation threshold is lowest. In clinical practice, most physicians do not modify placement once an acceptable threshold is reached. Additionally, sensation may be evoked by local muscle stimulation even when the nerve is not close enough to be incorporated into a thermal RF lesion. 
This is particularly true since the shape of the lesion is known to extend circumferentially along the active tip. In this regard, suboptimal needle placement technique (perpendicular rather than parallel trajectory) can result in adequate sensory stimulation while the lesion may be insufficient for coagulation of the nerve and relief of pain. A prospective study in 61 patients who underwent lumbar facet RFA after a positive block found no correlation between average sensory threshold and treatment results. ${ }^{268}$ However, the authors concluded that because sensory testing was optimized for each patient by adjusting the electrode in multiple planes before lesioning, the results should not be misinterpreted as meaning sensory testing should not be done. Rather, sensory testing is just one of many factors that include age, gender, genetics, sedation and baseline analgesics and comorbidities (eg diabetes) that could affect medial branch sensory perception. In a small observational study by Dreyfuss et $a l,{ }^{147}$ the authors found no correlation between the degree of multifidus muscle atrophy and treatment outcome or levels treated 17-26 months after denervation. In two small placebocontrolled studies performed in the cervical and lumbar spine that yielded positive results, the investigators did not use sensory testing, instead creating four to six empirical lesions per level based on anatomic landmarks. ${ }^{82} 212$

\section{Rationale for motor stimulation and evidence Improvement of efficacy}

Motor stimulation is usually performed at a $2 \mathrm{~Hz}$ frequency. There are two potential uses for motor testing: (1) to identify multifidus or other paraspinal muscle stimulation indicating proper placement ${ }^{23}$ and (2) to identify distal muscle contraction when the needle is in dangerous proximity to the ventral ramus or spinal nerve. In a prospective audit by Dreyfuss et $a l,{ }^{23}$ multifidus muscle stimulation without sensory stimulation resulted in a success rate of $87 \% 12$ months post-RFA. A retrospective study by Koh $e t \mathrm{al}^{269}$ provides guarded support for the assertion that motor stimulation may be used to ensure proximity to the targeted nerve. They stratified 68 patients who underwent lumbar medial branch RFA into three groups: complete twitching elicited (observation of paravertebral muscle contraction at all levels), partial twitching elicited (paravertebral muscle contractions observed at one or two levels) or no twitching elicited. In the 'no-twitch', 'partial twitch' and 'complete twitch' groups, the mean durations of benefit were 4.6, 5.8 and 7.0 months, respectively, with the proportion of successful procedures at 6 months being statistically greater in the 'complete twitch' than the 'no-twitch' group.

It is important to recognize that at $\mathrm{L} 5$, it is the dorsal ramus itself that is targeted, so motor stimulation should elicit visible contractions of the spinalis, longissimus and iliocostalis muscles. However, in practice, the elicitation of paravertebral muscle contractions is typically less prominent at L5. There are several explanations for this, including that at L5 it may be the medial branch (rather than the dorsal ramus) that is being denervated in some patients, that at higher lumbar levels it may be the dorsal ramus itself (rather than the medial branch) being lesioned in some patients, or that other factors are at play (eg, greater adipose tissue obscuring contraction, or greater atrophy at L5).

\section{Enhanced safety}

In some cases, eliciting muscle contraction may provide false confidence in needle placement when the motor nerve being stimulated does not actually innervate the facet joint (ie, cases of aberrant, non-medial branch innervation). ${ }^{127}$ For the purposes of enhancing safety, practitioners typically increase the voltage to $1.5-2 \mathrm{~V}$, or three times the sensory stimulation threshold for motor testing. ${ }^{270}$ The motor stimulation threshold may be important in preventing complications, as one case report described a patient who suffered an L5 sensory radiculopathy following L3-L5 dorsal ramus denervation whereby motor testing was not conducted above $1 \mathrm{~V}^{249}$ If no muscle contraction in the appropriate myotome is identified, most practitioners believe it is safe to proceed. After motor stimulation testing is completed, some systems require the electrode to be removed while LA is administered, which can result in inadvertent needle movement. In these cases, comparative images before and after anesthetic injection should be obtained to ensure the electrode position is identical. Additionally, many newer systems have a separate port that allows for the injection of LA without removing and replacing the electrode, which should obviate the need for additional images or testing. It is noteworthy that the SIS guidelines ${ }^{250}$ on RF neurotomy do not endorse motor stimulation before lumbar facet RFA, asserting that multiple fluoroscopic views and monitoring patients for lower leg pain are sufficient to prevent nerve root injury. However, there is at least one reported case of permanent dropped head syndrome occurring weeks after cervical RFA when motor stimulation was not performed, although the etiology and causal relationship to the procedure remain unclear. ${ }^{271}$

\section{Recommendations}

In summary, we recommend sensory stimulation when single lesions are anticipated; grade $\mathrm{C}$, low level of certainty. When multiple lesions are planned, the evidence for sensory stimulation is inconclusive; grade I, moderate level of certainty. For motor stimulation, we find that it may be beneficial for both safety and effectiveness purposes; grade B, low level of certainty.

\section{QUESTION 15: WHAT ARE THE MOST COMMON COMPLICATIONS OF FACET INTERVENTIONS, AND HOW CAN THEY BE MINIMIZED? \\ Background}

Diagnostic MBB and RFA of the nerve supply to the lumbar facet joints require placement of needles or RFA cannulas on the posterior elements of the lumbar vertebral column under image-guidance. The needles (22-gauge to 25 -gauge) or RF cannulas (16-gauge to 22-gauge) are placed at the junction of the superior articular and the transverse processes of the vertebra. The temperature generated at the tip of the cannula is usually between $80^{\circ} \mathrm{C}$ and $90^{\circ} \mathrm{C}$ and heating is generally performed for 1 to $3 \mathrm{~min}$. The risks from this procedure can be broadly classified as: vascular penetration and injury, procedure-related pain and dysesthesias, injury to non-target neural structures in proximity to the RFA probe, consequences of denervating surrounding muscles and impact on implanted electrical devices including pacemakers, cardioverter defibrillators, deep brain and spinal cord stimulators and spinal instrumentation.

\section{Vascular penetration and injury}

Vascular penetration and injury are possible during lumbar $\mathrm{MBB}$ and RFA procedures. The incidence of intravascular positioning of the needle tip during lumbar MBB varies from $3.7 \%$ to upward of $20 \% .^{106} 127143{ }^{272-274}$ In a study of 1433 lumbar MBBs performed in 456 patients, an incidence of $6.1 \%$ for vascular uptake was noted. ${ }^{272}$ Approximately one-third of these were identified by aspiration prior to injection, with the rest recognized on fluoroscopy following injection of contrast 
agent. Vascular penetration with or without the injection of LA is likely to result in a false-negative diagnostic block because of washout of the LA. In a study by Kaplan et $a l^{127}$ conducted in 18 volunteers, 6 subjects experienced vascular uptake during MBB (5 at one nerve, 1 at two nerves), with half of these individuals retaining the ability to perceive subsequent capsular distention (ie, possible false-negative block). Intravascular injection of LA is unlikely to cause harm because of the low volume administered, and the low probability of the presence of radicular 'feeder' vessels in the vicinity. Aspirating for blood prior to injection has high specificity $(97 \%$; $95 \%$ CI $95.6 \%$ to $98.4 \%$ ) but low sensitivity (41\%; $95 \%$ CI $29.2 \%$ to $53.7 \%$ ), making it a poor screening tool. ${ }^{274}$ When contrast is injected, it should ideally be performed using real-time fluoroscopy, as spot radiographs have a $59 \%$ sensitivity compared with live contrast injection. ${ }^{272}$ However, digital subtraction angiography is considered the reference standard for vascular uptake. In a study involving 344 diagnostic MBBs, the authors found a 19\% incidence of vascular uptake with digital subtraction, compared with $11 \%$ with real-time contrast administration and $6.7 \%$ with aspiration. ${ }^{106}$ The type of needle can also affect intravascular uptake during MBB, with one study showing a lower incidence with a pencil-point than a cutting needle (pencil-point needles may also carry a lower incidence of backache, which could result in a lower false-negative rate). ${ }^{274} 275$ Guidelines endorsed by SIS also recommend pre-injection of contrast with low volumes, between 0.1 and $0.3 \mathrm{~mL}$, in order to detect venous uptake and ensure the adequacy of spread. ${ }^{16}$

A study that reported on complications from $3162 \mathrm{MBBs}$ found superficial bleeding or hematomas in $0.1 \%-0.4 \%$ of the patients. ${ }^{273}$ Lumbar MBB and RFA are currently classified as 'low-risk' procedures in the guidelines on spinal procedures in patients on anticoagulant and antiplatelet medications formulated collaboratively by the American Society of Regional Anesthesia and Pain Medicine (ASRA) and other societies. ${ }^{276}$ This risk classification was based on a study by Endres et $a l^{277}$ that reported a $0 \%$ complication rate in 1836 patients who continued their anticoagulant therapy. Whereas no bleeding complications were observed among individuals who continued their anticoagulant therapy, a total of nine adverse events were reported among the 2296 patients who discontinued their anticoagulant therapy. An earlier survey study conducted among 325 members of ASIPP found that thromboembolic events were three times more likely than bleeding complications after interventional spine procedures. These events were more severe and common when anticoagulants were discontinued, while there was no difference in the reported occurrence of bleeding complications stratified by whether or not anticoagulants were continued. ${ }^{273}$ Based on the literature, the ASRA anticoagulation guidelines committee placed thoracic and lumbar MBB and RFA in the lowrisk procedure category, especially in patients who are at a high risk of thromboembolic events. This is consistent with guidelines from the SIS, ${ }^{278} 279$ and represented a change from the previous version of the ASRA guidelines issued in 2015, in which thoracolumbar procedures were classified as 'intermediate risk'. ${ }^{280}$ However, the SIS guidelines acknowledged the limited data on bleeding complications when large-bore cannulas are employed for denervation. The ASRA and SIS committees further recommended that MBB and RFA procedures be performed with imaging guidance in multiple planes, with special attention to lateral views to ensure that the needle is not advanced into the vicinity of the vascular structures in the neuroforamen.

In 2019, ASIPP published anticoagulation guidelines that placed lumbar facet IA injections, MBB and RFA in the moderate risk category. ${ }^{281}$ ASIPP's guidelines allow for continuation of aspirin, antiplatelet agents and platelet aggregation inhibitors for moderate-risk procedures, although they recommend discontinuing vitamin $\mathrm{K}$ antagonists, thrombin inhibitors, heparin and antifactor Xa medications.

\section{Recommendations}

The committee recommends checking for intravascular placement of the needle tip by aspirating and visualizing the spread of contrast on fluoroscopy in real-time prior to performing MBB to reduce false-negative results. This should ideally be done in a manner such that the total injectate dose (LA and contrast) is kept as low as possible to minimize the effect on LA dispersion; grade $\mathrm{C}$ recommendation, low level of certainty.

The committee also recommends that non-heparin anticoagulants be continued in the peri-procedure period for patients undergoing MBB or RFA, especially in patients at high risk of thromboembolic complications. Healthcare providers considering discontinuation of anticoagulants should consult with the physician prescribing these medications, and discuss these recommendations with the patient (ie, shared decision model) prior to making any changes; grade $\mathrm{B}$ recommendation, moderate level of certainty.

\section{RFA-related pain and numbness}

RFA of the lumbar MBB can be associated with tenderness, pain, hypoesthesia or dysesthesia and limitations of movement due to the thermal lesion around the target nerves. Release of proinflammatory cytokines is one postulated mechanism for postprocedural discomfort. Neuropathic pain in the skin overlying the lumbar paraspinal muscles possibly resulting from transection of the lateral branches of the lumbar dorsal rami during lumbar facet RFA was first reported in $1981 .^{282}$ A retrospective chart review of 116 RFA procedures performed in 92 patients reported an incidence of $3.3 \%$ for localized back pain lasting $>3$ weeks. $^{283}$ In an observational study of 34 patients, localized pain lasting up to 1 week after the procedure was reported in all patients, with 6 reporting back numbness for up to 3 weeks. ${ }^{284}$ In a prospective study comparing two approaches with cannula placement for lumbar medial branch RFA in 68 patients, 6 patients $(8.8 \%)$ reported persistent back pain after the RFA, with 3 having features of neuropathic pain that lasted longer than 3 months. ${ }^{285}$

These adverse effects are usually minor and self-limiting, although several studies have sought to identify ways to prevent them. Dobrogowski et al ${ }^{286}$ performed an RCT comparing the impact of administering $10 \mathrm{mg}$ of pentoxifylline, $10 \mathrm{mg}$ of methylprednisolone acetate (MPA) or saline following RFA of the lumbar medial branches but prior to removal of the RFA cannula in 45 patients. The authors reported a significant decrease in local tenderness and postprocedure soreness in patients who received pentoxifylline or MPA, but not in those receiving saline. In the saline group, $26.7 \%$ of patients had severe local tenderness 1 week after the procedure which disappeared in three of four individuals by 1 month. No patients in the MPA or pentoxifylline groups reported severe tenderness after the procedure. ${ }^{286}$ However, a more recent retrospective study performed in 164 patients who underwent lumbar medial branch RFA found no difference in the incidence of postprocedure neuritis between individuals who received postneurotomy steroids (6.4\%) compared with those who did not $(6.9 \%) .{ }^{287}$ Of note, an ex vivo study found that injecting steroids with LA prior to RFA can reduce lesion size. ${ }^{246}$ 


\section{Recommendations}

The committee recommends that physicians inform patients about the common adverse effects of RFA including pain, dyesthesias and numbness lasting from a few days to a few weeks following lumbar facet joint denervation. Injection of steroid through the cannula after ablation but prior to its removal may reduce pain and discomfort following RFA; grade C recommendation, low level of certainty.

\section{Injury to spinal cord or nerve roots}

Injury to the spinal cord (upper lumbar procedures) or nerve roots after lumbar facet RFA is possible but rare. The spinal nerve, and especially the dorsal root ganglion, is in proximity to the target site for medial branch neurotomy. Anterior misplacement of the electrode into the neuroforamen can result in the active tip of the RF electrode being situated near the nerve root. A case report described new sensory symptoms in the dermatomal distribution of the fifth lumbar nerve following RFA of the third to fifth lumbar medial branches and dorsal rami. ${ }^{249}$ Another study that reported on complications from $3162 \mathrm{MBBs}$ found irritation of the nerve roots occurred in $0.1 \%$ of the patients, but found no long-term neural deficits. ${ }^{273}$ Sensory and motor stimulation to reduce the probability of proximity of the RF cannula tip to the spinal nerve root traversing in the foramen have been advocated for preventing injury to the spinal nerves, but the evidence is inconclusive.

\section{Recommendations}

The committee recommends the use of true anteroposterior, ipsilateral oblique ('Scotty-dog') and true lateral views on fluoroscopy during placement of RFA cannulas to ensure that the tips are outside of the neural foramina. Absence of sensorimotor responses in a radicular distribution in response to test stimulation prior to RFA may also reduce the probability of injury to the spinal cord and spinal nerve roots; grade $\mathrm{B}$ recommendation, low level of certainty.

RFA-related degeneration of spinal anatomy and musculature The multifidus muscle, the most medial of the deep intrinsic spinal muscles, contributes to segmental stability in the lumbar spine. ${ }^{288}$ RFA of the medial branches innervating the lumbar facet joints results in denervation of this muscle, but the physiological implications of this phenomenon are unclear. Dreyfuss et $a l^{147}$ conducted a study on five patients who had undergone unilateral lumbar RFA. MRI of the lumbar spine was performed 17-26 months after denervation. Diffuse atrophy of the lumbar multifidus was noted in all patients, but was not limited to the levels of RFA even though post-RFA electromyography indicated denervation of multifidus muscles only at the levels where RFA was performed. None of the patients had recurrence of pain or evidence of spinal instability. ${ }^{147}$ In a larger case series of 27 patients, MRI was done prior to and following lumbar RFA to assess the bulk of the multifidus, and for evidence of disc and facet joint degeneration. ${ }^{289}$ No change in muscle mass or degeneration of the facet joints was observed, although a greater amount of disc degeneration was noted compared with unaffected levels (14.9\% vs 4.6\%).

It is important to note that at the level of the fifth lumbar vertebra, it is the dorsal ramus itself that is targeted. Based on characteristic innervation patterns, this should result in segmental denervation of the iliocostalis (a component of the erector spinae muscle), which is involved in back extension through lateral branch innervation, and the longissimus muscle (another component of the erector spinae muscle), which helps maintain an erect spine and contributes to lateral flexion, and is innervated by the intermediate branch. However, the stronger contractions that are typically observed at the second to the fourth lumbar vertebral levels suggest that, at least in some people, the iliocostalis and longissimus muscles may also be stimulated during motor testing, and denervated during ablation. This hypothesis is supported by unpublished data showing that it is the contraction of the longissimus and iliocostalis muscles during facet joint nerve motor stimulation that is most prominent (unpublished data from Avanos, personal communication from Jeffrey Petersohn), and a case report demonstrating denervation of both the multifidus muscle and erector spinae muscle groups after lumbar facet RFA. ${ }^{290}$ Finally, loss of paraspinal extensor muscle action has been reported following multilevel, unilateral RFA for denervation of the upper cervical facet joints. This patient required surgical stabilization of the cervical spine. ${ }^{271}$

\section{Recommendations}

The committee recommends a comprehensive discussion with patients about the potential short-term and long-term impact of lumbar facet joint RFA on spinal anatomy. It should be explained to patients that morphological changes to spinal muscles will not result in adverse clinical outcomes in most patients. However, recommending PT regimens aimed at restoring the function of paraspinal muscles prior to and after RFA may improve outcomes; grade $\mathrm{C}$ recommendation, low level of certainty.

\section{Impact of RFA on existing implanted devices}

Monopolar RFA of innervation to lumbar facet joints involves the use of electrical current that emerges from the tip of the RF cannula and flows through the body before exiting through the grounding pad. Magnetic fields created from use of shortwave diathermy can result in interference with functioning of implanted electric devices such as deep brain ${ }^{291}$ or spinal cord stimulators. There is some evidence that bipolar RFA may be safer than monopolar. ${ }^{292}$ However, safe use of monopolar RFA has been reported in a patient with deep brain stimulators with one of the implanted pulse generators located in the anterior abdominal wall. ${ }^{150}$ Safe and successful bipolar RFA to treat cervical and lumbar facetogenic pain in two patients with automated implantable cardioverter defibrillators has also been reported. $^{292}$ When the grounding pad is placed on the lower extremity, lumbar RFA should theoretically carry a lower risk of device interference than for procedures performed in the neck. The American Society of Anesthesiology recommends that the grounding electrode be placed at least $15 \mathrm{~cm}$ away from pacing leads for both permanent pacemakers and implantable cardiac defibrillators. $^{293}$

Use of bipolar RF mode may be preferable to unipolar for risk minimization because of the smaller induced electromagnetic field. If using unipolar RF, placing the grounding pad close to the neurotomy site will reduce the size of the induced electromagnetic field. This will minimize the risk of heating the neurostimulator battery and electrodes. However, placing the grounding pad too close to the neurotomy site can increase the risk of tissue burns, particularly when using high current, long activation times, and the use of conductive fluid, since the energy has less tissue through which to dissipate.

\section{Recommendations}

Healthcare teams responsible for managing the implanted device (eg, neurology, cardiology, pain medicine) should be consulted 
regarding the planned RFA procedure. If RFA is performed, implanted electrical devices such as neurostimulators should be programed to an output of zero volts and turned off before the procedure, and the risks of device damage discussed with the patient. For pacemakers and defibrillators, the cardiology team and device manufacturer should be consulted prior to facet joint medial branch RFA, and their recommendations followed (eg, program pacemaker to asynchronous mode). Using no or judicious sedation will allow the physician to communicate effectively with the patient and to detect any potential injury to the central nervous system or cardiovascular decompensation at an early stage. A deactivated neurostimulator should be turned on following the RFA procedure and reprogrammed to preprocedural settings; grade $\mathrm{C}$ recommendation, low level of certainty.

\section{Tissue burns}

Skin burns from either extension of the lesion into the dermis or equipment malfunction (eg, electrical faults, insulation breaks in the electrodes, generator malfunction or incorrect application of the electrical dispersive (aka grounding pad)), have been reported. ${ }^{294-297}$ Skin burns resulting from direct extension have been described in areas such as the knee where there is less tissue between the target nerve and the skin, and may be more likely to occur with larger lesions. ${ }^{294}$ Although RFA in the back is extremely unlikely to result in skin burns in even the thinnest patients, lesion extension into paraspinal muscles may manifest as increased procedure-related pain. As noted above, placing a grounding pad too close to neurotomy site can increase the risk of skin burns, especially with aggressive lesioning techniques. Strategies to reduce the potential for skin burns during RFA have previously been published and include the use of a large electrical dispersive pad constructed with conductive metal and adhesive polymer gel, positioning the grounding pad with the longest side facing the RF electrode, and for high-risk procedures, consideration of the use of dual grounding pads. ${ }^{298}$

\section{Recommendations}

We recommend checking all equipment to ensure that it is properly functioning, and positioning monopolar RF grounding pads in an optimal location and orientation. Applying a large, properly positioned grounding pad on a lower extremity that is dry, clean shaven and devoid of scars or tattoos may minimize the risk of tissue burns; grade B recommendation, moderate-to-high level of certainty.

\section{Impact of RFA on spinal instrumentation in proximity of the procedure}

Cadaver studies have shown that anterior lumbar interbody spinal fixation is associated with less facet joint capsular strain at the level of fixation plate. ${ }^{299}$ Previous spine surgery is also associated with a higher false-positive rate of $\mathrm{MBB}$, and a lower success RFA rate. ${ }^{54} 133$ It should also be noted that during placement of pedicle screws, many surgeons intentionally or unintentionally also sever the medial branches. Yet, it is not uncommon for patients who have had spine surgery with instrumentation to undergo lumbar facet joint RF denervation at levels adjacent to the operated segments. Concerns have been expressed that the use of RFA in patients with existing posterior spinal instrumentation can cause thermal injury to surrounding structures through heating of the hardware. ${ }^{300} 301$ However, an observational study of 44 lumbar facet joint RFA procedures in patients with posterior spinal instrumentation did not find any evidence of superficial or deep burns, denervation of the lateral branches or ventral rami, or coagulation of blood vessels. ${ }^{302}$

\section{Recommendations}

Multiplanar fluoroscopic imaging-guided RFA technique should be used to ensure that the RF cannula is not in contact with the pedicle screw to avoid thermal injury to tissues surrounding implanted spinal hardware; grade $\mathrm{C}$ recommendation, low level of certainty.

\section{QUESTION 16: SHOULD THERE BE DIFFERENT STANDARDS IN SELECTING PATIENTS FOR RADIOFREQUENCY ABLATION} IN CLINICAL TRIALS AND CLINICAL PRACTICE? Key concepts of clinical trial design and disparities in interpretation

Clinical trials are the reference standard to determine the efficacy and effectiveness of novel therapeutics to treat pain. Early phase clinical trials employ strict selection criteria in order to reduce variables that may affect outcomes, and maximize the chance of establishing efficacy. As the therapy moves through the different phases of development, selection criteria are loosened in order to evaluate outcomes in 'real-world' patient populations that better reflect effectiveness. Trying to estimate real-world effectiveness based on rigorously performed efficacy studies is challenging, as increasing exclusiveness undermines generalizability. ${ }^{303}$ It is difficult to determine where diagnostic facet blocks and RFA fall on this continuum since there is abundant (yet often conflicting) literature evaluating nearly every aspect of the treatment, as discussed in this review. Therefore, some variables may require more stringent selection criteria to evaluate in clinical trials while others may warrant more liberal criteria that aim to maximize generalizability. ${ }^{36}$

A key concept of clinical trials is that methodology should be contingent on the question being answered (eg, animal studies to determine safety, dosing or treatment parameters; phase III to determine efficacy). ${ }^{304}$ Consequently, the design of facet joint studies, including selection criteria, should be tailored to the study's purpose. Studies generally seek to extend our knowledge in a given area (ie, they do not seek to re-test or re-litigate established facts), but a gray area of contention in the interventional pain treatment theater is that there is disagreement on what is established. For example, whereas most interventional physicians agree on the efficacy of facet joint RFA, there is no such consensus in the general medical community. This can lead to differences in interpretation of the extant interventional literature, and for pain physicians to eschew performing pure efficacy studies later in a procedure's lifespan, with that gap being filled by non-interventionalists who are not as attuned to nuances that could improve treatment outcomes. This is highlighted in a review on epidural steroid injections that found that both clinical trials and evidence-based reviews led by physicians who perform the procedure are much more likely to yield positive conclusions than those conducted by non-interventionalists. ${ }^{305}$ There is widespread agreement on designing studies to optimize the likelihood of answering the question being asked, and that studies designed for one purpose should not be used to draw conclusions on others (ie, comparative-effectiveness studies with liberal selection criteria should not be used to assess efficacy). ${ }^{24} 2527$

It is important to recognize that what may be best for an individual person and justifiable in a clinical trial may not be in the best interest of society, or even for an individual practitioner. For example, interventions that are incredibly costly and 
time-consuming, but provide only a marginal increase in efficacy may be not be cost-effective on a macrolevel. However, the conduct of early phase clinical trials does not usually reflect clinical practice. Inclusion and exclusion criteria tend to be longer and more rigorous in clinical trials, and the additional costs incurred by being more selective in enrollment and meticulous in performance often pale in comparison to the overall cost of product or drug development.

\section{Patient selection}

Similar to all treatments, patient selection for diagnostic facet blocks plays a critical role in determining the likelihood of a positive outcome. There is consensus that failure of at least 3 months of conservative therapy is a reasonable threshold that should be implemented in both clinical trials and practice, although practice guidelines could allow flexibility in cases of extenuating circumstances. The cut-off for clinical trials is similar to what was advocated by an international panel of experts for epidural steroid injection studies, and is predicated on the observation that the natural prognosis is favorable for back pain in individuals with acute pain, even without treatment. ${ }^{306}$ There is scant evidence supporting specific physical examination signs or imaging to diagnose facetogenic pain or predict treatment outcomes, so selection should be adapted according to the specific question being addressed.

Patient selection in clinical trials designed to determine efficacy must employ stringent selection criteria to eliminate likely non-responders (eg, individuals with depression, those on high doses of opioids), ensure that participants have the index condition being studied (ie, reduce false-positive rates for MBB), and maximize the chances for technical success even when doing so may not be cost-effective (ie, performing sensory stimulation, creating multiple lesions, utilizing relatively expensive systems that enhance lesion size). However, practitioners on the frontlines treating pain often have different goals. For example, although patients who are depressed and sleep poorly, or are on temporary disability or opioids because of back pain, may not be candidates for a clinical trial aimed at determining efficacy, the upside of treatment in these patients is substantial.

\section{Technique for diagnostic facet block}

The goal of the diagnostic block is for the LA to be delivered to the target without extraneous flow to non-targeted structures. There is little controversy over the volume of the injectate, as low volumes have been shown to enhance specificity for $\mathrm{MBB}$ and positive predictive value for RF procedures. ${ }^{9899172}$ The use of contrast, and its ability to detect spread patterns for a less viscous LA solution, is more controversial. For epidural injections, the results are mixed regarding the correlation between the spread of contrast dye, and the spread of LA and sensory blockade. ${ }^{307} 308$ The incidence of vascular uptake may be high enough to affect outcomes in small clinical trials that aim to determine efficacy (false-negative blocks) and therefore low volumes $(<0.3 \mathrm{~mL})$ of contrast are recommended. However, the injection of contrast, especially gadolinium in those with allergies to iodinated contrast, is not without risk. ${ }^{309} 310$ Since the anticipated effect will be much smaller on larger pragmatic trials and in individual patients, its use may not be necessary in all circumstances (ie, the risks and costs may exceed benefits). The use of fluoroscopy is the reference standard for MBBs in both clinical trials and practice, as correct needle position is integral for validity and is unlikely without direct visualization. However, we recommend using CT guidance for IA injections in clinical trials due to the high failure rate of IA injections with fluoroscopy. ${ }^{18}$ Sedation has been shown to result in high falsepositive rates for diagnostic spinal injections ${ }^{160}$ and individuals who require sedation for MBB should be excluded from clinical trials.

\section{Patient-reported outcomes for diagnostic MBB}

The cut-off for designating an MBB as positive is one of the most controversial areas in pain medicine. The studies demonstrating no difference in the predictive value of $\geq 50 \%$ to $<80 \%$ pain reduction vs $\geq 80 \%$ pain reduction are of higher quality than studies that reported a higher predictive value for an $\geq 80 \%$ cut-off, including the only prospective study to examine this question $^{6}$; hence we recommend using $\geq 50 \%$ for clinical trials, with planned subgroup analyses stratified by per cent pain relief. Given the significant false-positive rate of uncontrolled MBB, it is advantageous that multiple blocks, preferably placebocontrolled, be used to enhance diagnostic accuracy in clinical trials whose aim is to determine efficacy. ${ }^{209}$

\section{Technique for RFA}

The goal of RFA is to interrupt as much of the innervation to the facet joint as possible. This is achieved by aligning the exposed needle tip as close to the target innervation and creating as large a lesion as possible, while minimizing damage to non-targeted tissues. The workgroup agrees that visualizing the anatomic location of the needle tip is the most important step. Motor stimulation should be used for safety and can provide confirmation of correct placement by the elicitation of spinal muscle contractions, but may be difficult to discern in patients with obesity, at lower lumbar levels, and in individuals with muscle atrophy. Similarly, sensory stimulation can provide assurance of proximity to the targeted nerve(s), but may be difficult to distinguish from local tissue stimulation, is affected by multiple other factors and was not shown to correlate with RFA outcomes in a prospective study ${ }^{268}$ Therefore, the use of sensory stimulation is not always necessary in clinical practice, but should be used in clinical trials in the absence of an aggressive lesion strategy. The workgroup agrees that larger lesions are relatively easy to effect and may increase the chance of a successful outcome; for this reason, the standards should not differ between clinical trials and practice (use of large-gauge electrodes, temperature $\geq 80^{\circ} \mathrm{C}$, longer lesion times to reduce lesion variability).

\section{Recommendations}

This committee interprets the literature to date as demonstrating that lumbar medial branch RFA is efficacious for those patients selected through rigorous methods. Therefore, by relaxing these stringent criteria and performing planned subgroup analyses stratified by percent pain relief, we can further clarify expected outcomes. Studies with the objective of proving efficacy should use the most rigorous selection criteria possible, which may entail multiple blocks with cut-off thresholds exceeding 50\% pain relief.

We believe that employing different standards for clinical practice and clinical trials, particularly those that purport to show efficacy, is reasonable (table 11). These differences reflect the different goals for investigators, patients and physicians. Specific areas in which criteria may differ include patient selection (with clinical practice erring on the side of enhanced access to care) for facet blocks and RFA. For RF technique, strategies to maximize lesion size that carry minimal additional risks and costs should ideally be similar between clinical trials and practice; grade A evidence, moderate level of certainty. 


\begin{tabular}{|c|c|c|}
\hline Factor & Clinical trial & Clinical practice \\
\hline \multicolumn{3}{|l|}{ Patient selection } \\
\hline $\begin{array}{l}\text { Failure of conservative } \\
\text { treatment }\end{array}$ & At least 3 months & $\begin{array}{l}\text { Preferably } 3 \text { months, but may } \\
\text { be less in certain circumstances } \\
\text { (eg, incapacitating pain with } \\
\text { strong suspicion of facetogenic } \\
\text { origin, competitive athlete, } \\
\text { military deployment) }\end{array}$ \\
\hline Physical examination & No recommendation & No recommendation \\
\hline Diagnostic imaging & No recommendation & No recommendation \\
\hline \multicolumn{3}{|l|}{ Facet block technique } \\
\hline \multicolumn{3}{|l|}{ Injectate volume: } \\
\hline Medial branch block & $\leq 0.5 \mathrm{~mL}$ & $\leq 0.5 \mathrm{~mL}$ \\
\hline Intra-articular block & $<1.5 \mathrm{~mL}$ & $<1.5 \mathrm{~mL}$ \\
\hline \multicolumn{3}{|l|}{ Imaging: } \\
\hline Medial branch block & Fluoroscopy & Fluoroscopy \\
\hline Intra-articular block & CT & Fluoroscopy or CT \\
\hline Contrast & $0.1-0.3 \mathrm{~mL}$ & With or without contrast \\
\hline Sedation & None & Not routinely \\
\hline \multicolumn{3}{|l|}{ Patient-reported outcomes } \\
\hline Pain relief cut-off & $\begin{array}{l}\geq 50 \% \text {, consider subgroup } \\
\text { analysis for higher thresholds } \\
\text { in efficacy studies }\end{array}$ & $\begin{array}{l}\geq 50 \% \text {, with lower cut- } \\
\text { offs considered in certain } \\
\text { circumstances (eg, other } \\
\text { metrics of improvement } \\
\text { achieved) }\end{array}$ \\
\hline Multiple blocks & $\begin{array}{l}\text { Strongly consider for efficacy } \\
\text { studies }\end{array}$ & Not routinely \\
\hline $\begin{array}{l}\text { Repeat diagnostic MBB for } \\
\text { repeat RFA }\end{array}$ & No & No \\
\hline \multicolumn{3}{|l|}{ RFA techniqueRFA technique } \\
\hline Stimulation & $\begin{array}{l}\text { Motor necessary; sensory } \\
\text { recommended in the absence } \\
\text { of multiple lesions }\end{array}$ & $\begin{array}{l}\text { Motor strongly recommended; } \\
\text { sensory at discretion of } \\
\text { practitioner }\end{array}$ \\
\hline Needle size & $\begin{array}{l}\text { Large (preferably at least } \\
\text { 18-gauge) }\end{array}$ & Large \\
\hline Temperature & $80^{\circ} \mathrm{C}-90^{\circ} \mathrm{C}$ & $80^{\circ} \mathrm{C}-90^{\circ} \mathrm{C}$ \\
\hline Duration & Preferably at least $2 \mathrm{~min}$ & At least $1.5 \mathrm{~min}$ \\
\hline $\begin{array}{l}\text { Multiple lesions and/ or other } \\
\text { techniques to increase lesion } \\
\text { size }\end{array}$ & $\begin{array}{l}\text { Necessary in the absence } \\
\text { of clear-cut stimulation } \\
\text { benchmarks }\end{array}$ & Depends on circumstances \\
\hline
\end{tabular}

$M B B$, medial branch block; RFA, radiofrequency ablation.

\section{QUESTION 17: IN WHICH PATIENTS SHOULD REPEAT RADIOFREQUENCY ABLATION BE CONSIDERED, AND WHAT IS THE LIKELIHOOD FOR SUCCESS? DO REPEAT DIAGNOSTIC BLOCKS NEED TO BE REPEATED?}

Rationale for repeating RFA and likelihood of success

Pain relief after RFA of the facet joint nerves is durable compared with steroid injections, but still time-limited. ${ }^{18} 23311-313$ As a result, in current clinical practice RFA is commonly repeated on recurrence of pain. Educating patients about the possibility of temporary relief and the potential for repeated treatment is a part of the informed consent process for this treatment, and information about the likelihood of success with repeated treatment is central to this discussion. A 2012 systematic review by Smuck et al examined the literature on the success of repeat lumbar RFA. ${ }^{314}$ From seven qualifying studies that provided data on repeat RF outcomes, the unweighted average success rate of repeat RFA was approximately $80 \%$ in patients who experienced a good outcome from the first RFA procedure, typically defined as at least $50 \%$ relief of pain at 3 months. The 3 -month cut-off for designating an RFA procedure as a success is based on a study by Cohen et al in which 15 patients and 5 pain physicians were surveyed in preparation for a randomized trial of RF outcomes. ${ }^{7}$ These repeat RFA results differed somewhat between lumbar and cervical RFA studies, with a 59\% success rate based on the two qualifying lumbar studies $(\mathrm{n}=29)$ and an $88 \%$ success rate based on the five qualifying cervical studies $(\mathrm{n}=114)$. The average duration of pain relief was also similar following repeat RFA compared with the initial RFA response (10 months). Alternatively, when response to the first RFA did not meet the 3-month cut-off for a positive outcome, repeat RFA was less successful (38\% based on data from the five cervical spine studies, lumbar data not available).

Additional studies that were not included in the abovementioned systematic review, because of publication date or not meeting selection criteria, shed further light on the effectiveness of repeat RFA. A prospective cohort study by Rambaransingh et $a l^{315}$ examined outcomes in patients with successful response to an initial lumbar medial branch RFA who underwent a second $(\mathrm{n}=58)$ and third $(\mathrm{n}=29)$ RFA treatment, demonstrating the repeatability of treatment success. Clinically meaningful mean improvements in pain and disability were observed after each of the RFA treatments, and without statistical differences in treatment duration or effect size between the first, second and third RFAs (mean pain score reductions of 3.2, 3.3 and 4.1, respectively). Son et al performed a retrospective analysis in 60 patients who received one or two repeat lumbar medial branch RFAs after an earlier successful treatment. ${ }^{316}$ The first and second repeat RFAs were successful in $91 \%$ and $80 \%$ of cases, respectively, with no statistical differences in the duration of relief (mean duration 10.9 and 10.2 months after the initial and repeat procedures, respectively). Similar results were reported by Kim et al (95\% success rate with repeat RFA) in a retrospective cohort study evaluating 56 patients with facet joint pain following lumbar microdiscectomy who were treated with a repeat RFA when pain returned following a previously successful RFA. ${ }^{317}$ In this study, the proportion of patients with $>50 \%$ pain relief was $91 \%$ for the second procedure (mean duration of relief 10.2 months) and $80 \%$ after the third procedure (mean duration 9.8 months). More recently, MacVicar et al ${ }^{216}$ described outcomes from a prospective consecutive cohort $(\mathrm{n}=106)$ treated with lumbar RFA whereby 56\% experienced complete relief of pain, full restoration of function and no need for analgesic medications or other back pain treatments for a median duration of 15 months. Fifty-six per cent of these patients received repeat RFA (between one and five treatments) with all experiencing similar robust treatment effects and durations of benefit (median 13 months) following the repeat procedures.

In summary, there is good evidence to support repeat medial branch RFA, with a high likelihood of success (at least 80\%) in patients who experience at least $50 \%$ pain relief for a period of 3 months or longer following their initial RFA treatment. According to multiple studies, improvements in pain and function and duration of benefits are similar between repeat and initial lumbar facet RFA treatments.

\section{Rationale for durability and repeatability of RFA}

The mechanisms that underlie the durability of RFA outcomes remain under debate. The electrode temperature and duration of the RF delivery are intentionally chosen to cause axonal destruction and Wallerian degeneration of the medial branch nerve, but are not sufficient to injure the collagenous tissues that form the nerve sheath (ie, third-degree peripheral nerve injury based on the Sunderland nerve injury classification). ${ }^{248318}$ As a result, the proximal surviving axons can regenerate via the intact neural tube and re-establish facet joint innervation and pain perception. This is the most likely reason that some patients experience return of pain and need to repeat the procedure. What is 
less clear is the reason for the observed durability of RFA treatment effects, lasting 10 months or more based on a systematic review. ${ }^{314}$ Injured axons regenerate at a rate of $1-2 \mathrm{~mm} /$ day, although the rate depends on many factors and can vary significantly from individual to individual. ${ }^{319}$ Since the length of nerve from the axonal lesion to the lumbar facet joint is approximately $30-40 \mathrm{~mm}$, reinnervation could occur within 3-6 weeks. Regeneration is the primary form of nerve repair when $>90 \%$ of the axons are injured. In partial nerve injuries when only 20\%-30\% of the axons are affected, collateral sprouting from preserved axons can contribute to reinnervation. ${ }^{248}$ Some researchers have suggested that the prolonged pain relief observed from RFA results from the heat lesioning slowing nerve regeneration, or reinnervation. ${ }^{248} 320321$

\section{Rationale for not repeating prognostic blocks before repeat RFA}

Despite the known durability of RFA treatment outcomes, a substantial number of patients who respond to RFA will experience a return of pain. The pathophysiological mechanisms behind this are described in the preceding paragraph. Each study included in the systematic review by Smuck et al, ${ }^{314}$ and all of the individual studies discussed previously specified that a positive response to prognostic blocks was the criterion used to select patients for the initial RFA treatment. None comment about the role of repeat prognostic blocks in the decisions to repeat RFA, suggesting that repeat prognostic blocks did not play a role in the decision to repeat the denervation procedures, and thus are not necessary.

From a practical standpoint, when pain returns it may not be clear that it stems from the previous source. This can be particularly challenging when relief from the prior RFA lasts considerably longer than expected, as some patients have reported benefit lasting $>5$ years from a single RF treatment. ${ }^{216}$ As a result, physicians sometimes choose to repeat the prognostic blocks before repeating RFA. This may be more useful when a patient's description of the index pain has changed, or if the patient or physician is uncertain if the current pain is the same or similar to previous pain. To our knowledge, no studies provide data to help guide when repeat prognostic blocks are needed prior to repeating a previously successful RFA.

\section{Period of waiting}

Studies have demonstrated that patients with shorter duration of pain respond better to an initial RFA of the lumbar medial branches for facet joint pain, ${ }^{54}$ and sacral lateral branches for SI joint pain, ${ }^{200}$ than those with a longer duration. Whereas there are no data evaluating the effect that the duration of pain following a recurrence has on repeat RFA outcomes, based on this information, the relatively high success rate for repeat lumbar medial branch RFA, and the disability associated with lumbar facetogenic pain, one might reasonably surmise that repeat RFA should be performed shortly after symptoms recur. However, repeating RFA may have irreversible consequences if performed too early. Denervation of the paraspinal musculature including the multifidus muscle has been demonstrated to last over 12 months in some patients. ${ }^{147}$ When a muscle is denervated, it proceeds through several well-documented stages that are measured in months in most laboratory animals, but can take several years to denouement in humans. Immediately after denervation, immediate loss of function and microscopic muscle atrophy ensue. The second stage is characterized by increasingly severe muscle atrophy, which includes the loss of most sarcomeric organization. The final phase consists of irreversible, interstitial fibrosis, whereby muscle tissue is replaced by adipocytes. $^{322} 323$ Since there are reports of patients getting multiple repeat RFA procedures over a period of years, and motor units may be more susceptible to irrevocable long-term sequelae than nociceptors, performing repeat RFA multiple times preemptively (ie, before pain recurs) has the potential to result in irreversible damage to the paraspinal musculature.

\section{Recommendations}

The committee recommends repeating lumbar medial branch RFA on recurrence of pain in patients who experience a minimum of 3 months of improvement (and preferably 6 months improvement for multiple procedures) following a previous RFA. Given the drop-off in success rates reported in some studies and the mean duration of benefit, we recommend repeating the procedure no more than two times per year; grade B recommendation, moderate level of certainty.

The committee does not recommend routine use of repeat prognostic blocks before repeat lumbar medial branch RFA in patients who experience a recurrence of their baseline pain in a physiological time frame, but we recognize that they may be useful when it is unclear if the current pain is the same or similar to the pain experienced before the previous RFA; grade $\mathrm{C}$ recommendation, low level of certainty.

\section{DISCUSSION}

\section{Perspective and bias}

Facet-related procedures have become a deep-seated source of controversy in the pain medicine and general medical communities. An analysis of clinical trials and evidence-based reviews reveals that those performed by non-interventionalists are most likely to generate negative findings ${ }^{85} 90324$ compared with those performed by individuals who perform facet blocks and RFA,${ }^{81217325}$ which is similar to what has been found for epidural steroid injections. ${ }^{305} 326$ In the Analgesic, Anesthetic, and Addiction Clinical Trial Translations, Innovations, Opportunities, and Networks (ACTTION) guidelines on unique considerations for interventional studies, the authors attributed this discrepancy to better selection and technique for interventionalists, differences in interpretation that reflect differences in background and understanding, and bias on both sides of the debate (table 12). ${ }^{36}$

\section{Balancing access to care against maximizing success rates}

A major point of contention in developing our guidelines revolved around disparities in the perceived objectives. Whereas it was charged from the outset that these guidelines should be designed to inform care in clinical practice, creating a balance between maximizing access to care for a minimally invasive procedure with a low complication rate for which there are no reliable evidence-based treatment alternatives (ie, formulating guidelines with liberal selection criteria to minimize false-negative results) and devising more stringent criteria which would promote higher RFA success rates (ie, minimizing false-positive results) proved to be a formidable task. In the end, we opted to err on the side of greater access to care, relying on education, peerreview and regulatory bodies to limit and prevent overuse.

Overuse is not limited to facet interventions, as studies have shown significant geographic variations in spine surgery and epidural steroid injection rates, with minimal correlation between the number of procedures performed and disability rates. ${ }^{327-329}$ Overuse may be an inevitable byproduct of a feefor-service payment system, although the incentives for high 


\begin{tabular}{|c|c|c|}
\hline Topic & Recommendation/Findings & Level of evidence and certainty \\
\hline $\begin{array}{l}\text { Value of history and physical examination to select } \\
\text { patients for blocks }\end{array}$ & $\begin{array}{l}\text { There are no examination or historical signs that reliably predict response to lumbar facet blocks. Paraspinal tenderness } \\
\text { and radicular symptomatology may be weakly predictive of positive and negative blocks, respectively. The levels targeted } \\
\text { should be based on clinical presentation (eg, tenderness, pain patterns, imaging if available). }\end{array}$ & Grade C, low level of certainty \\
\hline $\begin{array}{l}\text { Correlation between imaging and facet block and } \\
\text { RFA outcomes, and whether imaging is necessary } \\
\text { before blocks }\end{array}$ & $\begin{array}{l}\text { There is moderate evidence for SPECT before MBB. } \\
\text { There is weak evidence for SPECT before IA blocks. } \\
\text { There is weak evidence for MRI, CT and scintigraphy before MBB and IA blocks. }\end{array}$ & $\begin{array}{l}\text { Grade C, moderate level of certainty } \\
\text { Grade D, low level of certainty } \\
\text { Grade D, low level of certainty }\end{array}$ \\
\hline $\begin{array}{l}\text { Requirement of conservative treatment including } \\
\text { physical therapy before facet blocks }\end{array}$ & $\begin{array}{l}\text { Consistent with clinical practice guidelines, we recommend a 3-month trial of different conservative treatments before } \\
\text { facet joint interventions. }\end{array}$ & Grade C, low level of certainty \\
\hline \multirow[t]{2}{*}{$\begin{array}{l}\text { Necessity of image guidance for lumbar facet blocks } \\
\text { and RFA }\end{array}$} & $\begin{array}{l}\text { We recommend CT or preferably fluoroscopy be used for lumbar MBB, although ultrasound may be considered in certain } \\
\text { contexts. For IA injections, we recommend CT, although fluoroscopy can be considered in some cases. }\end{array}$ & Grade C, low level of certainty \\
\hline & For RFA, we recommend using fluoroscopy. & Grade B, low level of certainty \\
\hline Diagnostic and prognostic value of facet blocks & $\begin{array}{l}\text { IA injections are theoretically more diagnostic than MBB, although they are characterized by a high technical failure rate } \\
\text { and poorer predictive value before RFA. Both MBB and IA injections are better than saline injections as prognostic tools } \\
\text { before RFA. }\end{array}$ & Grade B, low level of certainty \\
\hline MBB vs IA injections before RFA & $\begin{array}{l}\text { MBB should be the prognostic injection of choice before RFA. IA injections may be used for both diagnostic and therapeutic } \\
\text { purposes in some individuals (eg, young people with inflammatory pain, people at risk of RFA complications). }\end{array}$ & Grade C, moderate level of certainty. \\
\hline Effect of sedation on diagnostic and prognostic utility & Consistent with guidelines, sedation should not be routinely used in the absence of individual indications. & $\begin{array}{l}\text { Grade B, low-to-moderate level of } \\
\text { certainty }\end{array}$ \\
\hline Ideal volume for facet blocks & $\begin{array}{l}\text { Lumbar MBB should be performed with a volume } \leq 0.5 \mathrm{~mL} \text { to prevent spread to adjacent structures, and IA injections } \\
\text { should be done with a volume }<1.5 \mathrm{~mL} \text { to prevent aberrant spread and capsular rupture. }\end{array}$ & Grade C, low level of certainty \\
\hline Therapeutic benefit from MBB and IA injections & $\begin{array}{l}\text { We recommend against the routine use of both therapeutic MBB and IA injections, although we acknowledge there may be } \\
\text { some contexts in which these can be useful (eg, prolonged relief from prognostic blocks, contraindications to RFA). }\end{array}$ & Grade D, moderate level of certainty \\
\hline $\begin{array}{l}\text { Cut-off for designating a prognostic block as positive } \\
\text { and use of non-pain score outcome measures }\end{array}$ & $\begin{array}{l}\text { We recommend that } \geq 50 \% \text { pain relief be used as the threshold for designating a prognostic block as positive, but recognize } \\
\text { that using higher cut-off values may result in higher RFA success rates. Secondary outcomes such as activity levels may also } \\
\text { be considered when deciding whether to proceed with RFA. }\end{array}$ & Grade B, moderate level of certainty \\
\hline Number of prognostic blocks performed before RFA & $\begin{array}{l}\text { We recommend a single block. Although using multiple blocks may improve RFA success rates, it will also result in patients } \\
\text { who might benefit from RFA being denied treatment. }\end{array}$ & $\begin{array}{l}\text { Grade C, low-to-moderate level of } \\
\text { certainty }\end{array}$ \\
\hline Evidence for large RF lesions & $\begin{array}{l}\text { There is indirect evidence, and limited direct evidence, that techniques that result in larger lesions (eg, larger electrodes, } \\
\text { higher temperatures, longer heating times, proper electrode orientation, fluid modulation) improve outcomes. }\end{array}$ & $\begin{array}{l}\text { Grade C, low level of certainty that larger } \\
\text { lesions increase the chance of capturing } \\
\text { nerves. } \\
\text { Grade I, low level of certainty that larger } \\
\text { lesions increase duration of pain relief. }\end{array}$ \\
\hline Electrode orientation & We recommend positioning the electrode in an orientation near-parallel to the nerve. & Grade B, low level of certainty \\
\hline Use of sensory and motor stimulation before RFA & $\begin{array}{l}\text { Sensory stimulation should be used when single lesions are anticipated. } \\
\text { When multiple lesions are planned, the evidence for sensory stimulation is inconclusive. } \\
\text { Motor stimulation may be beneficial for safety and effectiveness purposes. }\end{array}$ & $\begin{array}{l}\text { Grade C, low level of certainty } \\
\text { Grade I, moderate level of certainty } \\
\text { Grade B, low level of certainty }\end{array}$ \\
\hline \multirow[t]{8}{*}{ Mitigating complications } & $\begin{array}{l}\text { Intravascular uptake can adversely affect the validity of } \mathrm{MBB} \text { and we recommend aspiration and real-time contrast } \\
\text { injection. }\end{array}$ & Grade C, low levelof certainty \\
\hline & $\begin{array}{l}\text { Anticoagulation medications should be continued for facet blocks and RFA, and cases that might warrant discontinuation } \\
\text { should be discussed with relevant healthcare providers. }\end{array}$ & Grade B, moderate level of certainty \\
\hline & Injection of steroid after RFA may prevent neuritis. & Grade C, low levelof certainty \\
\hline & Confirming electrode placement in multiple views andusing sensorimotor testing may reduce the risk of nerveroot injury. & Grade B, low levelof certainty \\
\hline & $\begin{array}{l}\text { RFA can result in paraspinal muscle degeneration andpossibly disc degeneration, though the clinical relevanceof this is } \\
\text { unclear. We recommend a discussion of thispossibility with patients, and consideration of physicaltherapy before and after } \\
\text { RFA to reduce the risk. }\end{array}$ & Grade C, low levelof certainty \\
\hline & $\begin{array}{l}\text { Interference with implanted electrical devices can occur,and physicians should consult with relevant healthcareteams } \\
\text { regarding recommendations (eg, programmingpacemakers to asynchronous mode, turning offneurostimulators). Bipolar } \\
\text { modes may be safer thanmonopolar, and grounding pads should be placed awayfrom implanted cardiac devices, but not } \\
\text { too close to theneurotomy site (risk of tissue burn). Avoid excessivesedation. }\end{array}$ & Grade C, low levelof certainty \\
\hline & $\begin{array}{l}\text { Burns may occur from equipment malfunction or lesionextension to the skin (less likely). Checking equipment, and properly } \\
\text { positioning the grounding on a dry, cleanshaven lower extremity devoid of scars may minimize thisrisk. }\end{array}$ & $\begin{array}{l}\text { Grade B,moderate-to-highlevel of } \\
\text { certainty }\end{array}$ \\
\hline & $\begin{array}{l}\text { Spine surgery is associated with lower RFA success rates, and physicians should check placement of RF probes inmultiple } \\
\text { fluoroscopic views and avoid contact withhardware to prevent thermal injury. }\end{array}$ & Grade C, low levelof certainty \\
\hline $\begin{array}{l}\text { Difference in standards between clinical trials and } \\
\text { clinical practice }\end{array}$ & $\begin{array}{l}\text { Providers involved in clinical trials and clinical practice may have different goals that warrant different selection and } \\
\text { performance criteria. Areas that might warrant discrepancies include the use of contrast during MBB, number of blocks } \\
\text { performed, prognostic block cut-off for identifying an RFA candidate and use of sensorimotor stimulation. }\end{array}$ & Grade A, moderate level of certainty \\
\hline \multirow[t]{2}{*}{ Repeating RFA } & $\begin{array}{l}\text { We recommend repeating RFA in individuals who obtained at least } 3 \text { (and preferably } 6 \text { ) months of relief, up to two times } \\
\text { per year. The success rate for repeat RFA decreases for successive procedures but remains above } 50 \% \text {. }\end{array}$ & Grade B, moderate level of certainty \\
\hline & $\begin{array}{l}\text { Repeating prognostic blocks is not routinely necessary in patients who experience a recurrence of their baseline pain in a } \\
\text { physiological timeframe. }\end{array}$ & Grade C, low level of certainty \\
\hline
\end{tabular}

IA, intra-articular; LA, local anesthetic; MBB, medial branch block; RF, radiofrequency; RFA, radiofrequency ablation; SPECT, single photon emission computed tomography.

procedure utilization are multifarious. For example, a depressed, overweight patient with marital problems and sleep abnormalities who is on disability and opioids for back pain may be a great candidate for facet interventions because of the huge upside of the minimally invasive treatment, but from a payer's perspective the same patient may be a poor candidate because they are statistically unlikely to benefit. ${ }^{305} 330-332$ Increases in utilization alter the risk-to-benefit ratio for procedures, as laxer selection tends to reduce the likelihood of benefit. This is complicated by the fact that an insurer is unlikely to reap the financial benefits for a patient who returns to work, or staves off an impending divorce.
For pain medicine procedures, utilization is not uniformly distributed. One study found the top $10 \%$ of pain medicine proceduralists perform $36.6 \%$ of all spinal procedures, which is ninefold higher than the lowest $10 \%$. $^{333}$

\section{Recommendations in the absence of high-quality evidence}

The requirements for FDA approval of devices differ from those of medications in that they are less rigorous. This fact, along with the inherent challenges in performing randomized trials for procedures (eg, recruitment, blinding, funding for expensive 
procedures), has led to a relative paucity of evidence. However, as Altman and Bland so eloquently stated nearly 25 years ago, the absence of evidence does not equate to the evidence of absence. ${ }^{334}$

The United States Preventive Services Task Force guidelines have previously been adapted for pain medicine procedures, ${ }^{30-33}$ and are flexible enough to allow for recommendations based on evidence outside the realm of traditional clinical trials. This holds particularly true for fundamental concepts (ie, the use of imaging to perform a procedure that nearly everyone acknowledges requires visualization), technical aspects (ie, electrode orientation) and reducing complications. Regarding technical aspects, if one operates under the premise that RFA exerts its beneficial effects from interrupting the neural pathway from the facet joints, and that failure to capture the neural target is a potential source of treatment failure, then it becomes axiomatic that strategies to enhance lesion size have the potential to reduce technical failures. This is the same argument that was used for decades to justify selective nerve blocks and electrodiagnostic testing before decompression surgery, which only later were shown in clinical trials to be predictive for outcome. ${ }^{171} 335$ For complications, it is nearly impossible to power a randomized trial to detect rare events such as serious complications, so that other tools such as case-control studies and registries must be used to draw conclusions. ${ }^{336}$ As an example, in the multispecialty working group guidelines on epidural steroid injections, the authors unanimously concluded that imaging be used for cervical injections and that only non-particulate steroids be administered for cervical transforaminal injections, despite the absence of any randomized trials demonstrating safety. ${ }^{337} \mathrm{In}$ fact, concluding safety based on non-significant differences in adverse events between groups in randomized trials is considered to be evidence of 'spin'. 338

\section{Guideline limitations}

Unlike standards which generally come from an undisputed authority and are limited in application, guidelines tend to be more flexible, providing recommendations on areas of uncertainty. However, what may be an appropriate treatment approach for one patient may not work for another. An example might be proceeding straight to RFA without a diagnostic block in an elderly person with pronounced facet joint degeneration on imaging, who is on anticoagulants for a high-risk condition, and is from out of state or country.

These guidelines should thus serve as a framework to guide care, not as immutable standards. Similar to the US Centers for Disease Control and Prevention opioid guidelines, ${ }^{339}$ which have been criticized for being taken out of context by some insurance carriers and limiting access to care, payers should consider context, unique clinical considerations and provider and patient input, rather than mandating inflexible application. ${ }^{340} 341$

A second limitation was the high number of participants in our workgroup representing multiple countries and professional organizations, which is more than what is typically recommended to achieve consensus, but was necessary to ensure the participation of multiple stakeholder organizations. This led to the creation of subcommittees for individual questions, which were sent to the entire committee after editing by the Committee Chair. The use of small subcommittees to develop recommendations can result in an inability to come up with the best answer, while the large number of participants in the main committee can lead to inefficiency and failure to consider everyone's opinion.
Third, we did not grade the studies we included, as current grading scales focus on methodological shortcomings of clinical trials, but fail to consider the more important aspects of selection and technique. ${ }^{342}$ For grading scales involving non-randomized studies, there is no consensus on which instruments are the most valid, and the same limitations apply. ${ }^{333}$ Grading studies also requires considerable time and involves reconciling discrepancies. A major downside of guidelines that have taken years to assemble is that they are often out-of-date on some subjects by the time they are published.

Fourth, recommendations by nature are influenced by the opinions and clinical experience of the group, which in our case contained only academically accomplished interventional pain physicians. This was done because the questions we considered were mostly technical, rather than overarching ones such as effectiveness. It is therefore possible that including more private practitioners, non-pain physicians and even patients may have led to different conclusions.

Finally, our guidelines were designed to prioritize patients' needs, but patients' needs may not be the only consideration for policy recommendations. Practices that are suboptimal from an individual patient's perspective (or even the entire population of lumbar facet joint pain sufferers) may be utilitarian from society's standpoint in order to prevent overuse, preserve confidence from payers and regulators, and control costs. An example of this might be requiring a cut-off threshold for designating a prognostic block as positive, rather than leaving it up to patients as to whether they achieved enough benefit to proceed with RFA.

\section{Literature gaps and areas for future research}

We chose 17 questions to address in these guidelines, but this list is by no means exhaustive. In many cases, the answers to the questions we addressed will be controversial precisely because there are gaps in the literature. Areas of controversy include all aspects of lumbar facet joint arthropathy, such as the value of history, physical examination and imaging to select block candidates, how to perform and interpret diagnostic injections, technical aspects of neuroablation and how to synthesize the existing evidence on RFA. Table 13 outlines some areas ripe for future research.

\section{CONSENSUS}

The presubmission version of these guidelines was sent to participating organizations on 9 October 2019, and approved by all who voted by 8 November 2019, except for the American Society of Anesthesiologists, who requested a 3-week extension. There was $100 \%$ consensus among the committee members (coauthors) for each recommendation. Nine of the 13 organizations approved every recommendation, with one (SIS) dissenting on questions 10 (cut-off for designating a facet block as positive) and 11 (number of blocks that should be performed before RF ablation). Specifically, SIS believes the cut-off for a positive block should be $80 \%$ rather than $50 \%$, and that two positive blocks should be routinely required in the absence of mitigating circumstances. The American Pain Society disbanded during the development of the guidelines and did not vote. These guidelines were approved en bloc by the American Society of Anesthesiologists' Administrative Council and Committee on Pain Medicine, but were not voted on by their Board of Directors or House of Delegates. The Departments of Defense and Veteran Affairs did not vote on the document per internal regulations (ie, these guidelines were not solicited and funded by those organizations), 


\begin{tabular}{|c|c|}
\hline Minor areas & Major areas \\
\hline Refine the means to identify target nerves (eg, real-time electromyography, more reliable stimulation technique). & $\begin{array}{l}\text { Develop safer and more efficient means for medial branch RFA (eg, laser } \\
\text { therapy, high-intensity focused ultrasound). }\end{array}$ \\
\hline Determine the best way to prevent major and minor complications (eg, nerve injury, neuritis). & $\begin{array}{l}\text { Identify ways to prolong benefit from RFA (eg, by injecting factors that } \\
\text { inhibit nerve regeneration). }\end{array}$ \\
\hline $\begin{array}{l}\text { Identify non-ablative treatments for lumbar facet arthropathy (eg, tools to identify responders to IA steroids or to } \\
\text { prolong benefit from steroids, pharmacotherapy, integrative treatments). }\end{array}$ & $\begin{array}{l}\text { Develop tools (eg, imaging, biomarkers, questionnaires) to identify painful } \\
\text { facet joints. }\end{array}$ \\
\hline Perform comparative-effectiveness studies to determine the optimal selection criteria and technique. & $\begin{array}{l}\text { Develop predictive modeling tools (ie, the use of history, examination } \\
\text { findings, psychosocial metrics and imaging) to improve prognosis and } \\
\text { better foretell outcomes. }\end{array}$ \\
\hline $\begin{array}{l}\text { Enhance precision of diagnostic blocks (eg, identify optimal injection volumes, number and types of blocks, amount } \\
\text { of LA, needle location, needle size). }\end{array}$ & $\begin{array}{l}\text { Investigate role of regenerative therapies in reducing or reversing pain } \\
\text { from arthritic facet joints. }\end{array}$ \\
\hline
\end{tabular}

IA, intra-articular; LA, local anesthetic; RFA, radiofrequency ablation

but sent representatives (the US Army Pain Medicine Consultant to the Surgeon General and the Director of Interventional Pain Management) to participate in guideline development, and they concurred with all recommendations.

\section{CONCLUSIONS}

In summary, these multiorganizational facet intervention guidelines are meant to serve as a blueprint to guide care in an era characterized by increasingly polarized views, where there is often a lack of communication between parties with different opinions. These guidelines should not be misconstrued as unalterable standards, nor can they account for every possible variation in presentation or treatment circumstance. Similar to all facets of medicine, the decision about when to implement treatment, how to interpret treatment outcomes and how best to weigh risks and benefits based on unique patient considerations should be made on an individualized basis (ie, personalized medicine) after sufficient discussion with the patient. As has been alluded to previously, evidence-based pain medicine should include consideration of the best-available research, and take into account clinical experience and expertise, as well as patient values and preferences. ${ }^{344}$

\section{Author affiliations}

${ }^{1}$ Anesthesiology, Pain Medicine Division, Johns Hopkins School of Medicine, Baltimore, Maryland, USA

${ }^{2}$ Anesthesiology, Imperial College Healthcare NHS Trust Haemodialysis Clinic Hayes Satellite Unit, Hayes, UK

${ }^{3}$ Anesthesia and Pain Management, University of Toronto and University Health

Network - Toronto Western Hospital, Toronto, Ontario, Canada

${ }^{4}$ Anesthesiology, Rush University Medical Center, Chicago, Illinois, USA

${ }^{5}$ Spine \& Nerve Centers, Charleston, West Virginia, USA

${ }^{6}$ Anesthesiology, University of Cincinnati College of Medicine, Cincinnati, Ohio, USA

Anesthesiology, Mayo Clinic, Rochester, Minnesota, USA

${ }^{8}$ Anesthesiology, Wake Forest School of Medicine, Winston-Salem, North Carolina, USA

${ }^{9}$ Physical Medicine \& Rehabilitation, Vanderbilt University School of Medicine, Nashville, Tennessee, USA

${ }^{10}$ Anesthesiology, Tripler Army Medical Center, Tripler Army Medical Center, Hawaii, USA

${ }^{11}$ Dept of Anesthesiology, Seoul National University College of Medicine, Seoul, The Republic of Korea

${ }^{12}$ Center for Pain Medicine, Summa Western Reserve Hospital, Cuyahoga Falls, Ohio, USA

${ }^{13}$ Dept of Physical Medicine and Rehabilitation, VA Greater Los Angeles Healthcare System, Los Angeles, California, USA

${ }^{14}$ Pain Diagnostics and Interventional Care, Sewickley, Pennsylvania, USA

${ }^{15}$ Carolinas Pain Institute, Winston Salem, North Carolina, USA

${ }^{16}$ Advanced Pain Therapy, Hattiesburg, Mississippi, USA

${ }^{17}$ Dept. of Orthopaedic Surgery, Division of Physical Medicine \& Rehabilitation, Stanford Medicine, Stanford, California, USA

${ }^{18}$ Anesthesiology, Critical Care and Multidisciplinary Pain Center, Ziekenhuis OostLimburg, Lanaken, Belgium
${ }^{19}$ Anesthesiology and Pain Medicine, Maastricht University Medical Center, Maastricht, The Netherlands

${ }^{20}$ Anesthesiology, Duke Medicine, Durham, North Carolina, USA

${ }^{21}$ Anesthesiology, UCSD Medical Center-Thornton Hospital, San Diego, California, USA

${ }^{22}$ Neurology, VA Healthcare Center District of Columbia, Washington, District of Columbia, USA

Twitter Asokumar Buvanendran @Kumar_ASRA,Tim Deer @doctdeer and Samer Narouze @NarouzeMD

Acknowledgements The authors would like to thank Angie Stengel for her administrative assistance in coordinating conference calls and outreach to participating organizations, and Zared 0 . Cohen for his assistance with reference checking.

Contributors SPC's institution has received research funding from Avanos, and in the past 3 years he has served as a consultant for Abbott and Medtronic. SPC: concept design, committee chair, developed initial list of questions and outline, participated in writing and editing manuscript. Other authors: assisted with refinement of questions, participated in writing and editing manuscript.

Funding This work was supported in part by the Uniformed Services University, Department of Physical Medicine \& Rehabilitation, Musculoskeletal Injury Rehabilitation Research for Operational Readiness (MIRROR) (HU00011920011). The American Society of Regional Anesthesia and Pain Medicine contracted with Sarah Staples, MA, ELS, for assistance with manuscript preparation. Dr Cohen received funding for his role from MIRROR, Uniformed Services University of the Health Sciences, US Department of Defense.

Disclaimer Since the document has neither been presented to nor approved by either the ASA Board of Directors or House of Delegates, it is not an official or approved statement or policy of the Society. Variances from the recommendations contained in the document may be acceptable based on the judgment of the responsible anesthesiologist. The views expressed do not reflect the official policy or position of the Department of Defense, the Department of Veterans Affairs or the US Government.

Competing interests TD: consultant for Abbott, Axonics, Nalu, Saluda, Medtronic, Vertiflex (Boston Scientific), Nevro, Vertos, Vertiflex, SPR. Funded research: Vertiflex, Vertos, Abbott, Saluda, SPR. Minor Equity: Bioness, Vertiflex, Vertos, Saluda, SPR. SPC: funded research: Avanos Consultant: Abbott, Medtronic, Boston Scientific David Provenzano: consultant for Avanos, Boston Scientific, Medtronic, Nevro, Esteve and Salix Research support: Medtronic, Nevro, Stimgenics and Abbott.

Patient consent for publication Not required.

Provenance and peer review Not commissioned; externally peer reviewed.

Open access This is an open access article distributed in accordance with the Creative Commons Attribution Non Commercial (CC BY-NC 4.0) license, which permits others to distribute, remix, adapt, build upon this work non-commercially, and license their derivative works on different terms, provided the original work is properly cited, an indication of whether changes were made, and the use is noncommercial. See: http://creativecommons.org/licenses/by-nc/4.0/.

\section{ORCID iDs}

Steven P Cohen http://orcid.org/0000-0001-5928-2127

W Michael Hooten http://orcid.org/0000-0001-5645-6355

Jan van Zundert http://orcid.org/0000-0002-5389-2036 


\section{REFERENCES}

1 Falco FJE, Manchikanti L, Datta S, et al. An update of the systematic assessment of the diagnostic accuracy of lumbar facet joint nerve blocks. Pain Physician 2012;15:E869-907

2 Long DM, BenDebba M, Torgerson WS, et al. Persistent back pain and sciatica in the United States: patient characteristics. J Spinal Disord 1996;9:40-58.

3 Ko S, Vaccaro AR, Lee $S$, et al. The prevalence of lumbar spine facet joint osteoarthritis and its association with low back pain in selected Korean populations. Clin Orthop Surg 2014;6:385-91.

4 Kalichman L, Li L, Kim DH, et al. Facet joint osteoarthritis and low back pain in the community-based population. Spine 2008:33:2560-5

5 Kalichman L, Kim DH, Li L, et al. Computed tomography-evaluated features of spinal degeneration: prevalence, intercorrelation, and association with self-reported low back pain. Spine J 2010;10:200-8.

6 Cohen SP, Strassels SA, Kurihara C, et al. Establishing an optimal "cutoff" threshold for diagnostic lumbar facet blocks: a prospective correlational study. Clin J Pain 2013;29:382-91.

7 Cohen SP, Williams KA, Kurihara C, et al. Multicenter, randomized, comparative cost-effectiveness study comparing 0,1 , and 2 diagnostic medial branch (facet joint nerve) block treatment paradigms before lumbar facet radiofrequency denervation. Anesthesiology 2010;113:395-405.

8 Derby R, Melnik I, Lee J-E, et al. Correlation of lumbar medial branch neurotomy results with diagnostic medial branch block cutoff values to optimize therapeutic outcome. Pain Med 2012;13:1533-46.

9 Derby R, Melnik I, Choi J, et al. Indications for repeat diagnostic medial branch nerve blocks following a failed first medial branch nerve block. Pain Physician 2013;16:479-88.

10 Bogduk N, Holmes S. Controlled zygapophysial joint blocks: the travesty of costeffectiveness. Pain Med 2000;1:24-34.

11 Novak S, Nemeth WC. Re: cost-effectiveness of diagnostic medial branch blocks before radiofrequency denervation. The Spine Journal 2008;8:412-3.

12 Manchikanti L, Hirsch JA, Pampati V, et al. Utilization of facet joint and sacroiliac joint interventions in Medicare population from 2000 to 2014: explosive growth continues! Curr Pain Headache Rep 2016;20:58.

13 Starr JB, Gold L, McCormick Z, et al. Trends in lumbar radiofrequency ablation utilization from 2007 to 2016. Spine J 2019;19:1019-28.

14 Cohen SP, Huang JHY, Brummett C. Facet joint pain —advances in patient selection and treatment. Nat Rev Rheumatol 2013:9:101-16.

15 DePalma MJ, Ketchum JM, Saullo TR. Multivariable analyses of the relationships between age, gender, and body mass index and the source of chronic low back pain. Pain Med 2012;13:498-506

16 International Spine Intervention Society. Lumbar medial branch blocks. In: Bogduk N ed. Practice guidelines for spinal diagnostic and treatment procedures. 2nd edn. San Francisco: International Spine Intervention Society, 2013: 457-88.

17 Juch JNS, Maas ET, Ostelo RWJG, et al. Effect of radiofrequency denervation on pain intensity among patients with chronic low back pain: the mint randomized clinical trials. JAMA 2017;318:68-81.

18 Cohen SP, Doshi TL, Constantinescu OC, et al. Effectiveness of lumbar facet joint blocks and their predictive value before radiofrequency denervation: the face treatment study (FACTS). Anesthesiology 2018;129:517-35.

19 van Tilburg CWJ, Stronks DL, Groeneweg JG, et al. Randomised sham-controlled double-blind multicentre clinical trial to ascertain the effect of percutaneous radiofrequency treatment for lumbar facet joint pain. Bone Joint J 2016;98B:1526-33.

20 Belgian Health Care Knowledge Centre. Low back pain and radicular pain: assessment and management, 2017. Available: https://kce.fgov.be/sites/default/files/ atoms/files/KCE_287_Low_back_pain_Report.pdf [Accessed 5 Aug 2019].

21 United Kingdom National Institute for Health \& Care Excellence. Low back pain and sciatica in over 16S: assessment and management: invasive treatments. NICE guideline NG59. A., 2016. Available: https://www.nice.org.uk/guidance/ng59/ evidence/full-guideline-invasive-treatments-pdf-2726157998 [Accessed 5 Aug 2019].

22 Institute of Health Economics, Alberta, Canada. Evidence-Informed primary care management of low back pain. clinical practice guideline, 3 edition, 2015. Available: http://www.topalbertadoctors.org/download/1885/LBPguideline.pdf? 20160225091721 [Accessed 5 Aug 2019].

23 Dreyfuss $\mathrm{P}$, Halbrook B, Pauza K, et al. Efficacy and validity of radiofrequency neurotomy for chronic lumbar zygapophysial joint pain. Spine 2000;25:1270-7.

24 van Kuijk SMJ, van Zundert J, Hans G, et al. Flawed Study Design and Incorrect Presentation of Data Negatively Impact Potentially Useful Interventional Treatments for Patients with Low Back Pain: A Critical Review of JAMA 's MinT Study. Pain Pract 2018; 18:292-5.

25 McCormick ZL, Vorobeychik Y, Gill JS, et al. Guidelines for composing and assessing a paper on the treatment of pain: a practical application of evidencebased medicine principles to the mint randomized clinical trials. Pain Med 2018;19:2127-37
26 Juch JNS, Maas ET, Ostelo RWJG, Kapural L, Provenzano D, Narouze S, et al. Effect of radiofrequency denervation on pain intensity among patients with chronic low back pain: the mint randomized clinical trials. JAMA 2017;318:68-81.

27 Provenzano DA, Buvanendran A, de León-Casasola OA, et al. Interpreting the mint randomized trials evaluating radiofrequency ablation for lumbar facet and sacroiliac joint pain: a call from ASRA for better education, study design, and performance. Reg Anesth Pain Med 2018;43:68-71

28 U.S. department of health and human services, pain management best practices Interagency Task force. Pain management best practices Interagency Task force report: updates, gaps, inconsistencies and recommendations. Available: https:// www.hhs.gov/sites/default/files/pmtf-final-report-2019-05-23.pdf [Accessed $21 \mathrm{Sep}$ 2019].

29 U.S. preventive services Task force. grade definitions. Available: https://www.usp eventiveservicestaskforce.org/Page/Name/grade-definitions [Accessed 3 Nov 2017].

30 Cohen SP, Bhatia A, Buvanendran A, et al. Consensus guidelines on the use of intravenous ketamine infusions for chronic pain from the American Society of regional anesthesia and pain medicine, the American Academy of pain medicine, and the American Society of Anesthesiologists. Reg Anesth Pain Med 2018;43:1-46

31 Helm li S, Simopoulos TT, Stojanovic M, et al. Effectiveness of thermal annular procedures in treating discogenic low back pain. Pain Physician 2017;20:447-70.

32 Deer TR, Pope JE, Hayek SM, et al. The Polyanalgesic consensus conference (PacC): recommendations for intrathecal drug delivery: guidance for improving safety and mitigating risks. Neuromodulation 2017;20:155-76.

33 Deer TR, Narouze S, Provenzano DA, et al. The neurostimulation appropriateness consensus Committee (NACC): recommendations on bleeding and coagulation management in neurostimulation devices. Neuromodulation 2017:20:51-62.

34 Oxford centre for evidence-based medicine - levels of evidence (March 2009). Available: http://www.cebm.net/blog/2009/06/11/oxford-centre-evidence-basedmedicine-levels-evidence-march-2009 [Accessed 15 Jan 2018].

35 The grade Working Group. grade, 2016. Available: www.gradeworkinggroup.org [Accessed 18 Jan 2018].

36 Cohen SP, Wallace MS, Rauck RL, et al. Unique aspects of clinical trials of of invasive therapies for chronic pain: an ACTTION evidence-based review. Pain Rep 2019;4:e687.

37 Fairbank JCT, Park WM, McCALL IW, et al. Apophyseal injection of local anesthetic as a diagnostic aid in primary low-back pain syndromes. Spine 1981;6:598-605.

38 Helbig T, Lee CK. The lumbar facet syndrome. Spine 1988;13:61-4.

39 Jackson RP, Jacobs RR, Montesano PX. 1988 Volvo award in clinical sciences. facet joint injection in low-back pain. A prospective statistical study. Spine 1988;13:966-71.

40 Lewinnek GE, Warfield CA. Facet joint degeneration as a cause of low back pain. Clin Orthop Relat Res 1986:216???2222.

41 Lilius G, Laasonen EM, Myllynen P, et al. Lumbar facet joint syndrome. A randomised clinical trial. J Bone Joint Surg Br 1989;71:681-4.

42 Schwarzer AC, Aprill CN, Derby R, et al. Clinical features of patients with pain stemming from the lumbar zygapophysial joints. is the lumbar facet syndrome a clinical entity? Spine 1994;19:1132-7.

43 Schwarzer AC, Wang SC, Bogduk N, et al. Prevalence and clinical features of lumbar zygapophysial joint pain: a study in an Australian population with chronic low back pain. Ann Rheum Dis 1995;54:100-6.

44 Revel ME, Listrat VM, Chevalier XJ, et al. Facet joint block for low back pain: identifying predictors of a good response. Arch Phys Med Rehabil 1992;73:824-8.

45 Revel M, Poiraudeau S, Auleley GR, et al. Capacity of the clinical picture to characterize low back pain relieved by facet joint anesthesia. proposed criteria to identify patients with painful facet joints. Spine 1998;23:1972-6.

46 Young S, Aprill C, Laslett M. Correlation of clinical examination characteristics with three sources of chronic low back pain. The Spine Journal 2003;3:460-5.

47 Laslett M, Öberg B, Aprill CN, et al. Zygapophysial joint blocks in chronic low back pain: a test of Revel's model as a screening test. BMC Musculoskelet Disord 2004:5:43.

48 Laslett M, McDonald B, Aprill CN, et al. Clinical predictors of screening lumbar zygapophyseal joint blocks: development of clinical prediction rules. The Spine Journal 2006;6:370-9.

49 DePalma MJ, Ketchum JM, Trussell BS, et al. Does the location of low back pain predict its source? Pm R 2011;3:33-9.

50 Manchikanti L, Pampati V, Fellows B, et al. Prevalence of lumbar facet joint pain in chronic low back pain. Pain Physician 1999;2:59-64

51 Manchikanti L, Pampati V, Fellows B, et al. The inability of the clinical picture to characterize pain from facet joints. Pain Physician 2000;3:158-66.

52 Manchikanti L, Pampati V, Fellows B, et al. The diagnostic validity and therapeutic value of lumbar facet joint nerve blocks with or without adjuvant agents. Curr Rev Pain 2000;4:337-44.

53 Dolan AL, Ryan PJ, Arden NK, et al. The value of SPECT scans in identifying back pain likely to benefit from facet joint injection. Br J Rheumatol 1996;35:1269-73.

54 Cohen SP, Hurley RW, Christo PJ, et al. Clinical predictors of success and failure for lumbar facet radiofrequency denervation. Clin J Pain 2007;23:45-52 
55 Streitberger K, Müller T, Eichenberger U, et al. Factors determining the success of radiofrequency denervation in lumbar facet joint pain: a prospective study. Eur Spine J 2011;20:2160-5.

56 Conger A, Burnham T, Salazar F, et al. The effectiveness of radiofrequency ablation of medial branch nerves for chronic lumbar facet joint syndrome in patients selected by guideline-concordant dual comparative medial branch blocks. Pain Med 2019:pii: pnz248.

57 Cohen SP, Doshi TL, Kurihara C, et al. Nonorganic signs and their association with interventional treatment outcomes for low back pain. Anesth Analg 2020.

58 lanuzzi A, Little JS, Chiu JB, et al. Human lumbar facet joint capsule strains: I. during physiological motions. Spine J 2004;4:141-52.

59 Petersen T, Laslett M, Juhl C. Clinical classification in low back pain: best-evidence diagnostic rules based on systematic reviews. BMC Musculoskelet Disord 2017:18:188.

60 Boswell MV, Manchikanti L, Kaye AD, et al. A best-evidence systematic appraisal of the diagnostic accuracy and utility of facet (zygapophysial) joint injections in chronic spinal pain. Pain Physician 2015;18:E497-533.

61 Ackerman WE, Ahmad M. Pain relief with intraarticular or medial branch nerve blocks in patients with positive lumbar facet joint SPECT imaging: a 12-week outcome study. South Med J 2008;101:931-4.

62 Freiermuth D, Kretzschmar M, Bilecen D, et al. Correlation of ${ }^{(99 m)}$ Tc-DPD SPECT/ CT scan findings and diagnostic blockades of lumbar medial branches in patients with unspecific low back pain in a Randomized-Controlled trial. Pain Med 2015;16:1916-22.

63 Holder LE, Machin JL, Asdourian PL, et al. Planar and high-resolution SPECT bone imaging in the diagnosis of facet syndrome. J Nucl Med 1995;36:37-44.

64 Jain A, Jain S, Agarwal A, et al. Evaluation of efficacy of bone scan with SPECT/CT in the management of low back pain: a study supported by differential diagnostic local anesthetic blocks. Clin J Pain 2015;31:1054-9.

65 Koh WU, Kim SH, Hwang BY, et al. Value of bone scintigraphy and single photon emission computed tomography (SPECT) in lumbar facet disease and prediction of short-term outcome of ultrasound guided medial branch block with bone SPECT. Korean J Pain 2011:24:81-6.

66 Pneumaticos SG, Chatziioannou SN, Hipp JA, et al. Low back pain: prediction of short-term outcome of facet joint injection with bone scintigraphy. Radiology 2006;238:693-8.

67 Schwarzer AC, Wang S-chang, O'Driscoll D, et al. The ability of computed tomography to identify a painful zygapophysial joint in patients with chronic low back pain. Spine 1995;20:907-12.

68 Stojanovic MP, Sethee J, Mohiuddin M, et al. Mri analysis of the lumbar spine: can it predict response to diagnostic and therapeutic facet procedures? Clin J Pain 2010;26:110-5.

69 Cohen SP, Bajwa ZH, Kraemer JJ, et al. Factors predicting success and failure for cervical facet radiofrequency denervation: a multi-center analysis. Reg Anesth Pain Med 2007;32:495-503.

70 Sawicki LM, Schaarschmidt BM, Heusch P, et al. Value of ${ }^{18}$ F-FDG PET/MRI for the outcome of CT-guided facet block therapy in cervical facet syndrome: initial results. $J$ Med Imaging Radiat Oncol 2017:61:327-33.

71 Lin I, Wiles L, Waller R, et al. What does best practice care for musculoskeletal pain look like? eleven consistent recommendations from high-quality clinical practice guidelines: systematic review. Br J Sports Med 2019.

72 Arnold E, La Barrie J, DaSilva L, et al. The effect of timing of physical therapy for acute low back pain on health services utilization: a systematic review. Arch Phys Med Rehabil 2019;100:1324-38.

73 VA/DoD clinical practice guideline for diagnosis and treatment of low back pain, 2017. Available: https://www.healthquality.va.gov/guidelines/Pain/lbp/ VADoDLBPCPG092917.pdf [Accessed 9 Sep 2019].

74 AIM Specialty Health. Musculoskeletal Program Clinical Appropriateness Guidelines. Interventional Pain Management, 2019. Available: http://www.aimspecialtyhealth. com/PDF/Guidelines/2019/Jan01/AIM_Guidelines_MSK_Interventional-PainManagement.pdf [Accessed 9 Sep 2019].

75 Slade SC, Kent P, Patel S, et al. Barriers to primary care clinician adherence to clinical guidelines for the management of low back pain: a systematic review and metasynthesis of qualitative studies. Clin J Pain 2016;32:800-16.

76 Zheng P, Kao M-C, Karayannis NV, et al. Stagnant physical therapy referral rates alongside rising opioid prescription rates in patients with low back pain in the United States 1997-2010. Spine 2017:42:670-4

77 North American Spine Society. Nass coverage policy recommendations. facet joint interventions, 2014. Available: https://www.spine.org/Policy-Practice/CoverageRecommendations/About-Coverage-Recommendations [Accessed 9 Sep 2019].

78 BlueCross BlueShield of Tennessee Medical Policy Manual. Diagnosis and treatment of facet joint pain. corporate medical policy, 2018. Available: https://www.bcbst. com/mpmanual/Lumbar_Facet_Steroid_Injections_for_Treatment_of_Low_Back Pain.htm [Accessed 9 Sep 2019].

79 Cuenca-Martínez F, Cortés-Amador S, Espí-López GV. Effectiveness of classic physical therapy proposals for chronic non-specific low back pain: a literature review. Phys Ther Res 2018;21:16-22.
80 Miyamoto GC, Lin C-WC, Cabral CMN, et al. Cost-Effectiveness of exercise therapy in the treatment of non-specific neck pain and low back pain: a systematic review with meta-analysis. Br J Sports Med 2019;53:172-81.

81 van Kleef M, Barendse GAM, Kessels A, et al. Randomized trial of radiofrequency lumbar facet denervation for chronic low back pain. Spine 1999;24:1937-42.

82 Nath S, Nath CA, Pettersson K, et al. Percutaneous lumbar zygapophysial (facet) joint neurotomy using radiofrequency current, in the management of chronic low back pain: a randomized double-blind trial. Spine 2008;33:1291-7.

83 Tekin I, Mirzai H, Ok G, et al. A comparison of conventional and pulsed radiofrequency denervation in the treatment of chronic facet joint pain. Clin J Pain 2007:23:524-9.

84 van Wijk RMAW, Geurts JWM, Wynne HJ, et al. Radiofrequency denervation of lumbar facet joints in the treatment of chronic low back pain: a randomized, doubleblind, sham lesion-controlled trial. Clin J Pain 2005;21:335-44.

85 Leclaire R, Fortin L, Lambert $\mathrm{R}$, et al. Radiofrequency facet joint denervation in the treatment of low back pain: a placebo-controlled clinical trial to assess efficacy. Spine 2001:26:1411-7.

86 Cohen SP, Hayek S, Semenov Y, et al. Epidural steroid injections, conservative treatment, or combination treatment for cervical radicular pain: a multicenter, randomized, comparative-effectiveness study. Anesthesiology 2014; 121:1045-55

87 Bernstein IA, Malik Q, Carville S, et al. Low back pain and sciatica: summary of NICE guidance. BMJ 2017;356:i6748.

88 Jonckheer $\mathrm{P}$, Desomer A, Depreitere B, et al. Low back pain and radicular pain development of a clinical pathway. in: (KCE). HSRHBBHCKC, ED. KCE report 295 s. Brussels, 2017.

89 Wai EK, Rodriguez S, Dagenais S, et al. Evidence-Informed management of chronic low back pain with physical activity, smoking cessation, and weight loss. Spine J 2008;8:195-202

90 Foster NE, Anema JR, Cherkin D, et al. Prevention and treatment of low back pain: evidence, challenges, and promising directions. The Lancet 2018;391:2368-83.

91 Rathmell JP, Manion SC. The role of image guidance in improving the safety of pain treatment. Curr Pain Headache Rep 2012:16:9-18.

92 Purcell-Jones G, Pither CE, Justins DM. Paravertebral somatic nerve block: a clinical, radiographic, and computed tomographic study in chronic pain patients. Anesth Analg 1989;68:32-9.

93 Cohen SP. Postdural puncture headache and treatment following successful lumbar facet block. Pain Digest 1994;4:283-4.

94 Levinson DR. Medicare payments for facet joint injection services. Department of health and human services office of Inspector General on Medicare payments fo facet joint injection services, 2008. Available: http://oig.hhs.gov/oei/reports/oei-0507-00200.pdf [Accessed 9 Sep 2019].

95 Noridian Healthcare Solutions, LLC. Local coverage determination (LCD): facet joint injections, medial branch blocks, and facet joint radiofrequency neurotomy (L34995) 2018. Available: https://med.noridianmedicare.com/documents/10546/6990983/ Facet+Joint+Injections\%2C\%20Medial+Branch+Blocks\%2C\%2oand+Facet+ JOint+Radiofrequency+Neurotomy+LCD/4ec8edd6-7205-4697-8bfa-f7e482e08b3e [Accessed 9 Sep 2019].

96 Cigna Medical Coverage Policies. Musculoskeletal facet joint Injections/Medial branch blocks, 2019. Available: https://www.evicore.com/-/media/files/evicore/ provider/network-standard/cmm-201-facet-joint-injections.pdf [Accessed 9 Sep 2019].

97 UnitedHealthcare Commercial Medical Policy. Epidural steroid and facet joint injections for spinal pain. policy number: 2019T0004FF. effective date, 2019. Available: https://www.uhcprovider.com/content/dam/provider/docs/public/policies/ comm-medical-drug/epidural-steroid-facet-injections-spinal-pain.pdf [Accessed 9 Sep 2019].

98 Cohen SP, Strassels SA, Kurihara C, et al. Randomized study assessing the accuracy of cervical facet joint nerve (medial branch) blocks using different injectate volumes. Anesthesiology 2010;112:144-52.

99 Dreyfuss P, Schwarzer AC, Lau P, et al. Specificity of lumbar medial branch and L5 dorsal ramus blocks. A computed tomography study. Spine 1997;22:895-902.

100 Lynch MC, Taylor JF. Facet joint injection for low back pain. A clinical study. J Bone Joint Surg Br 1986;68-B:138-41.

101 Weininger M, Mills JC, Rumboldt Z, et al. Accuracy of CT guidance of lumbar facet joint block. AJR Am J Roentgenol 2013;200:673-6.

102 Ye L, Wen C, Liu H. Ultrasound-Guided versus low dose computed tomography scanning guidance for lumbar facet joint injections: same accuracy and efficiency. BMC Anesthesiol 2018;18:160.

103 Feigl GC, Dreu M, Kastner M, et al. Thermocoagulation of the medial branch of the dorsal branch of the Lumbal spinal nerve: Flouroscopy versus CT. Pain Med 2017:18:36-40.

104 Sites BD, Chan VW, Neal JM, et al. The American Society of regional anesthesia and pain medicine and the European Society of regional anaesthesia and pain therapy joint Committee recommendations for education and training in ultrasound-guided regional anesthesia. Reg Anesth Pain Med 2010;35:S74-80.

105 Wang D. Image guidance technologies for interventional pain procedures: ultrasound, fluoroscopy, and CT. Curr Pain Headache Rep 2018;22:6 
106 Kennedy DJ, Mattie R, Scott Hamilton A, et al. Detection of intravascular injection during lumbar medial branch blocks: a comparison of aspiration, live fluoroscopy, and digital subtraction technology. Pain Med 2016;17:pnv073-6.

107 Greher M, Kirchmair L, Enna B, et al. Ultrasound-Guided lumbar facet nerve block: accuracy of a new technique confirmed by computed tomography. Anesthesiology 2004;101:1195-200.

108 Greher M, Scharbert G, Kamolz L, et al. Ultrasound-Guided lumbar facet nerve block: a sonoanatomic study of a new methodologic approach. Anesthesiology 2004; 100:1242-8.

109 Han SH, Park KD, Cho KR, et al. Ultrasound versus fluoroscopy-guided medial branch block for the treatment of lower lumbar facet joint pain. Medicine 2017:96:e6655.

110 Wu T, Zhao W-hua, Dong Y, et al. Effectiveness of ultrasound-guided versus fluoroscopy or computed tomography scanning guidance in lumbar facet joint injections in adults with facet joint syndrome: a meta-analysis of controlled trials. Arch Phys Med Rehabil 2016;97:1558-63.

111 Galiano K, Obwegeser AA, Bodner G, et al. Ultrasound guidance for facet joint injections in the lumbar spine: a computed tomography-controlled feasibility study. Anesth Analg 2005;101:579-83.

112 Galiano K, Obwegeser AA, Walch C, et al. Ultrasound-Guided versus computed tomography-controlled facet joint injections in the lumbar spine: a prospective randomized clinical trial. Reg Anesth Pain Med 2007;32:317-22.

113 Gofeld M, Bristow SJ, Chiu S. Ultrasound-Guided injection of lumbar zygapophyseal joints: an anatomic study with fluoroscopy validation. Reg Anesth Pain Med 2012;37:228-31

$114 \mathrm{Ha}$ DH, Shim DM, Kim TK, et al. Comparison of ultrasonography- and fluoroscopyguided facet joint block in the lumbar spine. Asian Spine J 2010;4:15-22.

115 Hales CM, Carroll MD, Fryar CD, et al. Prevalence of obesity among adults and youth: United States, 2015-2016. Atlanta, GA: U.S. Centers for Disease Control and Prevention. NCHS Data Brief No. 288, 2017. https://www.cdc.gov/nchs/products/ databriefs/db288.htm

116 Rauch S, Kasuya Y, Turan A, et al. Ultrasound-Guided lumbar medial branch block in obese patients: a fluoroscopically confirmed clinical feasibility study. Reg Anesth Pain Med 2009;34:340-2.

117 Cohen SP, Raja SN. Pathogenesis, diagnosis, and treatment of lumbar zygapophysial (facet) joint pain. Anesthesiology 2007;106:591-614.

118 Greher M, Moriggl B, Peng PWH, et al. Ultrasound-Guided approach for L5 dorsal ramus block and fluoroscopic evaluation in unpreselected cadavers. Reg Anesth Pain Med 2015:40:713-7.

119 Heo J-Y, Lee J-W, Kim C-H, et al. The validation of ultrasound-guided target segment identification in thoracic spine as confirmed by fluoroscopy. Clin Orthop Surg 2017;9:472-9.

120 Mahato NK. Facet dimensions, orientation, and symmetry at L5-S1 junction in lumbosacral transitional states. Spine 2011;36:E569-73.

121 Gofeld M, Brown MN, Bollag L, et al. Magnetic positioning system and ultrasound guidance for lumbar Zygapophysial radiofrequency neurotomy. Reg Anesth Pain Med 2014;39:61-6.

$122 \mathrm{NCI}$ dictionary of cancer terms. Available: https://www.cancer.gov/publications/ dictionaries/cancer-terms/def/diagnosis [Accessed 1 Apr 2019].

123 Hogan QH, Abram SE. Neural blockade for diagnosis and prognosis. Anesthesiology 1997:86:216-41.

124 Thomas M, Eriksson SV, Lundeberg T. A comparative study of diazepam and acupuncture in patients with osteoarthritis pain: a placebo controlled study. Am J Chin Med 1991;19:95-100.

125 de Craen AJM, Tijssen JGP, de Gans J, et al. Placebo effect in the acute treatment of migraine: subcutaneous placebos are better than oral placebos. J Neurol 2000;247:183-8.

126 Saito T, Steinke H, Miyaki T, et al. Analysis of the posterior ramus of the lumbar spinal nerve: the structure of the posterior ramus of the spinal nerve. Anesthesiology 2013;118:88-94.

127 Kaplan M, Dreyfuss P, Halbrook B, et al. The ability of lumbar medial branch blocks to anesthetize the zygapophysial joint. Spine 1998;23:1847-52.

128 Auteroche P. Innervation of the zygapophyseal joints of the lumbar spine. Anat Clin 1983:5:17-28.

129 Bogduk N. A commentary on appropriate use criteria for sacroiliac pain. Pain Med 2017:18:2055-7.

130 Curatolo M, Bogduk N. Diagnostic blocks for chronic pain. Scand J Pain 2010;1:186-92.

131 Brummett C, Cohen S. Pathogenesis, diagnosis, and treatment of zygapophyseal (facet) joint pain. In: Benzon H, ed. Practical management of pain. 5th ed. Philadephia: Elsevier, 2014.

132 Ackerman WE, Munir MA, Zhang J-M, et al. Are diagnostic lumbar facet injections influenced by pain of muscular origin? Pain Pract 2004;4:286-91.

133 Cohen SP, Larkin TM, Chang AS, et al. The causes of false-positive medial branch (facet joint) blocks in soldiers and retirees. Mil Med 2004;169:781-6.

134 Cohen SP, Moon JY, Brummett CM, et al. Medial branch blocks or intra-articular injections as a prognostic tool before lumbar facet radiofrequency denervation: a multicenter, case-control study. Reg Anesth Pain Med 2015;40:376-83.
135 Holz SC, Sehgal N. What is the correlation between facet joint radiofrequency outcome and response to comparative medial branch blocks? Pain Physician 2016;19:163-72.

136 Bogduk N. International spinal injection Society guidelines for the performance of spinal injection procedures. Clin J Pain 1997;13:285-6.

137 Dreyfuss PH, Dreyer SJ, Vaccaro A. Lumbar zygapophysial (facet) joint injections. The Spine Journal 2003:3:50-9

138 Marks RC, Houston T, Thulbourne T. Facet joint injection and facet nerve block: a randomised comparison in 86 patients with chronic low back pain. Pain 1992:49:325-8

139 Nash T. Facet joints: intra-articular steroids or nerve block? Pain Clinic 1990;3:77-82.

140 Schwarzer AC, Aprill CN, Derby R, et al. The relative contributions of the disc and zygapophyseal joint in chronic low back pain. Spine 1994;19:801-6.

141 Li J, Muehleman C, Abe Y, et al. Prevalence of facet joint degeneration in association with intervertebral joint degeneration in a sample of organ donors. J. Orthop. Res. 2011:29:1267-74.

142 van Zundert J, Vanelderen P, Kessels A, et al. Radiofrequency treatment of facetrelated pain: evidence and controversies. Curr Pain Headache Rep 2012:16:19-25.

143 Verrills P, Mitchell B, Vivian D, et al. The incidence of intravascular penetration in medial branch blocks: cervical, thoracic, and lumbar spines. Spine 2008:33:E174-7.

144 Greater Manchester Combined Authority. Greater Manchester Eur policy statement on: facet joint injections GM Ref: GM070, version: 2.1 (1 October 2018). Available: http://northwestcsu.nhs.uk/BrickwallResource/GetResource/d5f134e0-aab1-4be39475-3f973f126423 [Accessed 30 Aug 2019].

145 Birkenmaier C, Veihelmann A, Trouillier H-H, et al. Medial branch blocks versus pericapsular blocks in selecting patients for percutaneous cryodenervation of lumbar facet joints. Reg Anesth Pain Med 2007;32:27-33.

146 Schütz U, Cakir B, Dreinhöfer K, et al. Diagnostic value of lumbar facet joint injection: a prospective triple cross-over study. PLoS One 2011;6:e27991.

147 Dreyfuss $P$, Stout $A$, Aprill C, et al. The significance of multifidus atrophy after successful radiofrequency neurotomy for low back pain. PM\&R 2009;1:719-22

148 Wu PB, Date ES, Kingery WS. The lumbar multifidus muscle in polysegmentally innervated. Electromyogr Clin Neurophysiol 2000;40:483-5.

149 Barbieri M, Bellini M. Radiofrequency neurotomy for the treatment of chronic pain: interference with implantable medical devices. Anestezjol Intens Ter 2014;46:162-5.

150 Osborne MD. Radiofrequency neurotomy for a patient with deep brain stimulators: proposed safety guidelines: table 1. Pain Med 2009:10:1046-9.

151 Smith HS, Colson J, Sehgal N. An update of evaluation of intravenous sedation on diagnostic spinal injection procedures. Pain Physician 2013;16:SE217-28.

152 Cucuzzella TR, Delport EG, Kim N, et al. A survey: conscious sedation with epidural and zygapophyseal injections: is it necessary? The Spine Journal 2006;6:364-9.

153 Kim N, Delport E, Cucuzzella T, et al. Is sedation indicated before spinal injections? Spine 2007;32:E748-52.

154 Chou R. Pharmacological management of low back pain. Drugs 2010;70:387-402.

155 Frölich MA, Zhang K, Ness TJ. Effect of sedation on pain perception. Anesthesiology 2013:118:611-21.

156 Manchikanti L, Damron KS, Rivera JJ, et al. Evaluation of the effect of sedation as a confounding factor in the diagnostic validity of lumbar facet joint pain: a prospective, randomized, double-blind, placebo-controlled evaluation. Pain Physician 2004; 7:411-7.

157 Manchikanti L, Pampati V, Damron KS, et al. A randomized, prospective, doubleblind, placebo-controlled evaluation of the effect of sedation on diagnostic validity of cervical facet joint pain. Pain Physician 2004:7:301-9.

158 Manchikanti L, Pampati V, Damron K. The role of placebo and nocebo effects of perioperative administration of sedatives and opioids in interventional pain management. Pain Physician 2005;8:349-55.

159 Manchikanti L, Pampati V, Damron KS, et al. The effect of sedation on diagnostic validity of facet joint nerve blocks: an evaluation to assess similarities in population with involvement in cervical and lumbar regions (ISRCTNo: 76376497). Pain Physician 2006;9:47-51.

160 Cohen SP, Hameed H, Kurihara C, et al. The effect of sedation on the accuracy and treatment outcomes for diagnostic injections: a randomized, controlled, crossover study. Pain Med 2014;15:588-602.

161 Erdek MA, Halpert DE, Fernández MG, et al. Assessment of celiac plexus block and neurolysis outcomes and technique in the management of refractory visceral cancer pain. Pain Med 2010;11:92-100.

162 Dreyfuss $P$, Cohen $S$, Chen AS, et al. Is immediate pain relief after a spinal injection procedure enhanced by intravenous sedation? PM\&R 2009:1:60-3.

163 Kubulus C, Schmitt K, Albert N, et al. Awake, sedated or anaesthetised for regional anaesthesia block placements?: a retrospective registry analysis of acute complications and patient satisfaction in adults. Eur J Anaesthesio 2016:33:715-24.

164 American Society of Anesthesiologists. Statement on anesthetic care during interventional pain procedures for adults. Available: https://www.asahq.org/ standards-and-guidelines/statement-on-anesthetic-care-during-interventional-painprocedures-for-adults [Accessed 25 Mar 2019]. 
165 Spine intervention Society (SIS). conscious sedation. Available: https://www. spineintervention.org/news/386491/New-FactFinder-on-Conscious-Sedation.htm [Accessed 25 Mar 2019].

166 Smith HS, Chopra P, Patel VB, et al. Systematic review of the role of sedation in diagnostic spinal interventional techniques. Pain Physician 2009;12:195-206.

167 Triffterer L, Machata A-M, Latzke D, et al. Ultrasound assessment of cranial spread during caudal blockade in children: effect of the speed of injection of local anaesthetics. Br J Anaesth 2012;108:670-4.

168 Rosenberg PH, Saramies L, Alila A. Lumbar epidural anaesthesia with bupivacaine in old patients: effect of speed and direction of injection. Acta Anaesthesio/ Scand 1981;25:270-4.

169 Gomes S, Drakidis A, Silva P, et al. Spread of fluid: role of tip configurations in needles. Skin Res Technol 2018;24:235-41.

170 Choi J, Kim N, Smuck M, et al. Effect of injectate viscosity on epidural distribution in lumbar transforaminal epidural steroid injection. Pain Res Manag 2019;2019:1-6.

171 Cohen SP, Hurley RW. The ability of diagnostic spinal injections to predict surgical outcomes. Anesth Analg 2007;105:1756-75.

172 Huang JHY, Galvagno SM, Hameed M, et al. Occipital nerve pulsed radiofrequency treatment: a multi-center study evaluating predictors of outcome. Pain Med 2012:13:489-97.

173 Rocha ID, Cristante AF, Marcon RM, et al. Controlled medial branch anesthetic block in the diagnosis of chronic lumbar facet joint pain: the value of a three-month follow-up. Clinics 2014:69:529-34.

174 Manchikanti L, Singh V, Falco FJE, et al. Evaluation of lumbar facet joint nerve blocks in managing chronic low back pain: a randomized, double-blind, controlled trial with a 2-year follow-up. Int J Med Sci 2010;7:124-35.

175 Manchikanti L, Singh V, Falco FJE, et al. Lumbar facet joint nerve blocks in managing chronic facet joint pain: one-year follow-up of a randomized, double-blind controlled trial: clinical trial NCT00355914. Pain Physician 2008;11:121-32

176 Wahezi SE, Alexeev E, Georgy JS, et al. Lumbar medial branch block volumedependent dispersion patterns as a predictor for ablation success: a cadaveric study. PM\&R 2018;10:616-22.

177 Glover JR. Arthrography of the joints of the lumbar vertebral arches. Orthop Clin North Am 1977;8:37-42.

178 Kennedy DJ, Fraiser R, Zheng P, et al. Intra-articular steroids vs saline for lumbar z-joint pain: a prospective, randomized, double-blind placebo-controlled trial. Pain Med 2018

179 Fuchs S, Erbe T, Fischer H-L, et al. Intraarticular hyaluronic acid versus glucocorticoid injections for nonradicular pain in the lumbar spine. J Vasc Interv Radiol 2005; 16:1493-8

180 Carette S, Marcoux S, Truchon R, et al. A controlled trial of corticosteroid injections into facet joints for chronic low back pain. N Engl J Med Overseas Ed 1991;325:1002-7.

181 Dory MA. Arthrography of the lumbar facet joints. Radiology 1981;140:23-7.

182 Moran R, O'Connell D, Walsh MG. The diagnostic value of facet joint injections. Spine 1988:13:1407-10.

183 Bogduk N. The lumbar mamillo-accessory ligament. its anatomical and neurosurgical significance. Spine 1981;6:162-7.

184 Maigne J-Y, Maigne R, Guerin-Surville H. The lumbar mamillo-accessory foramen: a study of 203 lumbosacral spines. Surg Radiol Anat 1991;13:29-32.

185 Barnsley L, Lord SM, Wallis BJ, et al. Lack of effect of intraarticular corticosteroids fo chronic pain in the cervical zygapophyseal joints. N Engl J Med 1994;330:1047-50.

186 Kennedy DJ, Huynh L, Wong J, et al. Corticosteroid injections into lumbar facet joints: a prospective, randomized, double-blind placebo-controlled trial. Am J Phys Med Rehabil 2018:97:741-6

187 Ribeiro LH, Furtado RNV, Konai MS, et al. Effect of facet joint injection versus systemic steroids in low back pain: a randomized controlled trial. Spine 2013;38:1995-2002.

188 Egsmose C, Lund B, Andersen RB. Hip Joint Distension in Osteoarthrosis: A Tripleblind Controlled Study Comparing the Effect of Intra-articular Indoprofen with Placebo. Scand J Rheumatol 1984;13:238-42.

189 Datta S, Lee M, Falco FJE, et al. Systematic assessment of diagnostic accuracy and therapeutic utility of lumbar facet joint interventions. Pain Physician 2009:12:437-60.

190 Coutinho AE, Chapman KE. The anti-inflammatory and immunosuppressive effects of glucocorticoids, recent developments and mechanistic insights. Mol Cell Endocrinol 2011;335:2-13.

191 Aasbjerg K, Torp-Pedersen C, Vaag A, et al. Treating allergic rhinitis with depot-steroid injections increase risk of osteoporosis and diabetes. Respir Med 2013;107:1852-8

192 Kerezoudis P, Rinaldo L, Alvi MA, et al. The effect of epidural steroid injections on bone mineral density and vertebral fracture risk: a systematic review and critical appraisal of current literature. Pain Med 2018;19:569-79.

193 Dworkin RH, Turk DC, Wyrwich KW, et al. Interpreting the clinical importance of treatment outcomes in chronic pain clinical trials: IMMPACT recommendations. J Pain 2008;9:105-21.
194 Fujiwara A, Tamai K, Yamato M, et al. The relationship between facet joint osteoarthritis and disc degeneration of the lumbar spine: an MRI study. Eur Spine $J$ 1999:8:396-401.

195 Weishaupt D, Zanetti M, Hodler J, et al. Mr imaging of the lumbar spine: prevalence of intervertebral disk extrusion and sequestration, nerve root compression, end plate abnormalities, and osteoarthritis of the facet joints in asymptomatic volunteers. Radiology 1998;209:661-6.

196 Cavanaugh JM, Ozaktay AC, Yamashita HT, et al. Lumbar facet pain: biomechanics, neuroanatomy and neurophysiology. J Biomech 1996;29:1117-29.

197 Oken BS. Placebo effects: clinical aspects and neurobiology. Brain 2008:131:2812-23.

198 Kroll HR, Kim D, Danic MJ, et al. A randomized, double-blind, prospective study comparing the efficacy of continuous versus pulsed radiofrequency in the treatment of lumbar facet syndrome. J Clin Anesth 2008;20:534-7.

199 Cohen SP, Stojanovic MP, Crooks M, et al. Lumbar zygapophysial (facet) joint radiofrequency denervation success as a function of pain relief during diagnostic medial branch blocks: a multicenter analysis. Spine J 2008;8:498-504.

200 Cohen SP, Strassels SA, Kurihara C, et al. Outcome predictors for sacroiliac joint (lateral branch) radiofrequency denervation. Reg Anesth Pain Med 2009;34:206-14

201 Manchikanti L, Pampati S, Cash KA. Making sense of the accuracy of diagnostic lumbar facet joint nerve blocks: an assessment of the implications of 50\% relief, $80 \%$ relief, single block, or controlled diagnostic blocks. Pain Physician 2010;13:133-43.

202 Carette S, Leclaire R, Marcoux S, et al. Epidural corticosteroid injections for sciatica due to herniated nucleus pulposus. N Engl J Med 1997:336:1634-40.

203 Friedly JL, Comstock BA, Turner JA, et al. A randomized trial of epidural glucocorticoid injections for spinal stenosis. N Engl J Med 2014;371:11-21.

204 U.S. Food and drug administration center for drug evaluation and research. guidance for industry analgesic indications: developing drug and biological products, 2014. Available: https://www.fda.gov/downloads/drugs/guidancecomplianceregulatoryinfo rmation/guidances/ucm384691.pdf [Accessed 26 Aug 2019].

205 McCormick ZL, Marshall B, Walker J, et al. Long-Term function, pain and medication use outcomes of radiofrequency ablation for lumbar facet syndrome. Int J Anesth Anesth 2015;2:pii: 028.

206 Derby R, Melnik I, Lee J-E, et al. Cost comparisons of various diagnostic medial branch block protocols and medial branch neurotomy in a private practice setting. Pain Med 2013;14:378-91.

207 Carragee EJ, Tanner CM, Khurana S, et al. The rates of false-positive lumbar discography in select patients without low back symptoms. Spine 2000:25:1373-81.

208 Schwarzer AC, Aprill CN, Derby R, et al. The false-positive rate of uncontrolled diagnostic blocks of the lumbar zygapophysial joints. Pain 1994; 58:195-200.

209 Lord SM, Barnsley L, Bogduk N. The utility of comparative local anesthetic blocks versus placebo-controlled blocks for the diagnosis of cervical zygapophysial joint pain. Clin J Pain 1995:11:208-73.

210 Rocha ID, Cristante AF, Marcon RM, et al. Controlled medial branch anesthetic block in the diagnosis of chronic lumbar facet joint Pain: the value of a three-month follow-up. Clinics 2014;69:529-34.

211 Kellegren JH. On the distribution of pain arising from deep somatic structures with charts of segmental pain areas. Clin Sci 1939;4:35-46.

212 Lord SM, Barnsley L, Wallis BJ, et al. Percutaneous radio-frequency neurotomy for chronic cervical zygapophyseal-joint pain. N Engl J Med 1996;335:1721-6.

213 Gallagher J, Petriccione di Vadi PL, Wedley JR, et al. Radiofrequency facet joint denervation in the treatment of low back pain: a prospective controlled double-blind study to assess its efficacy. Pain Clinic 1994;7:193-8

214 van Eerd M, de Meij N, Dortangs E, et al. Long-Term follow-up of cervical facet medial branch radiofrequency treatment with the single posterior-lateral approach: an exploratory study. Pain Pract 2014;14:8-15.

215 McCormick ZL, Reddy R, Korn M, et al. A prospective randomized trial of prognostic genicular nerve blocks to determine the predictive value for the outcome of cooled radiofrequency ablation for chronic knee pain due to osteoarthritis. Pain Med 2018;19:1628-38.

216 MacVicar J, Borowczyk JM, MacVicar AM, et al. Lumbar medial branch radiofrequency neurotomy in New Zealand. Pain Med 2013;14:639-45.

217 Lee $\mathrm{C}-\mathrm{H}$, Chung CK, Kim CH. The efficacy of conventional radiofrequency denervation in patients with chronic low back pain originating from the facet joints: a metaanalysis of randomized controlled trials. Spine $J$ 2017:17:1770-80.

218 Ball RD. The science of conventional and water-cooled monopolar lumbar radiofrequency rhizotomy: an electrical engineering point of view. Pain Physician 2014:17:E175-211.

219 Cohen SP, Rathmell JP. Tackling the technical challenges that hinder the success of facet joint radiofrequency treatment for spinal pain. Reg Anesth Pain Med 2010;35:327-8 
220 Provenzano DA. Think before you inject: understanding electrophysiological radiofrequency principles and the importance of the local tissue environment. Reg Anesth Pain Med 2014;39:269-71.

221 Giles LGF, Taylor JR. Human zygapophyseal joint capsule and synovial fold innervation. Rheumatology 1987;26:93-8.

222 Roberts SL, Burnham RS, Ravichandiran K, et al. Cadaveric study of sacroiliac joint innervation: implications for diagnostic blocks and radiofrequency ablation. Reg Anesth Pain Med 2014:39:456-64.

223 Zhou L, Schneck CD, Shao Z. The anatomy of dorsal ramus nerves and its implications in lower back pain. Neurosci Med 2012;03:192-201.

224 Lord SM, McDonald GJ, Bogduk N. Percutaneous radiofrequency neurotomy of the cervical medial branches: a validated treatment for cervical zygapophysial joint pain Neurosurg Quarterly 1998;8:288-304.

225 Haemmerich D. Biophysics of radiofrequency ablation. Crit Rev Biomed Eng 2010;38:53-63.

226 Podhajsky RJ, Sekiguchi Y, Kikuchi S, et al. The histologic effects of pulsed and continuous radiofrequency lesions at $42^{\circ} \mathrm{C}$ to rat dorsal root ganglion and sciatic nerve. Spine 2005;30:1008-13.

227 Pennes HH. Analysis of tissue and arterial blood temperatures in the resting human forearm. J Appl Physiol 1948;1:93-122.

228 Goldberg SN, Gazelle GS, Mueller PR. Thermal ablation therapy for focal malignancy: a unified approach to underlying principles, techniques, and diagnostic imaging guidance. AJR 2000;174:323-31.

229 Organ LW. Electrophysiologic principles of radiofrequency lesion making. App/ Neurophysiol 1976;39:69-76.

230 Cosman ER, Dolensky JR, Hoffman RA. Factors that affect radiofrequency heat lesion size. Pain Med 2014;15:2020-36.

231 Bogduk N, Macintosh J, Marsland A. Technical limitations to the efficacy of radiofrequency neurotomy for spinal pain. Neurosurgery 1987:20:529-35

232 Provenzano DA, Cosman ER, Wilsey JT. Hypertonic sodium chloride preinjectate increases in vivo radiofrequency ablation size: histological and magnetic resonance imaging findings. Reg Anesth Pain Med 2018;43:776-88.

233 Provenzano DA, Watson TW, Somers DL. The interaction between the composition of preinjected fluids and duration of radiofrequency on lesion size. Reg Anesth Pain Med 2015;40:112-24.

234 Cosman Jr. ER, Gonzalez CD. Bipolar radiofrequency lesion geometry: implications for palisade treatment of sacroiliac joint pain. Pain Pract 2011;11:3-22.

235 Kim YN, Rhim H, Choi D, et al. The effect of radiofrequency ablation on different organs: ex vivo and in vivo comparative studies. Eur J Radiol 2011:80:526-32.

236 Steiner P, Botnar R, Goldberg SN, et al. Monitoring of radio frequency tissue ablation in an interventional magnetic resonance environment. Preliminary ex vivo and in vivo results. Invest Radiol 1997;32:671-8.

237 Eckmann MS, Martinez MA, Lindauer S, et al. Radiofrequency ablation near the bone-muscle interface alters soft tissue lesion dimensions. Reg Anesth Pain Med 2015;40:270-5.

238 Provenzano DA, Lassila HC, Somers D. The effect of fluid injection on lesion size during radiofrequency treatment. Reg Anesth Pain Med 2010;35:338-42.

239 Provenzano DA, Liebert MA, Somers DL. Increasing the $\mathrm{NaCl}$ concentration of the preinjected solution enhances monopolar radiofrequency lesion size. Reg Anesth Pain Med 2013:38:112-23.

240 Vallejo R, Benyamin R, Tilley DM, et al. An ex vivo comparison of cooledradiofrequency and bipolar-radiofrequency lesion size and the effect of injected fluids. Reg Anesth Pain Med 2014;39:312-21.

241 Cohen SP, Hurley RW, Buckenmaier CC, et al. Randomized placebo-controlled study evaluating lateral branch radiofrequency denervation for sacroiliac joint pain. Anesthesiology 2008;109:279-88.

242 Breen MS, Lazebnik RS, Fitzmaurice M, et al. Radiofrequency thermal ablation: correlation of hyperacute Mr lesion images with tissue response. J Magn Reson Imaging 2004;20:475-86

243 Breen MS, Lazebnik RS, Nour SG, et al. Three-Dimensional comparison of interventional Mr radiofrequency ablation images with tissue response. Comput Aided Surg 2004;9:185-91.

244 Morland C, Pettersen MN, Hassel B. Hyperosmolar sodium chloride is toxic to cultured neurons and causes reduction of glucose metabolism and ATP levels, an increase in glutamate uptake, and a reduction in cytosolic calcium. Neurotoxicology 2016:54:34-43.

245 Goldberg SN, Ahmed M, Gazelle GS, et al. Radio-Frequency thermal ablation with $\mathrm{NaCl}$ solution injection: effect of electrical conductivity on tissue heating and Coagulation-Phantom and porcine liver study. Radiology 2001:219:157-65.

246 Tiyaprasertkul W, Perez J. Injection of steroids before radiofrequency ablation has a negative impact on lesion size. Reg Anesth Pain Med 2014;39:189-91.

247 Wang H, Helm ER, Yung H. Effects of anesthetic fluid injectates on lesion sizes in cooled radiofrequency ablation. Spine 2017;42:E130-5.

248 Choi EJ, Choi YM, Jang EJ, et al. Neural ablation and regeneration in pain practice. Korean J Pain 2016;29:3-11.
249 Abbott Z, Smuck M, Haig A, et al. Irreversible spinal nerve injury from dorsal ramus radiofrequency neurotomy: a case report. Arch Phys Med Rehabil 2007;88:1350-2.

250 International Spine Intervention Society. Lumbar medial branch thermal neurotomy. In: Bogduk N, ed. Practice Guidelines for Spinal Diagnostic and Treatment Procedures. 2nd edition. San Francisco: International Spine Intervention Society, 2013: 514-22.

251 Gordon T, English AW. Strategies to promote peripheral nerve regeneration: electrical stimulation and/or exercise. Eur J Neurosci 2016:43:336-50.

252 Lundborg G. Nerve regenration and repair: a review. Acta Orthop Scand 1987:58:145-69.

253 Seddon HJ, Medawar PB, Smith H. Rate of regeneration of peripheral nerves in man. J Physiol 1943;102:191-215.

254 Gofeld M, Faclier G. Radiofrequency denervation of the lumbar zygapophysial joints-targeting the best practice. Pain Med 2008;9:204-11.

255 Dreyer SJ, Dreyfuss PH. Low back pain and the zygapophysial (facet) joints. Arch Phys Med Rehabil 1996;77:290-300.

256 Rees WES. Multiple bilateral subcutaneous rhizolysis of segmental nerves in the treatment of the intervertebral disc syndrome. Ann Gen Prac 1971;26:126-7.

257 Shealy CN. Percutaneous radiofrequency denervation of spinal facets. treatment for chronic back pain and sciatica. J Neurosurg 1975;43:448-51.

258 Bogduk N, Long DM. Percutaneous lumbar medial branch neurotomy: a modification of facet denervation. Spine 1980;5:193-200.

259 Heavner JE, Boswell MV, Racz GB. A comparison of pulsed radiofrequency and continuous radiofrequency on thermocoagulation of egg white in vitro. Pain Physician 2006;9:135-7.

260 Cosman ER, Cosman ER. Electric and thermal field effects in tissue around radiofrequency electrodes. Pain Med 2005;6:405-24.

261 Lau P, Mercer S, Govind J, et al. The surgical anatomy of lumbar medial branch neurotomy (facet denervation). Pain Med 2004;5:289-98.

262 Chaudhry V, Glass JD, Griffin JW. Wallerian degeneration in peripheral nerve disease. Neurol Clin 1992;10:613-27.

263 Loh JT, Nicol AL, Elashoff D, et al. Efficacy of needle-placement technique in radiofrequency ablation for treatment of lumbar facet arthropathy. J Pain Res 2015;8:687-94.

264 Cheng J, Gutenberg LV, Dalton JE. Comparative long-term outcomes of lateral versus posterior approach to cervical facet medial branch radiofrequency ablation [abstract \#179]. Presented at: American Academy of Pain Medicine 2013 Annual Meeting; April 10-14, 2013; Fort Lauderdale, FL. Pain Med 2013;14:586.

265 Bogduk N, Wilson AS, Tynan W. The human lumbar dorsal rami. J Anat 1982;134:383-97.

266 Bogduk N. The innervation of the lumbar spine. Spine 1983;8:286-93.

267 Shuang F, Hou S-X, Zhu J-L, et al. Clinical anatomy and measurement of the medial branch of the spinal dorsal ramus. Medicine 2015;94:e2367.

268 Cohen SP, Strassels SA, Kurihara C, et al. Does sensory stimulation threshold affect lumbar facet radiofrequency denervation outcomes? A prospective clinical correlational study. Anesth Analg 2011;113:1233-41.

269 Koh JC, Kim DH, Lee YW, et al. Relationship between paravertebral muscle twitching and long-term effects of radiofrequency medial branch neurotomy. Korean J Pain 2017;30:296-303.

270 Paterno J, Rathmell JP, Gilligan C. Cryoanalgesia and radiofrequency ablation. In: Bajwa Z, Wootton RJ, Warfield CA, eds. Principles and practice of pain medicine. 3rd edn. New York: McGraw-Hill, 2016.

271 Stoker GE, Buchowski JM, Kelly MP. Dropped head syndrome after multilevel cervical radiofrequency ablation: a case report. J Spinal Disord Tech 2013:26:444-8

272 Lee CJ, Kim YC, Shin JH, et al. Intravascular injection in lumbar medial branch block: a prospective evaluation of 1433 injections. Anesth Analg 2008;106:1274-8.

273 Manchikanti L, Malla Y, Wargo BW, et al. Complications of fluoroscopically directed facet joint nerve blocks: a prospective evaluation of 7,500 episodes with 43,000 nerve blocks. Pain Physician 2012;15:E143-50.

274 Joo Y, Kim YC, Lee SC, et al. Impact of type of needle on incidence of intravascular injection during diagnostic lumbar medial branch block. Reg Anesth Pain Med 2016:41:392-7.

275 Eriksson AL, Hallén B, Lagerkranser M, et al. Whitacre or Quincke needles - does it really matter. Acta Anaesthesio/ Scand 1998;42:17-20

276 Narouze S, Benzon HT, Provenzano D, et al. Interventional spine and pain procedures in patients on antiplatelet and anticoagulant medications (second edition): guidelines from the American Society of regional anesthesia and pain medicine, the European Society of regional anaesthesia and pain therapy, the American Academy of pain medicine, the International neuromodulation Society, the North American neuromodulation Society, and the world Institute of pain. Reg Anesth Pain Med 2018:43:225-62.

277 Endres S, Shufelt A, Bogduk N. The risks of continuing or discontinuing anticoagulants for patients undergoing common interventional pain procedures. Pain Med 2017:18:403-9.

278 Anticoagulants BN. Practice Guidelines for Spinal Diagnostic and Treatment Procedures. 2nd edn. San Francisco, CA: International Spine Intervention Society, 2013: 9-14. 
279 Smith CC, Schneider B, McCormick ZL, et al. Standards division of the spine intervention Society. risks and benefits of ceasing or continuing anticoagulant medication for image-guided procedures for spine pain: a systematic review. Pain Med 2018;19:438-48.

280 Narouze S, Benzon HT, Provenzano DA, et al. Interventional spine and pain procedures in patients on antiplatelet and anticoagulant medications: guidelines from the American Society of regional anesthesia and pain medicine, the European Society of regional anaesthesia and pain therapy, the American Academy of pain medicine, the International neuromodulation Society, the North American neuromodulation Society, and the world Institute of pain. Reg Anesth Pain Med 2015;40:182-212.

281 Kaye AD, Manchikanti L, Novitch MB, et al. Responsible, safe, and effective use of antithrombotics and anticoagulants in patients undergoing interventional techniques: American Society of interventional pain physicians (ASIPP) guidelines. Pain Physician 2019;22:S75-128.

282 Bogduk N. Lumbar lateral branch neuralgia: a complication of rhizolysis. Med J Aust 1981;1:242-3

283 Kornick C, Scott Kramarich S, Lamer TJ, et al. Complications of lumbar facet radiofrequency denervation. Spine 2004;29:1352-4.

284 Roy C, Chatterjee N, Ganguly S, et al. Efficacy of combined treatment with medial branch radiofrequency neurotomy and steroid block in lumbar facet joint arthropathy. J Vasc Interv Radiol 2012;23:1659-64.

285 Moon JY, Lee PB, Kim YC, et al. An alternative distal approach for the lumbar medial branch radiofrequency denervation: a prospective randomized comparative study. Anesth Analg 2013;116:1133-40.

286 Dobrogowski J, Wrzosek A, Wordliczek J. Radiofrequency denervation with or without addition of pentoxifylline or methylprednisolone for chronic lumbar zygapophysial joint pain. Pharmacol Rep 2005;57:475-80.

287 Singh JR, Miccio VF, Modi DJ, et al. The impact of local steroid administration on the incidence of neuritis following lumbar facet radiofrequency neurotomy. Pain Physician 2019;22:69-74.

288 Wilke HJ, Wolf S, Claes LE, et al. Stability increase of the lumbar spine with different muscle groups. A biomechanical in vitro study. Spine 1995;20:192-8.

289 Smuck M, Crisostomo RA, Demirjian R, et al. Morphologic changes in the lumbar spine after lumbar medial branch radiofrequency neurotomy: a quantitative radiological study. Spine J 2015;15:1415-21

290 Stegemöller EL, Roper J, Hass CJ, et al. Changes in gait kinematics and lower back muscle activity post-radiofrequency denervation of the zygapophysial joint: a case study. Spine J 2015;15:e21-7.

291 Roark C, Whicher S, Abosch A. Reversible neurological symptoms caused by diathermy in a patient with deep brain stimulators. Neurosurgery 2008;62:E256.

292 Bautista A, Dadabayev A, Rosenquist E, et al. Bipolar radiofrequency neurotomy to treat neck and back pain in patients with automatic implantable cardioverter defibrillator. Pain Physician 2016;19:E505-9.

293 American Society of Anesthesiologists. Practice Advisory for the perioperative management of patients with cardiac implantable electronic devices: pacemakers and implantable cardioverter-defibrillators: an updated report by the American Society of anesthesiologists Task force on perioperative management of patients with cardiac implantable electronic devices. Anesthesiology 2011;114:247-61.

294 McCormick ZL, Walega DR. Third-Degree skin burn from conventional radiofrequency ablation of the inferiomedial genicular nerve. Pain Med 2018;19:1095-7

295 Saaiq M, Zaib S, Ahmad S. Electrocautery burns: experience with three cases and review of literature. Ann Burns Fire Disasters 2012;25:203-6.

296 Ogsbury JS, Simon RH, Lehman RA. Facet "denervation" in the treatment of low back syndrome. Pain 1977;3:257-63.

297 Katz SS, Savitz MH. Percutaneous radiofrequency rhizotomy of the lumbar facets. Mt Sinai J Med 1986;53:523-5.

298 Burnham T, Hilgenhurst G, McCormick ZL. Second-degree skin burn from a radiofrequency grounding pad: a case report and review of Risk-Mitigation strategies. $P M \& R$ 2019;11:1139-42.

299 Little JS, lanuzzi A, Chiu JB, et al. Human lumbar facet joint capsule strains: II. alteration of strains subsequent to anterior interbody fixation. The Spine Journal 2004;4:153-62.

300 Gazelka HM, Welch TL, Nassr A, et al. Safety of lumbar spine radiofrequency procedures in the presence of posterior pedicle screws: technical report of a cadaver study. Pain Med 2015;16:877-80.

301 Lamer TJ, Smith J, Hoelzer BC, et al. Safety of lumbar spine radiofrequency procedures in patients who have posterior spinal hardware. Pain Med 2016:17:1634-7

302 Ellwood S, Shupper P, Kaufman A. A retrospective review of spinal radiofrequency neurotomy procedures in patients with metallic posterior spinal instrumentation - is it safe? Pain Physician 2018;21:E477-82.

303 Srikanthan A, Vera-Badillo F, Ethier J, et al. Evolution in the eligibility criteria of randomized controlled trials for systemic cancer therapies. Cancer Treat Rev 2016;43:67-73.

304 Umscheid CA, Margolis DJ, Grossman CE. Key concepts of clinical trials: a narrative review. Postgrad Med 2011;123:194-204.
305 Cohen SP, Bicket MC, Jamison D, et al. Epidural steroids: a comprehensive, evidencebased review. Reg Anesth Pain Med 2013:38:175-200.

306 Bicket MC, Hurley RW, Moon JY, et al. The development and validation of a quality assessment and rating of technique for injections of the spine (aquarius). Reg Anesth Pain Med 2016;41:80-5

307 Slappendel R, Gielen MJ, Hasenbos MA, et al. Spread of radiopaque dye in the thoracic epidural space. Anaesthesia 1988;43:939-42.

308 Sjøgren P, Gefke K, Banning AM, et al. Lumbar epidurography and epidural analgesia in cancer patients. Pain 1989;36:305-9.

309 Benzon HT, Liu BP, Patel A, et al. Caution in using gadolinium-based contrast agents in interventional pain procedures. Anesth Analg 2018;127:1452-6.

310 Provenzano DA, Pellis Z, DeRiggi L. Fatal gadolinium-induced encephalopathy following accidental intrathecal administration: a case report and a comprehensive evidence-based review. Reg Anesth Pain Med 2019;44:721-9.

311 Gofeld M, Jitendra J, Faclier G. Radiofrequency denervation of the lumbar zygapophysial joints: 10-year prospective clinical audit. Pain Physician 2007:10:291-300.

312 Schofferman J, Kine G. Effectiveness of repeated radiofrequency neurotomy for lumbar facet pain. Spine 2004;29:2471-3.

313 Royal MA, Bhakta B, Gunyea I, et al. Radiofrequency neurolysis for facet arthropathy: a retrospective case series and review of the literature. Pain Practice 2002;2:47-52.

314 Smuck M, Crisostomo RA, Trivedi K, et al. Success of initial and repeated medial branch neurotomy for zygapophysial joint pain: a systematic review. $P M \& R$ 2012:4:686-92.

315 Rambaransingh B, Stanford G, Burnham R. The effect of repeated zygapophysial join radiofrequency neurotomy on pain, disability, and improvement duration. Pain Med 2010:11:1343-7.

316 Son JH, Kim SD, Kim SH, et al. The efficacy of repeated radiofrequency medial branch neurotomy for lumbar facet syndrome. J Korean Neurosurg Soc 2010;48:240-3.

$317 \mathrm{Kim} \mathrm{MH}$, Kim SW, Ju Cl, et al. Effectiveness of repeated radiofrequency neurotomy for facet joint syndrome after microscopic discectomy. Korean J Spine 2014:11:232-4.

318 Strohbehn JW. Temperature distributions from interstitial if electrode hyperthermia systems: theoretical predictions. Int J Radiat Oncol Biol Phys 1983:9:1655-67.

319 Robinson LR. Traumatic injury to peripheral nerves. Muscle Nerve 2000;23:863-73.

320 Fröhling MA, Schlote W, Wolburg-Buchholz K. Nonselective nerve fibre damage in peripheral nerves after experimental thermocoagulation. Acta Neurochir 1998:140:1297-302.

321 Bogduk N. Evidence-Informed management of chronic low back pain with facet injections and radiofrequency neurotomy. The Spine Journal 2008;8:56-64.

322 Carlson BM. The biology of long-term denervated skeletal muscle. Eur J Transl Myol 2014;24:3293.

323 Carraro U, Boncompagni S, Gobbo V, et al. Persistent muscle fiber regeneration in long term denervation. past, present, future. Eur J Trans/ Myol 2015;25:4832.

324 Maas ET, Ostelo RW, Niemisto L, et al. Radiofrequency denervation for chronic low back pain. Cochrane Database Syst Rev 2015;10:CD008572.

325 Manchikanti L, Hirsch JA, Falco FJE, et al. Management of lumbar zygapophysial (facet) joint pain. World J Orthop 2016;7:315-37

326 Wilkinson IM, Cohen SP. Epidural steroid injections. Curr Pain Headache Rep 2012;16:50-9.

327 Friedly J, Chan L, Deyo R. Geographic variation in epidural steroid injection use in Medicare patients. J Bone Joint Surg Am 2008;90:1730-7.

328 Deyo RA, Mirza SK. Trends and variations in the use of spine surgery. Clin Orthop Relat Res 2006:443:139-46.

329 Dorner TE, Helgesson M, Nilsson K, et al. Course and characteristics of work disability 3 years before and after lumbar spine decompression surgery- a national population-based study. Sci Rep 2018;8:11811.

330 Wilkens P, Scheel IB, Grundnes O, et al. Prognostic factors of prolonged disability in patients with chronic low back pain and lumbar degeneration in primary care: a cohort study. Spine 2013:38:65-74

331 Linton SJ. A review of psychological risk factors in back and neck pain. Spine 2000;25:1148-56.

332 Stubbs B, Koyanagi A, Thompson T, et al. The epidemiology of back pain and its relationship with depression, psychosis, anxiety, sleep disturbances, and stress sensitivity: data from 43 low- and middle-income countries. Gen Hosp Psychiatry 2016;43:63-70

333 Abbott ZI, Nair KV, Allen RR, et al. Utilization characteristics of spinal interventions. Spine J 2012;12:35-43.

334 Altman DG, Bland JM. Absence of evidence is not evidence of absence. Br Med J 1995;311:485.

335 Alrawi MF, Khalil NM, Mitchell P, et al. The value of neurophysiological and imaging studies in predicting outcome in the surgical treatment of cervical radiculopathy. Eur Spine J 2007;16:495-500.

336 Singh S, Loke YK. Drug safety assessment in clinical trials: methodological challenges and opportunities. Trials 2012;13:138.

337 Rathmell JP, Benzon HT, Dreyfuss P, et al. Safeguards to prevent neurologic complications after epidural steroid injections: consensus opinions from a 
multidisciplinary Working group and national organizations. Anesthesiology 2015;122:974-84.

338 Boutron I, Dutton S, Ravaud P, et al. Reporting and interpretation of randomized controlled trials with statistically nonsignificant results for primary outcomes. JAMA 2010;303:2058-64.

339 Dowell D, Haegerich TM, Chou R. CDC Guideline for Prescribing Opioids for Chronic Pain--United States, 2016. JAMA 2016;315:1624-45.

340 Dowell D, Haegerich T, Chou R. No shortcuts to safer opioid prescribing. N Engl J Med 2019:380:2285-7.
341 Kroenke K, Alford DP, Argoff C, et al. Challenges with implementing the centers for disease control and prevention opioid guideline: a consensus panel report. Pain Med 2019;20:724-35.

342 Lundh A, Gøtzsche PC. Recommendations by cochrane review groups for assessment of the risk of bias in studies. BMC Med Res Methodol 2008;8:22.

343 Kim SY, Park JE, Lee YJ, et al. Testing a tool for assessing the risk of bias for nonrandomized studies showed moderate reliability and promising validity. J Clin Epidemiol 2013:66:408-14.

344 Masic I, Miokovic M, Muhamedagic B. Evidence based medicine - new approaches and challenges. Acta Inform Med 2008;16:219-25. 